University of South Florida

DIGITAL COMMONS

Digital Commons @ University of

@ UNIVERSITY OF SOUTH FLORIDA

South Florida

USF Tampa Graduate Theses and Dissertations

USF Graduate Theses and Dissertations

7-10-2009

\title{
Establishing Creative Writing Studies as an Academic Discipline
}

Dianne J. Donnelly

University of South Florida

Follow this and additional works at: https://digitalcommons.usf.edu/etd

Part of the American Studies Commons, and the English Language and Literature Commons

\section{Scholar Commons Citation}

Donnelly, Dianne J., "Establishing Creative Writing Studies as an Academic Discipline" (2009). USF Tampa Graduate Theses and Dissertations.

https://digitalcommons.usf.edu/etd/3809

This Dissertation is brought to you for free and open access by the USF Graduate Theses and Dissertations at Digital Commons @ University of South Florida. It has been accepted for inclusion in USF Tampa Graduate Theses and Dissertations by an authorized administrator of Digital Commons @ University of South Florida. For more information, please contact digitalcommons@usf.edu. 
Establishing Creative Writing Studies as an Academic Discipline

by

Dianne J. Donnelly

A dissertation submitted in partial fulfillment

of the requirements for the degree of

Doctor of Philosophy

Department of English

College of Arts and Sciences

University of South Florida

Major Professor: Joseph Moxley, Ph.D.

John Fleming, Ph.D.

Hunt Hawkins, Ph.D.

Patrick Bizzaro, Ph.D.

Date of Approval:

July 10, 2009

Keywords: creative writing studies, pedagogy, workshop, theory, history

(C) Copyright 2009, Dianne J. Donnelly 


\section{TABLE OF CONTENTS}

$\begin{array}{ll}\text { Abstract } & \text { ii }\end{array}$

Introduction: The Emergence of Creative Writing Studies 1

The Disciplinary Status of Creative Writing Studies 5

The Emergence of Creative Writing Studies - Where to Begin? 8

Establishing Creative Writing Studies as an Academic Discipline 13

Section One: A Taxonomy of Creative Writing Pedagogies 15

Where Meaning Lies - A Multi-faceted Approach 21

$\begin{array}{ll}\text { Orientation of Critical Theories } & 26\end{array}$

The Objective Theory as New Criticism 27

$\begin{array}{ll}\text { Historical Antecedents } & 27\end{array}$

$\begin{array}{ll}\text { Pedagogical Practice } & 29\end{array}$

Pedagogical Practices: Text as Verbal Icon 30

Pedagogical Practices: The Ease of Teaching the New Critical Approach 35

$\begin{array}{ll}\text { Pedagogical Practices: Evaluation } & 37\end{array}$

Pedagogical Practices: Evaluating the Text as Final Authority 38

Pedagogical Practices: Teacher as Final Authority, as Exemplary Reader 43

Social Relations: Through a Lacanian Lens 46

New Criticism Theory: Final Arguments 52 
Historical Antecedents $\quad 54$

$\begin{array}{ll}\text { Pedagogical Practice } & 60\end{array}$

Pedagogical Practices: Discovery and Inspiration 61

Pedagogical Practices: The Expressivist Workshop 63

Pedagogical Practices: What to do About the Romantic Myth 64

Social Relations: Through a Lacanian Lens $\quad 67$

Expressivist Theory: Final Arguments $\quad 75$

$\begin{array}{ll}\text { The Mimetic Theory as Imitable Functions } & 77\end{array}$

$\begin{array}{ll}\text { Historical Antecedents } & 77\end{array}$

$\begin{array}{ll}\text { Pedagogical Practice } & 77\end{array}$

Social Relations: Through a Lacanian Lens $\quad 80$

Mimetic Theory: Final Arguments $\quad 81$

The Pragmatic Theory as Reader-Response 82

Historical Antecedents $\quad 82$

Pedagogical Practice $\quad 82$

The Complexities of Reader-Response Theory 84

How to Bring Reader-Response Theory into the Creative Writing 85

Classroom

$\begin{array}{ll}\text { Teaching Reader-Response Awareness } & 87\end{array}$

Teaching Reader-Response Strategies 90

Social Relations: Through a Lacanian Lens $\quad 92$

Reader-Response Theory: Final Arguments 93 
Section Two: The Writing Workshop Model

$\begin{array}{ll}\text { A Workshop Survey } & 97\end{array}$

$\begin{array}{ll}\text { Defining the Workshop Model } & 100\end{array}$

$\begin{array}{ll}\text { A Study of the Workshop Model } & 102\end{array}$

How Our Workshop History Informs Our Praxes 109

$\begin{array}{ll}\text { Perceptions and Practice } & 118\end{array}$

$\begin{array}{ll}\text { Our Students } & 118\end{array}$

$\begin{array}{ll}\text { Our Critics } & 126\end{array}$

$\begin{array}{ll}\text { Our Teachers } & 127\end{array}$

$\begin{array}{ll}\text { Our Workshop Pedagogy } & 129\end{array}$

Flexing the Workshop Space or Opening the Space to Alternatives 133

$\begin{array}{ll}\text { Our Lore } & 141\end{array}$

$\begin{array}{ll}\text { Developing Markers of Professional Difference } & 147\end{array}$

The Case for Reading and its Distinguishing Markers 148

The Case for Writing and its Distinguishing Markers 153

The Case for Responding and its Distinguishing Markers 156

The Case for Theory 164

The Workshop Model: Final Arguments 166

Section Three: The Academic Home for Creative Writing Studies 167

$\begin{array}{ll}\text { Control of Space, Domain, and Power } & 170\end{array}$

The Academic Home of Creative Writing Studies 171

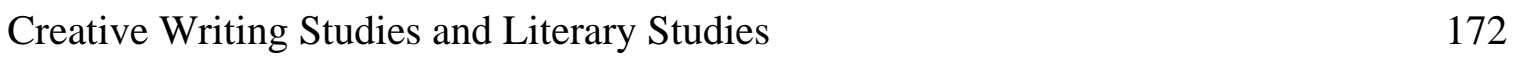

$\begin{array}{ll}\text { Creative Writing Studies and Cultural Studies } & 175\end{array}$ 
Independent Writing Programs

Creative Writing Studies and Composition Studies

The Academic Home for Creative Writing Studies

Conclusion: The Legitimacy of Creative Writing Studies 


\section{LIST OF FIGURES}

Figure 1. Artistic Communication Transaction

Figure 2. Abrams' Taxonomy of Theories

Figure 3. My Taxonomy of Theories 


\title{
ESTABLISHING CREATIVE WRITING STUDIES AS AN ACADEMIC DISCIPLINE
}

\section{DIANNE DONNELLY}

\begin{abstract}
The discipline of creative writing is charged "as the most untheorized, and in that respect, anachronistic area in the entire constellation of English studies (Haake What Our Speech Disrupts 49). We need only look at its historical precedents to understand these intimations. It is a discipline which is unaware of the histories that informs its practice. It relies on the tradition of the workshop model as its signature pedagogy, and it is part of a fractured community signaled by its long history of subordination to literary studies, its lack of status and sustaining lore, and its own resistance to reform. These factions keep creative writing from achieving any central core.

I argue for the advancement of creative writing studies. As a scholarly academic discipline, creative writing studies explores and challenges the pedagogy of creative writing. It not only supports, but welcomes intellectual analyses that may reveal new theories. Such theories have important teaching implications and insights into the ways creative writers read, write, and respond. My study explores the history of creative writing, its workshop model as its primary practice, and the discipline’s major pedagogical practices. Through its pedagogical and historical inquiry of the field, this
\end{abstract}


study has important implications to the development of creative writing studies. Its research includes a workshop survey of undergraduate creative writing teachers as well as scholarship in the field. My argument envisions a more robust, variable, and intelligent workshop model. It considers how an understanding of our pedagogical practices might influence our teaching strategies and classroom dynamics and how we might provide more meaning to the academy, our profession, and our diverse student body.

At a curricular level, my study offers course and program development, and it justifies the importance of including graduate level training for teacher preparation to further explore the field's history and pedagogy. Through my inquiries and research, I advance creative writing studies, define its academic home, and better position the discipline to stand alongside composition studies and literary studies as a separate-butequal entity, fully prepared to claim it own identity and scholarship. 


\section{INTRODUCTION: THE EMERGENCE OF CREATIVE WRITING STUDIES}

Creative writing stands once again at a crossroads. On one side of the road is creative writing, a discipline which is unaware of the histories and theories that informs its practice. As such, its "creative writing teachers are, of necessity, implicated in questions of theory and practice” (Bishop “On the Same Boat” para. 2). In fact, creative writing is charged "as the most untheorized, and in that respect, anachronistic area in the entire constellation of English studies (Haake What Our Speech Disrupts 49). We need only look at its historical precedents to understand these intimations.

It might be said that creative writing has stood at a crossroads many times in its history. Consider, for example, its years of promoting literature for its own sake until its intersection with postwar program expansion and rising enrollment. As patrons of university subsidies and recipients of National Endowment for the Arts (NEA) funding, this point of juncture led to hiring opportunities that triple what is available in today's job market. In the eighties, the road traveled by creative writing promoted the production of writers and teachers until the 1990s when once again, creative writing posed at a byroad; this one no longer in sync with a favorable marketplace.

Creative writing has been a field that avoids scholarship. It maintains the mysterious element of creativity and hires successful writers on the assumption that they make the best teachers. It relies on the tradition of the workshop model as its signature pedagogy. Even though student numbers might suggest creative writing's equal status 
with other disciplines in English studies, and in spite of Allan Tate's assurance that "Creative writing is here to stay, at least for a long time” (181), the discipline stands yet again at a crossroads. It does so, in part, because it is "an academic anomaly" (Tate 182). As a discipline, it is part of a fractured community signaled by its long history of subordination to literary studies, its lack of status and sustaining lore, and its own resistance to reform. These factions keep creative writing from achieving any central core in the academy.

Standing also on the byroad is creative writing studies, an emerging field of scholarly inquiry and research. As an academic discipline, it explores and challenges the pedagogy of creative writing. It not only supports, but welcomes intellectual analyses that may reveal new theories. Such theories have important teaching implications and insights into the ways creative writers read, write, and respond. In fact, as a necessary step in embracing its own identity and scholarship, creative writing studies considers its “markers of professional difference” (Ritter "Professional Writers” 208), those identifying features which distinguish its field from composition studies and literary studies. Finally, and this is a significant difference between the two enterprises, creative writing studies does not support the exclusivity of creative writers as teachers of its students.

Creative writing and creative writing studies are two distinct enterprises. Although both entities overlay in some ways, the primary differences between the two relate to inquiry and research. Whereas the curricular design of creative writing programs continues (and plans to continue) to offer value-added writing and reading strategies for students who want to develop their writing/reading skills and improve their works-in- 
progress, the ascending field of creative writing studies — as a separate program trackrethinks its pedagogy and scholarship and shifts its educational goals. Still in its nascent phase, creative writing studies must undergo necessary inquiries and research into its field in order to fully develop and be measured as an academic discipline. It must also establish markers of professional difference and training for its new teachers so as to continue its inquiry and research and to teach new skills to its students. The academic goal of creative writing studies is to stand alongside composition studies and literary studies as a separate-but-equal discipline.

I argue for the ascendancy of creative writing studies as an academic discipline. My study explores the history of creative writing, its workshop model as its primary practice, and the discipline's major pedagogical practices. Through its pedagogical and historical inquiry of the field, this study has important implications to the development of creative writing studies. Its research includes a workshop survey of undergraduate creative writing teachers based mostly in the United States, scholarship in the field, and my own teaching experience. My argument envisions a more robust, variable, and intelligent workshop model. It considers how an understanding of our pedagogical practices might influence our teaching strategies and classroom dynamics and how we might provide more meaning to the academy, our profession, and our diverse student body.

At a curricular level, my study offers course and program development to meet the needs of creative writing students at all levels, and it justifies the importance of including graduate level training for teacher preparation to further explore the field's 
history and pedagogy. The intent of my argument is to pilot creative writing studies into the future and to define its academic home.

This study is organized into three parts. The first explores the pedagogical practices in creative writing. Building on M. H. Abrams' "triangle" of author, work, and reader, I characterize the four major pedagogical theories in the creative writing classroom as New Critical, Expressive, Mimetic, and Reader-Response. The various theories all concern where teachers privilege meaning in the composing process. As part of my inquiry, I consider historical antecedents that impact the discipline’s practices (and in some cases its isolationist posture in the English department). Additionally, I explore the scope of teaching strategies and their implications. In addition to examining the historical antecedents and pedagogical practices of each theory, I find it useful to apply Lacanian theory as a means of comprehending the relationships between teachers and students and in understanding students' identities and their responses to writing instruction. My concern in this section is that teachers often fail to recognize the theories that underpin their practices or they resist changing the routine of their teaching instruction. Moreover, they might unintentionally confuse their students by practicing one pedagogical model in the classroom and another to evaluate students' work and performance. What I propose, then, is a four-part taxonomy of pedagogical practices so that, as appropriate, teachers may reconsider or modify their strategies and be clearer to students as to their expectations.

With a goal to ascend creative writing studies as an academic discipline, the second part of my argument explores the history and current practices of the workshop model. The workshop, now an interchangeable signifier for the practice of creative 
writing, is often cast negatively by critics who condemn its lack of rigor and intelligence. The function of the workshop model raises questions about its usefulness and about students' readiness, preparation and effort. My argument demonstrates that although the model continues to be creative writing's signature pedagogy, some teachers are in fact changing and expanding the shape of the model and collaborating with other disciplines such as performative art, digital technology, and film studies. This section outlines variable curricular and program designs at the undergraduate and graduate levels as an important part of creating opportunities for the teaching of new skills to creative writers. Additionally, this part advances creative writing studies as a distinct field through an identification of distinguishing markers in the ways creative writing students read, write, and respond in the workshop practice.

My final section regards the academic home of creative writing studies, weighing such factors as the current marginalization of creative writing in the English department and the discipline's possible mergence with literary studies, cultural studies, composition studies, or as one component in an independent writing program. In the end, I situate creative writing studies alongside composition studies and literary studies, as a pedagogically and programmatically sound entity fully empowered in its own identity and scholarship.

\section{The Disciplinary Status of Creative Writing Studies}

I want to lay some basic groundwork in terms of defining what is meant when we talk about creative writing studies as a discipline, as a profession, and as a field of study. While teaching is generally seen as a form of professional work, one that requires a great deal of specialized knowledge (Sykes et al 1985), the label "profession” is thought to be 
reserved for establishments of long standing such as law, medicine, and clergy. Other formations may develop and these are better known as “occupations,” which may aspire to be professions, but the initiation is apparently long and arduous. There are educational policy references that address reformations for professionalizing teaching, but allegedly, as educators, we are not there yet-teaching is an occupation. Still, many of us refer to teaching as a "profession.” Semantics and decades of general usage of the term around college campuses and conferences give us some unofficial card-carrying right, I suppose. What this amounts to is that creative writing studies cannot be measured against any uniformed standard of profession.

As a discipline or field of study, creative writing can already claim status in the English department through its specialized academic programs, its professional organization, conferences, and publications. Most importantly, it can be argued that creative writing is a professional body of knowledge. Creative writing's history is a hybrid of theories and practices drawn in part from composition studies and literary studies, of which, creative writing's practice today is still mostly affected. Although creative writing has drawn epistemologically from this base, it continues to constitute practices which are independent of those in composition studies and literary studies, praxes which are guided by writerly and readerly processes of creative writers. In many ways, then, creative writing is a thriving field.

In other ways, however, the discipline falls short in terms of its graduate career training to include teacher preparation, its articulated research agenda and academic forums, and in ways in which its practitioners might claim it as a research area. Creative writing's practitioners are less aware of the history that informs their practice and less 
certain how to theorize the principles that undergird their practices. Scholars often rebuke creative writing on the premise that it is not really a field of inquiry and research.

Professor Lee Shulman, President of Carnegie Foundation for the Advancement of Teaching, tells us that the professions of law, medicine, engineering, and the clergy have what he calls "signature pedagogies” (“Signature Pedagogies” 52), the salient, pervasive teaching practices that characterize a field. In law, we think of the Socratic-like questioning based on case study, and in medicine, clinical rounds are a standard. Creative writing's signature pedagogy is the writing workshop, and the model, given its personal nature, functions as a hybrid of New Criticism, social-expressivism, romanticism, mimesis, and social cognitivism. This is important to mention because the signature pedagogy of a profession often reflects the stability of that profession. In brief, as a signature pedagogy, the traditional workshop model, without a more rigorous and intellectual focus does not best represent the stability of creative writing as a discipline; or conversely, perhaps it better represents (again in its less-than-rigorous posture) as representative of creative writing's instability as a discipline.

Shulman notes that there are both advantages and disadvantages associated with a field’s signature pedagogy. These teaching practices are also “subject to change as conditions in the practice of the profession itself and in the institutions that provide professional service or care undergo larger societal change” (“Signature Pedagogies” 52). Shulman provides another caveat to consider, one which he refers to as "pedagogical inertia” ("Pedagogies of Uncertainty” para. 16). This can occur when teaching practices are sustained within a field simply because those practices have been around for a very long time. A parallel might be made to Stephen North’s concept of “lore” and its 
sustainable influence on practices and behavior. While Schulman might very well be addressing creative writing’s workshop model in this case, there seems, inferential in his address other functions that, once investigated, might reveal creative writing studies' potential for growth as an intellectual force. Bizzaro has long argued that "a discipline is characterized by what it construes as proof of evidence." ${ }^{\prime 1}$ Creative writing studies is differentiated from creative writing by its emphasis on collecting, compiling, and presenting data. This new studies area with its depth of inquiry, research, and scholarship will better define its professional body of knowledge in an even more useful way.

While history can shed insight into creative writing’s classroom praxes, Bizzaro notes, "The history of the moment must be on training the next generation of writing teachers while encouraging them at the same time to be writers." ${ }^{2}$ As a discipline centered on inquiry and research, creative writing studies is aligned with this twenty-first century goal.

\section{The Emergence of Creative Writing Studies-Where to Begin?}

As creative writing studies is still in its budding phase of development, the first step in its field of inquiry requires an exploration of the nature of its existing scholarship and research. Bizzaro contends that once creative writers have assessed what studies have been completed, once they have explored the nature of scholarship, they can then determine what remains to be completed in its field of inquiry. To be clear, efforts to establish creative writing studies as an academic discipline might include inquiries and research into the field's pedagogy and its history. Moreover, the advancement of creative

\footnotetext{
${ }^{1}$ This comment results from my email communications with Patrick Bizzaro. I want to note my appreciation of these dynamic and resourceful communications on the subject of creative writing studiesits history, its present state of affairs, and its future.

${ }^{2}$ ibid
} 
writing studies in the academy depends on institutional advocacies to include the support of creative writing faculty as well as public advocacies that might reconsider the lore of creative writing and the merits of creative writing studies as an academic discipline.

Two examples of scholarship which explore creative writing's pedagogy include studies by Patrick Bizzaro and Kelly Ritter. Both inquire into current practices in an effort to establish epistemological differences and claims for academic development. Bizzaro and Ritter are explicit about the need to assert our distinctive methodology from other subjects in English studies_-markers which creative writing teachers can then teach to their students through new course development. Ritter’s own very important scholarship reflects her survey and interview results of creative writing programs as an inquiry into the extent of training provided to prepare graduate students for the teaching of creative writing. She presents her findings in "Professional Writers/Writing Professional: Revamping Teacher Training in Creative Writing Ph.D. Programs” (2001). Bizzaro demonstrates research in creative writing by differentiating some of our disciplinary practices in "Research and Reflection in English Studies: The Special Case of Creative Writing” (2004). These published inquiries and research further advance what Mayers references, characteristically, as the pedagogical strand of creative writing studies.

Other scholarship that questions creative writing pedagogy and its relationship to English studies includes: Moxley’s edited collection Creative Writing in America: Theory and Pedagogy, Bishop’s Released Into Language: Options for Teaching Creative Writing, Bishop and Hans Ostrom’s edited collection Colors of a Different Horse: Rethinking Creative Writing Theory and Pedagogy, Patrick Bizzaro’s Responding to 
Student Poems, the edited collections of Anna Leahy Power and Identity in the Creative Writing Classroom: The Authority Project, and Kelly Ritter and Stephanie Vanderslice's Can it Really Be Taught?: Resisting Lore in Creative Writing Pedagogy, Tim Mayers (Re)Writing Craft: Composition, Creative Writing, and the Future of English Studies, Katharine Haake’s What Our Speech Disrupts: Feminism and Creative Writing Studies, Michelene Wandor's The Author is Not Dead, Merely Somewhere Else: Creative Writing Reconceived.

My own edited collection The Writing Workshop Model: Is It Still Working? (2010c) includes inquiries and studies of the workshop model as it relates to contact zones, hybrid models, epistemological differences, risks, vulnerabilities, conflicts, experimentation, spaces for radical openness, master classes, and implications for our writers in the Net generation, among other topics. Moreover, there are a host of essays not included in this catalogue of scholarship that questions current practices and offers epistemological differences.

The titles alone in this well-developed pedagogical strand of inquiry announce the kind of critical studies from which to consider in our future research. At the very least, such an inquiry into existing scholarship generates a sum of questions. For example, what can this strand of pedagogy tell us about creative writers' research methods and how they construct and construe data? How are these research methods different from other disciplines in English studies? What conclusions might be drawn in terms of other professional differences? In what ways does this breadth of scholarship reflect teaching practices and the ways creative writing students read and write? In what venues will 
creative writers publish their findings, present their questions, and/or compare their modes of instruction?

As it relates to programmatic changes, we might ask how what course development might creative writing teachers consider and offer so as to pass on new skills to their students. As it is critical to make important changes that reflect the unique nature of research and pedagogy in creative writing's current curricula, how might we reenvision and revise existing coursework? Bizzaro, specifically, refers to courses that are often taught by nonspecialists in the English department such as "Bibliography and Methods of Literature Research,” and “Literature: the Writer’s Perspective” (“Research and Reflection 308). These courses should be designed to reflect creative writing's specificity, its own bibliographies, and they must be taught with creative writers in mind.

Later, I argue for ways to apply more rigor and intelligence to the writing workshop and for ways to complement the model with course development and program trajectories at the undergraduate and graduate level. My study of the writing workshop provides important and necessary distinctions that detail how, in the model, creative writers read, write, and respond in ways that are markedly different than students of literary studies or composition studies. As such, this is one area that serves as an example of a pedagogical strand of inquiry that advances research and scholarship in creative writing studies.

In addition to the pedagogical strands of creative writing studies, Mayers includes institutional and theoretical historical strands as areas of inquiry, scholarship, and research. While D. G. Myers presents a macrocosmic overview of creative writing's history in The Elephant's Teach—managing as well, Mayers tells us, "to produce a 
foundational work in creative writing studies” (“One Simple Word” 222)—-there is still other work and approaches to take into account in this institutional substrand. One approach I take considers creative writing's institutional history in a new light as it speculates the ways in which composition and literary theories have informed our pedagogy and how this information leads to new understandings for the field of creative writing studies. Along the same lines, I study the polarization of creative writing and literary studies to reconstitute this history as an opportunity for exerting our presence and space in the emerging field of creative writing studies. Moreover, in surveying the major creative writing pedagogical practices, I link Lacanian theory to how we might view teacher-student relationships in the context of our pedagogical choices; thus, merging theory, inquiry, and practice in a new way.

Advocacy within the institution is critical to the success of our emerging enterprise. I give evidence of ways in which creative writing has "exhibited a powerful isolationist tendency, while existing nominally within English departments” (Mayers “One Simple Word” 224). To reverse this marginalization (no one can erase the history of creative writing's peripheral status) means positioning creative writers in a more visible and comfortable academic home. This situating requires an institutional advocacy measure that "would focus on examining and arguing for the proper place of creative writing and creative writers within existing academic structures" "One Simple Word" Mayers 224). To add to this dialogue, there are opportunities to rethink program development to better prepare creative writing students at variable degree and program levels. With this in mind, I outline specific options for creative writing and creative writing studies at the undergraduate, MFA and Ph.D. levels. 
Also at the academic advocacy level, Mayers offers opportunities for scholars in creative writing studies to intersect with compositionists as a means of "explor[ing] the implications of new electronic forms of text distribution” (225). I add to this dialogue and surface and affirm a long overdue argument by Bishop that creative writing courses provide value-added relevance as part of a general education requirement. Many more collaboration possibilities exist for creative writing studies in the field of media design, the fine arts, and the creative business industry—areas I discuss at further length. Finally, understanding the public lore of creative writing and the extent that popular images of the writer and the writing process surround and impact the credibility and effectiveness of creative writing as an academic discipline, and, thus, creative writing studies as a scholarly discipline, compel inquiries and research in this area, scholarship written with a more general audience in mind, and intensive public advocacy intervention. Kelly Ritter and Stephanie Vanderslice, along with contributors in their edited collection Can It Really Be Taught?: Resisting Lore in Creative Writing Pedagogy, have begun such an inquiry. I continue this conversation in my workshop scholarship. To diminish such lore would require not only considerable public attention but also considerate institutional advocacy. The acceptance of the emergence of creative writing studies depends on these advocacies.

\section{Establishing Creative Writing Studies as an Academic Discipline}

As a developing field of inquiry, scholarship, and research, creative writing studies can bring more meaning to the academy, its profession, and its student body as it establishes distinguishing features of its practice and implements a more intelligent and practical curricula design that includes the transfer of new skills to our creative writing 
students. Many questions remain as we proceed: What will our students draw from our classes? How will administrators view our developments? In what other ways might we claim our own identity through scholarship? As creative writing studies continues its valid inquiries into its practice and more formally establishes its body of professional knowledge, its goals, and its best direction, it does so with the farsightedness of a larger project of reconfiguring English studies.

Creative writing studies can participate in such a restructure, sophisticated in its understanding that the various disciplines within the English department have been rivals at times, partners at times. As the new discipline emerges, it does so with intentions to intersect and comingle with other disciplines, other departments, even community services. As the discipline matures and can refer to evidence of its own research methodology and collective data, creative writing studies will stand on equal ground with literary studies and composition studies because its academic degrees will confer upon academically-trained candidates, because its rigorous programs exist within the academy, and because it can locate its authority in its own scholarship.

My argument explores the pedagogical problems of the discipline, researches the field's history and teaching practices, and defines and distinguishes critical earmarks to differentiate the discipline from others. As a study of inquiry and research, my own scholarship justifies creative writing studies as an academic discipline. 


\section{SECTION ONE: A TAXONOMY OF CREATIVE WRITING PEDAGOGIES}

While the field of composition studies yields many useful taxonomies and axiologies on the teaching of writing, the field of creative writing studies is just beginning to emerge in this area of research. Composition's cognitive approaches, in particular, which sought correspondences between writing and learning and between how writers make decisions and choices in the writing process, might have served as a platform for parallel research in creative writing practice. It might have bridged a discussion from the writing and learning practices of creative writers to the ways in which we privilege certain teaching approaches and how these practices inform teaching planning, strategies and classroom structure. Likewise, the field of literary studies has concerned itself with the research and study of literature from multiple (albeit, conflicting) perspectives; presenting for creative writing, at a minimum, alternative methodologies for perceiving a text as verbal icon and for challenging master narratives.

What I discover when I survey the creative writing landscape for studies in teaching theories is limited. This is in spite of Wendy Bishop’s plea for creative writing research methodology, ethnographic studies, and teacher self-reports; and there is Moxley's proposal for the interrogation of creative writing practices-both published in the late eighties and both cited often in current scholarship. Their work has moved the field forward only incrementally, perhaps, because, as Moxley notes in 1989, creative writing teachers have a "relative lack of interest in pedagogy" (27). Creative writing's 
isolationist posture is “centuries old," which leads Bizzaro to conclude a requisite of creative writers' skepticism "of anything academic" ("Research and Reflections” 296). A mirroring of this "view of science-as-devourer [is] put forth perhaps most emphatically and influentially in America by Edgar Allan Poe” in his "In Sonnet—To Science”: 'Why preyest thou thus upon the poet's heart, / Vulture, whose wings are dull realities?” (Bizzaro “Research and Reflections” 296).

In general, creative writers seem to talk around the subject of research and pedagogy. The discipline often does not produce outcome data. It has little tangible evidence that affirms that our teaching methods improve student writing. In fact, because creative writing has often been defined by its writing workshop model, some in the field wonder if there is a substantial discipline from which to draw data on its teaching theories and practices, and if so, Shirley Geok-lin Lim questions "How should we begin to talk about such a discipline?” (151).

It may come as no surprise that creative writing lags in the study and theorizing of its teaching practices when we appreciate that the majority of graduate creative writing programs do not include coursework on the pedagogy of creative writing, and only a handful of such programs provides training in teacher preparation. Kelly Ritter, who surveyed Ph.D. creative writing programs in 2001, concludes "Most U.S. universities have no specific training in place that would prepare candidates to enter the creative writing classroom even remotely as well prepared as their rhetoric and composition Ph.D. counterparts" ("Professional Writers” 213). In my own university, even literature students often complete a practicum in the teaching of literary studies at the university level. The point to be made here is twofold: The first is that teacher training would assuredly 
include topics and/or courses in the history of creative writing, the theories behind pedagogical approaches, research methodologies in creative writing, contemporary issues in creative writing, and, possibly, curricula design. The second reason to champion teacher training is partly rolled into the first point in that an awareness of historical approaches lays the groundwork for important research studies that influence how we practice, how we teach our students, and where meaning lies in our classrooms. It stands to reason that an immersion in the field's history and in teacher training will lead to more critical rethinking of our modes of instruction and notions on how to communicate these approaches to our students.

Tim Mayers calls for an inquiry into the field's history beyond the contextualization of creative writing. There exists a few important historical inquires such as D.G. Myers’ The Elephants Teach (1996), Stephen Wilbers The Iowa Writers Workshop (1980), Patrick Bizzaro’s Responding to Student Poems (1993), and Paul Dawson's Creative Writing and the New Humanities (2005). Of the books mentioned, only Bizzaro and Dawson suggest ways to learn from creative writing's history and offer new avenues to approach its practice. What Mayers has in mind is for creative writing teachers to go beyond this historical research, to discover different ways to consider our history, new paths to contextualize its meaning, variable insights so we might see history in a different light. I suggest that there is still much we can learn from the history of creative writing (from Emerson's naming of creative writing in his The American Scholar in 1837 to contemporary creative writing praxes in university programs that inform our teaching practices). There exists significant data from which we can form conclusions 
related to our teaching approaches and by which we might better integrate strategic program development in light of the new challenges we face in the twenty-first century.

In the eighties, Wendy Bishop lamented that creative writing teachers knew little of the theory that informed their pedagogies, and as such, they could not voice the tenets behind their classroom practices because they lacked reference. More than a decade later, D. W. Fenza advances her concern when he says, "Few writers in the academy know the history of their own profession as teachers of writing” (para. 16). In fact, Bizzaro suggests practitioners "view creative writing as something that has stumbled, by chance alone, into academe” (“Research and Reflection 295”). What is more, because writers do not know their history, they miss opportunities to address the theoretical rationale of the practices in their classroom. As such, Fenza tells us that "they sometimes find it hard to defend their work against the scholars, the theorists and commentators who trivialize it" (para. 16). If we are to bring the relevancy of history to current teaching practices, then we must include the view of English department chairs such as Stephen Tatum of the University of Utah whose essay in the ADE Bulletin (1993) forewarns "The End of Creative Writing in the English Department.” While Tatum's discussion does not necessarily include the teaching of creative writing, he does regret the curricula of graduate programs which positions history (of genres, of literature) as an adversary to the creative writing candidate. His complaint has significance for the creative writing graduate who interviews for tenure-track positions today. This lack of history and its pertinence to a candidate's field and subsequently to her teaching opportunities is a reality we cannot ignore or resist in our reform. Given creative writing's changing goals, one which moves us from a generation of publishing writers to teachers performing in the 
creative industries of education and business, it is time, as Bizzaro urges, "to reconsider the way we think of creative writing as a teachable subject” ("Research and Reflections" 300).

It becomes difficult, I suggest, to ground theoretical underpinnings to our teaching pedagogy without such historical reference. Moreover, the lack of empirical data and investigative studies into creative writing's teaching praxes leaves much of what goes on in the creative writing classroom unexamined, untheorized. Consequently, creative writing continues to operate from a base of assumptions that is situated more on practice than on research. However, if creative writing practitioners can agree on the principle that what they teach in their creative writing classes filters down to how they teach their creative writing students, then it is possible to break this hypothesis down further to conclude that methods of pedagogy are driven by a teacher's perception of where meaning lies in the context of the writing process. What a teacher privileges as it relates to text, writer, reader, and reality (as an implicit or explicit world-view) is tied directly to her pedagogies, to the structure of her classroom, to her course planning, selection of readings, choice of exercises and assignments, reading practices, classroom management, workshop practice, social relations, and evaluation, justification, and the grading of course requirements.

As my research interest relies on history, pedagogical implications, and curricular design, what I propose is a four-part taxonomy of teaching approaches that converge, in part, on the principles underlying Berlin's analysis of teaching differences as those "located in the diverging definitions of the composing process itself" (256). Berlin insists that all pedagogy is ideological; any single approach supports an underlying set of values 
while questioning others. These rhetorical elements are often represented as a triangle, and as such, the element placed within the triangle assumes the greatest teacher emphasis. Pedagogy, as John Trimbur reminds us, is exacted by ideology.

Similarly, the operational pedagogy of creative writing teachers can be analyzed according to a set of interactions among the elements of the composing process. Equivalently, teaching differences of creative writing teachers are located as disparate privileging (rather than "definitions") of the composing process.

While Berlin identifies four principal pedagogical theories and concerns each with the way it interprets and associates writer, reality, audience, and language "to form a distinct world construct with distinct rules for discovering and communicating knowledge” (“Contemporary Composition” 766), his classifications and purposes do not necessarily align optimally for the case of creative writing pedagogy. The "dominant" composition teaching theories engage with, among other elements, principles of truth and its relationship with the world and to language, reality as it exists to the writer, and inductive versus deductive processes.

This is an oversimplification, of course, of the field's teaching constructs; however, there is more relevance in an analysis of creative writing's salient pedagogies and their strategies for communicating where meaning lies in the composing processes, in M. H. Abrams' four overriding theories of artistic transaction as outlined in The Mirror and the Lamp (1953). I approach my taxonomy of creative writing pedagogies by using Abrams' classifications to explain his: (1) objective theory - which describes New Criticism, a creative writing pedagogy that privileges meaning with the text, (2) expressivist theory - to detail expressivist functions of self-expression and Romanticism 
that place meaning for the creative writing teacher with the writer, (3) mimetic theory to discuss the imitable functions of the writer's world that emphasizes that meaning lies with the "universe," and (4) pragmatic theory - to characterize reader-response pedagogy that situates meaning with the reader.

Moreover, a second major strand in an axiological study of teaching practices involves the complicated social relations within the structure of our creative writing classrooms that are created, in part, by the constructs of our methods and philosophies. As practitioners, we tend to oversimplify the interactive and dialectical nature of the teacher-student relationship. However, when teachers can view their classroom dynamics through a Lacanian lens, they can better understand the actualities of students' behavior both in class and in their writing and how teacher-student interaction influences such behavior. More specifically, psychoanalytic theory (to the degree that it applies for my purposes) offers valuable and concrete assistance in explaining—through Lacanian theories of the Real, Imaginary, and Symbolic Orders, and the dynamics of transference and counter-transference-what goes on beneath the surface of our writing instruction and how we might decode it more constructively for ourselves and for our students.

\section{Where Meaning Lies - A Multi-Faceted Approach}

In Professing Literature: An Institutional History (1987), Gerald Graff contends that “no text is an island” (Professing Literature10). Todd F. Davis and Kenneth Womack add that "no form of theory or act of criticism is an island either" (1). Graeme Harper cautions us not to moor our students' learning to one specific island when he suggests in his introduction to Teaching Creative Writing that the "learning of creative writing” by our students "gains nothing at all from being considered the remit of only one type of 
learner or one type of teacher” (1). Fulkerson offers that "Even if you know where you want to go, a shrewd Cheshire Cat can point our more than one path to get you there, as well as some attractive ones that won't” (Fulkerson 424). Moreover-and this is an axiom borrowed from James Berlin’s taxonomy of composition pedagogical approaches—creative writing teachers must also be cognizant that through their determinable intent, they “are tacitly teaching a version of reality and the student's place and mode of operation in it” (“Contemporary Composition” 766).

My posture leans more toward not privileging any one element of the communication transaction, whether it is finding meaning with the text, the writer, or the reader. Instead, we must continue to challenge and question the underlying set of values Berlin associates with each pedagogy so as to acknowledge the assorted and changing ideological forces at work. Teachers can avoid such conflicts when they are aware of their own pedagogies, stay current with research and scholarship, and make adjustments along the way to their approaches. Assessing our own pedagogy is critical to what and how we pass on writerly and readerly skills to our students. While there is expected overlap as Abrams suggests_- “Although any reasonably adequate theory takes some account of all four elements, almost all theories ... exhibit a discernible orientation toward one only" (6) - teachers should be conscious of their pedagogical theories as much as this is possible.

Perhaps, it is even time for creative writing teachers to ask what alternative methods they might conceive in their classrooms. For example, creative writing teachers might begin with practices based in composition theory or literary studies theory and find new ways to apply such principles to the specifics of creative writing as they keep in 
mind the unique ways that creative writers think, read, and write. Haake concurs that there is value in engaging in a "spirit of interdisciplinary curiosity" as it "will help us reconstruct our own projects [pedagogies] in such a way as to respond not only to the needs of all our students but also to our own” ("If the Shoe Fits” 81). Stagnated as we may be on any one given practice, or worse, not knowing the implications of our practices, limits the direction of our teaching strategies, our course design, and our students' ability to broaden their knowledge and reading/writing skills. We must, as Haake notes, "reject as our purpose the unexamined, single-minded pursuit of the literary artifact,” and once we can move beyond the kind of funneled teaching that contains us, we "must then ask how we might begin to re-envision and transform not just our expectations of our students and their work, but those also of ourselves and our own work, at least within the context of our discipline” (If the Shoe Fits” 81). Such reenvisioning and transforming might include varying classroom methodology, experimenting with different approaches, and opening the creative writing course to the emergence of new theories that might come about as a result of conscious blurring of the lines between approaches. Studies and practices such as these propel creative writing studies forward as a separate and distinct discipline with research and scholarship of its own making.

As methods of pedagogy are driven by how we locate meaning in a text, one of my greatest concerns relates to model confusion, a case where teachers apply meaning in one composing structure, but evaluate according to another. Our reading and writing processes are informed over years of practice, and as such, when we teach these processes to our students, we must be careful of conflicting theories. Bishop cautions 
teachers that "it is possible to hold unexamined or conflicting theories and to be resistant to theoretical and practical changes” (Released 15). Too often teachers confuse their students when they apply differing motivating philosophies in the classroom, "guidance grounded in assumptions that simply do not square with each other” (Berlin “Contemporary Composition” 766). One approach may signify meaning in some element of practice (i.e. the reading of professional texts, the choice of writing prompts) and another as it relates to the evaluation emphasis (i.e. revision suggestions for student drafts, judgments of what constitutes “good writing”).

Model confusion comes about when teachers are unaware of their practices. Sharon Crowley shares why the teacher who is either unaware of his practices or does not examine his pedagogy, will tend to bewilder or mislead his students. Crowley hypothesizes how this might occur by noting "if a practitioner accepts recent lore concerning 'process pedagogy,' but has not altogether rejected traditional composition theory, it will be difficult for him to discern whether his particular combination of the two pedagogies entails contradictions or confusions” (qtd. in Bishop Released 15). Bishop complicates this practice when she adds that "Not only may a teacher implement conflicting pedagogical practices, she may overapply a model, which leads to classroom conditions that are just as restrictive as the ones she has abandoned” (Released 15).

My aim in this four-part perspective is to deliver a clear and comprehensible view of what goes on in the creative writing classroom. This taxonomy of the four major creative writing pedagogies will help teachers examine and name their pedagogical practices and to root their methods and philosophies in one or more of the four pedagogies. I trace the historical antecedents of the four major teaching theories and 
demonstrate their current classroom practice, and, in each case, I outline the location of the teacher's authority in the composing process and the implications of such privilege. As a result, this study helps practitioners become aware of their pedagogies and the theories that underpin these practices. Such scholarship helps teachers present clearer writer processes to their students and adds to research which is necessary to develop creative writing studies.

Ideologically based methods, values, and emphases influence current approaches to evaluate student writing. We must continue to examine these approaches. Whenever possible, creative writing teachers must be aware of how their history informs their pedagogy. They must define their practice and be aware of where they place meaning in the communication transaction and how their privileging affects their pedagogy and their students. It is important, also to consider the affecting student relations in the creative writing classroom; perhaps a Lacanian perspective would be helpful.

At the very least, instructors can extend their pedagogical understandings by, as Gerald Graff suggests, “teaching the conflicts” (“Conflict Pedagogy” 277) in their courses, sharing with students how the shapes of their pedagogies are influenced by where they privilege meaning in the composing process, and in this dialogue, they should aim for clarity in terms of what they consider and regard in their evaluative processes. My worry is that too many of us will become numb to the repetition in the organizing principles of our classroom, and if I can play with the pronouns of Katherine Haake's words in "Dismantling Authority: Teaching What we do not Know," I would ask: How many of us "hear [ourselves] tell the same stories, say the same things— to teach, as it were, what [we] already knew?” (99). To continue her thought printed in What Our 
Speech Disrupts, Perhaps it is time to acknowledge that there is no longer any one way in creative writing teaching, and to begin to ask what are the many ways there are?”(3). This taxonomy begins such a dialogue.

\section{Orientation of Critical Theories}

The nature and value of a work of art, the work's relationship to other variables (the writer, the audience, the universe), and the work as an autonomous whole, constitute, for Abrams, the principal categories for defining, classifying, and analyzing a work of art, as well as the major criteria by which the value of a work is judged. Like Berlin, Abrams' framework is best represented by a triangle. Unlike Berlin, who opens the triangle’s center space for insertion of the element which receives the greatest emphasis, Abrams fixes the work of art as "the thing to be explained" (6) in the center of his triangle. The relationship between the work to the artist, audience, and universe is indicated by directional arrows as noted below.

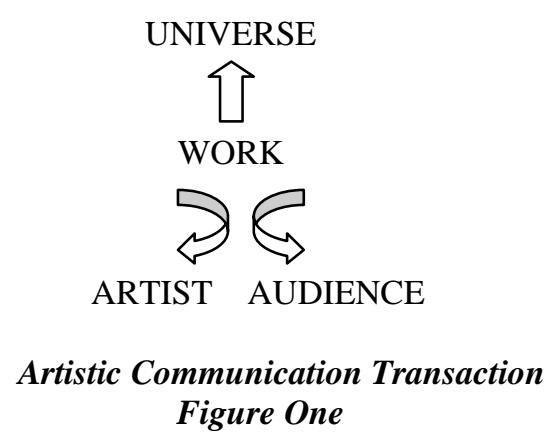

Abrams is careful to observe that the four elements which he defines as "the total situation of a work of art” (6), vary "according to the theory in which they occur” (7). For the purpose of my analysis, the centrality of the work of art in Abrams' framework is seen in more fluid or positional terms as are the remaining composing elements. The important schema is the teacher's motivational philosophy to any of the core composing 
processes: the work, the writer, the reader, or the universe-or in the language of Abrams’ corresponding pedagogical theories: the Objective, the Expressive, the Mimetic, and the Pragmatic. In my theoretical framework, I refer to Abrams’ Objective Theory as “New Criticism.” I maintain his Expressive Theory, but I split this theory into two strands: Self-Expressive and Romantic. The Mimetic Theory in the creative writing classroom remains predominantly the same as in Abrams' application although I also refer to it as an “Imitable Theory.” I get a bit more specific with Abrams’ Pragmatic Theory and name it Reader-Response Theory. The diagrams for Abrams' taxonomy of theories and my taxonomy of theories are listed below:

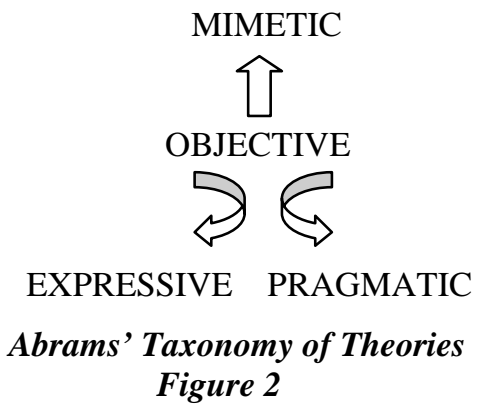

\section{The Objective Theory as New Criticism}

\section{Historical Antecedents}

New Criticism functioned as a departure from the historical study of literature in the early 1920 s to one in which the formalist characteristics and study of literature would be viewed from a technical standpoint. The passage of poet-critics into academia during the 1920s and 1930s coincided with, and was in part facilitated by, this practical criticism. The criticism for these young poet-critics grew out of their practical interest in writing poetry. In fact, it was through the tenets of the texts and the critical ways of 
reading by poets working as critics that soon advanced New Criticism as the dominant literary ideology. The key figure in this theory was T. S. Eliot, whose performance as critic and poet so impressed the academy that it was possible for poetry to be thought of as a "wholly respectable undertaking” (Weiss 152). This, in turn, helped to shape the American poets who came onto the academic scene in the 1940s, among them Robert Lowell, Elizabeth Bishop, John Berryman (who would go on to teach at the Iowa Workshop), and Randall Jarrell (Myers The Elephants Teach 129), the latter who would go on to claim of New Criticism’s overall effect: “I do not believe there has been another age in which so much extraordinarily good criticism of poetry has been written.” The new critical approach to poetry during this period literally "swept the country" (Weiss 152).

Once creative writing became "an institutional site for the literary authority of writers” (Dawson 76), the practice of the workshop (which includes the close reading of student manuscripts) became situated and grounded on the principles of practical criticism, and creative writing concerned itself with analytical and evaluative perspectives of the text as a finished product. Between World War II and the term of the Vietnam Era, New Criticism mobilized as a means for teachers to remain apolitical in the university system. Bizzaro explains:

Well known is the theory that in the post World War II period, when university professors were anxious about having their political preferences called into question, the New Criticism, by virtue of its elevation of the text as authority for meaning, made the study of literature apolitical and, as a result, safer than innocent membership in certain social clubs. (Responding 236) 
In addition to wartime civics sustaining New Criticism as a measure of political privacy, Bizzaro concludes that the number of "literary specialist" graduates over the forty year span between World War II and the Vietnam Era led to the teaching of New Criticism in the academy. As such, it is not surprising that New Critical pedagogy and its privileging of the text persists as a major theoretical strand in our creative writing classrooms.

We know that once New Criticism became established in the university, its practitioners turned their scrutiny onto the internal structure of poems, applying the technique of close reading as a pedagogical tool. In this manner, New Criticism is linked to creative writing in that "it devised an operational pedagogy - practical criticism - to promote its views of literature" (Dawson 76). The New Critics did more than anyone to advance the cult of autonomy; consider first, the widespread promulgation of Understanding Poetry as the quintessential textbook, and secondly, as an attachment to the book, a Letter to the Teacher on which Brooks and Warren dictated: "though one may consider a poem as an instance of historical and ethical documentation, the poem in itself, if literature is to be studied as literature, remains finally the object of study" (qtd. in Myers The Elephants Teach 130). Despite the fact that many say New Criticism is no longer a viable approach to the study of literature, it remains steadfast over the sovereignty of the poem [and fiction] so that it prevails more unflinchingly in the creative writing classroom than anywhere else. Here, it not only "survives and is prospering," as a pedagogical practice, but it also "seems to be powerless only because its power is so pervasive that we are ordinarily not even aware of it” (Dawson 105).

\section{* Pedagogical Practice}


Some, like Jane Thomkins, suggest that we have not renounced New Critical methods of reading and evaluating as these are the principles that "everyone still carries around in their heads, whether they've been studying post-structuralism for twenty years or have only begun to study it today" (qtd. in Bizzaro Responding 39). For those who argue that creative writing pedagogy does not emphasize evaluation of the finished product as a New Critics tenet, but rather measures instead, the "process, perhaps biographical, historical, developmental, intentionalist” variables of student writing, Tilly Warnock offers that "Our practices in responding to texts still seem tied to New Criticism's concern for unity and intensity of words-on-the-page” (qtd. in Bizzaro Responding 39).

We can pick up the stitches of New Criticism, initiated by the early twentiethcentury partisans of criticism and locate their tight weave in the fabric of today's creative writing pedagogy. In particular, the practice of privileging texts as verbal icons, the ease of teaching from a New Critical perspective, and the standards of evaluation-its interpretation of the text as finished product, the teacher as exemplary reader, and the issue of appropriation and text manipulation alone-are components of both interest and concern.

\section{$>$ Pedagogical Practices :Texts as verbal icons}

The teacher who places authority on the "work" or "text," regards the work in isolation from any external reference. She "analyzes it as a self-sufficient entity constituted by its parts in their internal relations, and sets out to judge it solely by criteria intrinsic to its own mode of being” (Abrams 26). Her teaching strategies extend to an "objective orientation,” which affect all aspects of her teaching practice. In the creative 
writing classroom, where the object of criticism is the text, many teachers still depend on New Critical methods as a dominant pedagogy. Francine Prose, in her chapter entitled "Reading Like a Writer," shares ways in which she learned to write. Her process and lessons for new writers echo New Critical ideology when she shares how she reads "more analytically, conscious of style, of diction, of how sentences were formed and information was being conveyed, how the writer was structuring a plot, creating characters, employing detail and dialogue” (3). These elements, in their most basic forms, are the analytical and technical functions of a New Critical approach to a text. Prose suggests that "[a] good teacher can show [students] how to edit [their] work, how to appreciate as she does, "that writing, like reading, was done one word at a time, one punctuation mark at a time ... 'putting every word on trial for its life': changing an adjective, cutting a phrase, removing a comma, and putting the comma back in” (3). Following the tenets of New Criticism, Prose states she "read[s] closely, word by word, sentence by sentence, pondering each deceptively minor decision the writer has made,” "unpacking” the story as it is sometimes referred. In this method, students read published stories and their peers' work, scouting for elements of craft, "tracing patterns," "cracking a code,” beginning, as many of us do, as close readers.

Once creative writing became "an institutional site for the literary authority of writers," the practice of the workshop (which includes the close reading of student manuscripts) as the field's "signature" pedagogy became situated and grounded on the principles of practical criticism, and the discipline concerned itself with analytical and evaluative perspectives of the text as a finished product. Ostrom recognizes the New Critical perspective in the workshop setting and teacher materials. He suggests, this 
objective theory persists "to a large extent" as "it still dictates the terminology—and the view of the text as verbal icon—in workshops, anthologies, reviews, and books on writing” (xv). The practice of New Critics “to examine a poem” as a means of "examin[ing[ its construction—with the ruthless skepticism of someone who might have constructed it differently," is not unlike craft-based pedagogy, a practice of reading stories for the models of craft present in today's creative writing courses.

Because of its focus on craft elements, on what Ostrom refers to as "durable Aristotelian aesthetic ideas” (xv), New Critical methods can often lead, in the workshopping of student texts, to an editorial direction, to a "simple attention to technique," and, as a result, issues that go beyond the text as an isolated object are not addressed as students are to read only the words on the page. Tim Mayers reiterates the influence of "[t]he technique-oriented Iowa workshop model," which he stipulates worked well for many students in terms of "helping them toward revisions that enabled them to publish their creative work and, in some cases, helping them earn credentials that landed them jobs as professors of creative writing” ((Re)Writing Craft 144). The latter, of course, perpetuated the recycling of New Critical pedagogical methods.

In fact, Mark McGurl suggests that the influence of New Criticism is evident in all of Flannery O’ Connor's published work. O’Connor had attended the Iowa Workshop for two years. She studied with Robert Penn Warren whose textbook/anthology he coauthored with Cleanth Brooks was publically endorsed by O’Connor as her "bible.” Eileen Pollack, another Iowa Workshop graduate, speaks generally of the "New Critical approach” being “in the air” (547) at the Iowa Workshop. As it relates to O’Connor, Pollack claims "the tenets of the New Criticism shows itself in the care with which she 
selects and arranges every concrete detail, every bit of dialogue, every gesture and larger action, whether to render the setting authentic or a character believable.” In fact, Pollack points to us, O'Connor "gave the Misfit [in "A Good Man is Hard to Find”] a black hat because that is what a man of his age and station would wear" (Pollack 552).

Pollack and Mayers both echo my position that New Critical approaches in the creative writing classroom need to be identified as such; then re-evaluated as useful pedagogical tools among the many others we offer to students.

To further illustrate the extent of the New Critic method in creative writing classrooms, Hal Blythe and Charlie Sweet define "the techniques approach" in their characterization of variable teaching strategies in creative writing classrooms. The authors include a 1913 definition of this method by Columbia professor George Krapp as a "tendency on the part of some college instructors to place a great stress on the teaching of practical technique in literature” (qtd. in Blythe 312). This techniques approach sounds very much like the New Critical practice of emphasizing inherent qualities in writing as a literal practice and pedagogical tool. Blythe and Sweet add to this description, noting the approach is one which emphasizes the illustration of technical components in readings so that students might internalize the technique and then offer their own version. "The underlying belief of this approach," the authors write, "is that the proper understanding of and practice with poetic, dramatic, creative nonfiction, and fictional techniques produce the works" (313). While the technique, in its "practicality” can "demystify[y]” writing with its appeal "to the rational, democratic person—you too can learn to be a writer—-the approach can also, the authors rightly note, "be abused by plot wheels, formulaic writing, 
and how-to-books that taken to the nth degree suggest that writing is pure craft” (Blythe 313).

In fact, a good deal of promotion for New Criticism’s evaluative and taxonomic language of craft and technique still comes in the form of creative writing "how-tobooks," guided textbooks not so far removed from the syllabic texts of the 1930s. This particularly holds true for Understanding Poetry, its sections "punctuated" with "close readings” of the poem “as poem.” The text went through its fourth edition in 1976 (which bespeaks of the long-lastingness of New Criticism's effects), and its companion volume Understanding Fiction (1943) followed the same close analysis of language and structure. Cleanth Brooks published Modern Poetry and the Tradition-sometimes cited as the best introduction to the New Criticism—in 1939. Two years later, New Criticism appeared as the name of John Crowe Ransom’s 1941 text (Graff Professing Literature153), and the movement may have peaked in literary history, but its insidious practice remains dominant in the creative writing classroom.

Pick up almost any creative writing handbook to find a table of contents neatly compartmentalized into “Elements of Fiction” (plot, characterization, setting, point of view, voice) or "Elements of Poetry” (meter, metaphor, rhythm, rhyme, style) as the case may be, complete with a synopsis of each craft element (best practices, pitfalls, what to consider, define, describe, differentiate, explore)—a virtual “how-to,” followed by exemplary stories or poems that model the elements of craft. As a graduate student, teaching her own undergraduate workshops, Pollack discovered as I had, that, not surprisingly, the dozens of textbooks and anthologies that were modeled along the lines of Understanding Fiction (1943). Pollack also notes that no matter how much she 
encouraged students to ignore/rebel/change up the covenants of New Critical techniques in her own creative writing classes, "the principles that Brooks and Warren set forth in Understanding Fiction still exert a powerful influence on any writer who comes anywhere near the academy” (547).

I certainly do not dispute the importance of close reading or craft-based pedagogy as these rudiments work well for beginning students. Additionally, a case can be made that there is an element in relief for students who workshop their peers' stories in that the attention is on the text rather than the author who sits just a desk or two away in the same circle as they do. My argument against the New Critical approach is that there seems to be a tendency for many teachers to rely on this study of craft in its simplest form, and in doing so, there is an expectation that students will learn by osmosis—-here's how it is done-here's what it should look like—now it's your turn-you try it. Janet Burroways’ 2007 handbook, titled Imaginative Writing: The Elements of Craft. A popular textbook for classroom usage, is a good example of this New Criticism prescriptive style.

\section{Pedagogical Practices: The Ease of Teaching the New Critic Approach}

Part of the dominance and popularity of New Criticism in the field of academic criticism in university English departments in this early to mid-twentieth century (and later) can be traced to its ease of teaching such that any need for prerequisite knowledge and/or course preparation was minimal. Katharine Haake reports such an ease when she says, "What could it take, after all, to sit around in a circle and explain to my students how to make their stories better" ("If the Shoe Fits” 77). Christopher Clausen, author of “Reading Closely Again,” considers also the ease in learning the New Critical method. He adds "any student with an interest in literature, regardless of a presence or absence of 
a background in any other field of study, could become proficient in the New Critical method.” Correspondingly, Clausen reports, "no professor of literary studies was required to subtract from the study of literature in order to impart these backgrounds to his students.” Gerald Graff comments on what he has seen as the dependence of New Criticism as a necessary support for teachers. He cites his own teaching experience as an example, noting:

It was perhaps the instructors who needed the New Criticism most . . . From my own experience ... in a stepped up $\mathrm{PhD}$ program of the early sixties, I can testify that usually I was lucky to be one evening ahead of my undergraduate classes. I remember the relief I experienced as a beginning assistant professor when I realized that by concentrating on the text itself I could get a good discussion going about almost any literary work without having to know anything about its author, its circumstances of composition, or the history of its reception. Furthermore, as long as the teaching situation was reduced to a decontextualized encounter with a work, it made no difference that I did not know how much the students knew or what I could assume about their high school or other college work - just as it made no difference that they had no more basis for inferring anything about me than I had about them. Given the vast unknowns on both sides of the lectern, "the work itself” was indeed our salvation. (Professing Literature 178-9) Similar to Graff's discussion, William E. Cain claims that from day one of a creative writing course, "teacher and students can read and respond to poems, exchange views about tone, paradox, and imagery, and make discriminations about relative degrees of complex thought and feeling in texts" (101). Cain admires the "democratic" 
functionality of this practice. He contends "teacher and students gather round a common object, and all strive to give the most detailed and sensitive reading possible. Such a method quickly enables the student to feel accomplished as a "reader." He or she is empowered to see the writers' techniques or elements of craft. Cain suggests this leads students to "experience[e] the pleasure of a new kind of expertise" (101).

\section{$>$ Pedagogical Practices: Evaluation}

J.E. Spingarn, who first provided the name "New Criticism" in 1910, posits that the central question of criticism (of any art form) asks: "Has [the artist] or has he not created a work of art?” (Myers The Elephants Teach). Allen Tate asks a similar question: "What as literary critics are we to judge?” (qtd. in Cain). For the New Critics, evaluative criterion for judging what is "good writing" was not based on the subjectivity of taste. Rather, the determination of a "work of art" was conducted according to a set of standards. Questions of whether an artist has created a work of art are answered, by New Critics, through an analysis that considers if "the work has the same sort of stable and 'objective' status as a language, [which] exist[s] in a 'collective ideology,' governed by enduring 'norms"” (Lynn 259). For example, a "close reading” reveals "how the formal elements of the literary work, often thought of as a poem, create and resolve tension and irony” (Lynn 259). The valuated "norm,” in this case, is that "[g]reat works control profound tensions” (Lynn 259). As such, these types of standards would be the ones upon which a poem would be measured.

To add to this, the ultimate goal to ascertain a text's meaning by offering a close analysis of the text is made possible by way of an exemplary reader. To take this one step further, not only is the text seen as the final authority of such determination, but its 
exemplary reader, through his or her elicitation of the text's meaning, is viewed as the final authority as well. When a teacher places meaning solely on the text in the composing process, she gives the text final authority in the evaluating practice, and she claims herself to be the final authority as an exemplary reader.

\section{Pedagogical Practices: Evaluating the Text as Final Authority}

The problem with a New Critical approach is one of perspective. The text exists in isolation, as "words on the paper," never as an incomplete work, but rather, according to Edward White, as a finished product "in general in order to be criticized” (qtd. in Bizzaro Responding 236), particularly, Bizzaro tells us, "when held alongside what Nancy Sommers calls an "ideal text” ("Research and Reflections” 236). Additionally, a New Critical approach becomes complicated because whenever a text is objectified or is perceived as final authority, the reading of student work and the workshop dialogue that follows, traditionally, silences the author. This silence is witnessed as a consequence of the overt discussion of students' poems and stories but also in the exclusion of any possible biographical coincidence the writer may have to the speaker of a poem or a fictional character in a story. In other words, no authorial intent or biographical nature let alone social or cultural contextualization embraces or implicates the author. In this type of singularly focused reading of the student text does not "grant to the student possible intentions or insights not yet present on the page” (Edward White qtd. in Responding 53).

While Mayers does not suggest that "all creative writing teachers bring New Critical sensibilities to their classroom," he reports that:

my experience in creative writing classes has been governed by the implicit understanding that the student text, though worthy of intense scrutiny and 
criticism, should be conceived as occupying a sphere all its own, largely outside the bounds of economic, social, and material realities, largely outside of any rhetorical relationship to the world in which it presumably must operate.

((Re)Writing Craft 139)

With this method, there is ease in avoiding social and political implications when the focus is "so sharply on the student text as to obscure any questions about whether, and how, the individual student text might fit into a larger textual network" ((Re)Writing Craft 139). Indeed, New Critic advocates might accuse those teachers who permit social/historical commentary in the classroom as authorities with the "political clarity" our students lack. In the effort to create political citizenry, some teachers enforce their own theories and determinations as justifiable, and as evaluators of our students' work. Some teachers might ask what kind of vulnerable posturing do we insist (consciously or not) for our students, but one that acquiesces to our view?

Prioritizing the text by giving the words on the page power proves limiting for groups of our students. For example, Nicole Cooley who works at an urban multi-cultural public university, finds the New Critical reading strategy which excludes extrinsic factors to be "problematic" for her class "because many of her students have been silenced outside of the classroom for too long” (101). She sees the New Critical workshop practice as one that decenters her writers and prompts an unhealthy silencing of her students' differences.

The focus on the text as authority has caused poetry to become disengaged from a wider audience for those like Dana Gioia, because it perpetuates itself through academia. If what Gioia says is true in his essay "Does Poetry Matter?” then teachers should be 
taking time outside of their workshop-centered classrooms (a coveted place where many vehemently hold is the only place where time can be spent on student writing) to explore ways in which their students' texts address/represent aesthetic and political sensibilities? Chris Green suggests that, indeed, creative writing practitioners should explore extrinsic influences when he proposes that "before asking how students can better write "good" poems," we should "look beyond the gaze of the sublime reader and ask how students can write useful poems” (159). By “useful” Green means “a workshop where the class readership acts to represent the rhetorical circumstances of interpretive communities outside the university” (154). Creative writing teachers foster this view of exclusion when they center their focus on the authority of the text.

Rather than apply New Critical methods in her creative writing course, Cooley, for one, circumvents such blinders to the outside world when she extends the boundaries of the canonized works as the primary reading choice for a creative writing course. In this manner, she advocates a textually-based class "in which students read other texts as models for their own work.” As a result, the dialogue of these non-canonical literary texts (with "literary" defined as culturally- and/or historically-valued) becomes a more appropriate location for which to "stage the issues and teach our ways of reading for workshop” (191). David Radavich agrees with this approach, insisting that in addition to teaching the "particulars of form and evocative expression," creative writing courses "worth their enrollment" should teach "reading, critical thinking, and awareness of historical context” (111).

For example, after a discussion of a story's architecture, its use of language, and the choices writers make related to point of view, scene construction, voice, dialogue, 
characterization, setting, and plot structure as they apply, teachers might attempt to contextualize the story at other levels. A creative writing class might read Charlotte Gilman's “The Yellow Wallpaper” from a sociological, political, or psychological perspective, extending considerations beyond the tale of female insanity and mayhem. Students could talk about the struggle against the wallpaper's "bars," the women lost in its “torturing” pattern, the challenge of nineteenth-century patriarchal ideologies.

By extension, a creative writing class could segue from professional stories to their own by letting the fiction they read resonate with their personal stories. They might discuss how characters battle against their own hideous paper, their discontents, their insurgent revolts against that which imprisons them. One student might write about the atrocities of domesticity, her story beginning with a protagonist who considers the bruises she hides under the shawl she wears at her husband's funeral. Another writer could construct a story about man against machine, writing about the crushing effects of its well-greased part, the ambiguity of the narrator's gender purposely intended. A creative writer can develop a character who makes it a point to avoid the year 2006 in his time travels because it is the real trigger of the war, because the seeds of annihilation are ignored by Americans who had more important things to worry about, such as the rising costs of prescription drugs and how their vice president had accidentally shot his friend on a hunting trip. One story might deal with a girl's separation, the first week away from family and friends, the longest she's ever gone without sleep, the crack in the ceiling, the reason this is the cheapest dorm, the girl, who used to be her best friend, who now calls her "fatty." To avoid reading the text as final authority, we might link stories with our 
own, talk about their social impact, and the cultural and historical considerations that influence what and how we write.

We might surpass a linear reading of professional stories by taking our discussions beyond the summary of the plot, the description of characters, and the elements of craft when we consider the works as a textual sphere, one which has a multiplicity of readings, contexts, and relationships with the public world. We might choose some specific facet, some internal aspect, and compare it to other stories. The cosmetics of death, for example, its variance from culture to culture and from person to person are central in stories like "In the Cemetery Where Al Jolson is Buried" by Amy Hempel, Tolstoy’s “The Death Of Ivan Ilych,” Tim O’Brien’s “The Things They Carried," or "Indignus," a student story in which a girl decides on a trip "because maybe [she's] become too comfortable," because it's been one year since he died. She thinks "how he must have shuddered on his bike, its metal frame, pedaling through the traffic towards the hospital. Alone.” Students learn to develop rhetorical perspectives when they write brief essays in which one story is viewed in light of another, and in this manner, we include the public realm, taking time for "reflection on the very enterprise of creative writing as it relates to larger social, political, and rhetorical trends” (Mayers (Re)Writing Craft 48).

When teachers and students challenge the exclusivity of the text as final authority then more variable approaches to reading and writing can open spaces for more experimentation and direction. Such an inquiring perspective leads us to question the view of the text as final authority. Cooley asks important questions, such as: "What can we learn from literary criticism and theory if we approach creative writing with a more 
inclusive pedagogy?” We should also ask how might we challenge literary codes? Who decides what makes for good writing? Who decides "what is a poem? What is a story? What is a play?” Instead of implanting “in our students a set of unexamined values for them to deploy in their own work," Cooley's class, for instance, discusses what makes "good writing" as they examine the confines of the canon. She encourages teachers to "break the rules,” "reconfigure generic categories,” "challenge literary codes.” Along the same lines, Katharine Haake comes to question the text as verbal icon. She admits that she thought she wanted her students to "view their texts as autonomous literary artifacts, separate from their real selves and subject to analysis”; and so she began, considering how Francois Camoin once began with her: "if you want to build a funhouse, a set of working blueprints would prove useful” (qtd. in "If Shoe Fits" 78). But then she worried over "her students struggle to analyze their own textuality" ("If Shoe Fits" 78). In response to Scott Russell Sanders' urging that we "concentrate on 'artistic criteria' as the only aspect of writing over which we have any “control,” Haake justly questions “whose criteria are these? Where did they come from?” (“If Shoe Fits” 85).

$>$ Pedagogical Practices: Teacher as Final Authority, as Exemplary Reader In Bizzaro's comprehensive view of the ways teachers respond to students' texts in his book Responding to Student Poems (1993), he notes his sense that teachers "have historically appropriated their students' writings," and that part of this concern is secondary to the limited attention paid to "how we should comment on our students' work" ("Wings on the Invisible” 85). In an effort to avoid the appropriation of students' texts- “its values are the values expressed in most teachers' interpretations of their students' texts"-Bizzaro applies theories "heretofore employed only with 'sanctioned' 
literature” as a reading strategy when he reads and evaluates students' poems (“Wings on the Invisible” 85). He references Alberta Turner’s findings in Poets Teaching (1980), a collection of student work and teacher responses to show us that most poet commentaries advance a text-based approach to interpreting students’ poems. One contributor offers: teachers tend to view the poem as an entity in isolation, "a little world of words," which either engages the reader and is deemed a success or fails to engage the reader and, as a result needs to be revised [reminiscent of Spingarn's inquiry: "Has (the artist) or has he not created a work of art?”] Second, teachers tend to assert the authority of the exemplary reader when they model a teacher-centered method for teaching revision skills. (qtd. in Bizzaro Responding 42)

An example of the latter form of teacher assertion is the instructor who "takes the student poem as his own and verbalizes changes he would make to the text if the poem were his” (qtd. in Bizzaro Responding 42). Another illustration is a teacher such as Paul Cook (not a contributor to Turner's collection) who "takes a blue pencil [in an effort to transfer his copyediting skills to the student] and escorts the student through his or her story in an attempt to cultivate, in that student, the value of good editing” (247). Richard Hugo's defines the exemplary reader perspective when he says, "If I can, I talk as if I'd written the poem myself and try to find out why and where it went wrong" (qtd. in Bizzaro Responding 55). These illustrations demonstrate New Critical values: "the teacher's authority arises from reading a large number of other poems in a wide range of forms and styles” (Bizzaro Responding 42).

What happens when New Critical values are put into practice with student writing? Bizzaro notes an "unwanted though mostly unavoidable by-product of using the 
text-based methodology" ("Research and Reflections" 23) occurs when "teachers do what seems most natural and instinctive in the traditional classroom: quickly provide students who have not had adequate reading experiences with the information they need to write poetry" or fiction in the form of text appropriation ("Research and Reflections" 23). He refers to composition theorists Sommers, Brannon and Knoblauch, who "have argued that such appropriation is unwanted since it takes the authority for writing away from students, subordinating them to the authority of their master-teachers” (Responding 239). Sommers, he reminds us "found that teachers employ many of the same kinds of comments when responding to student writing from the New Critical perspective,” noting there was, in fact, "an accepted, albeit unwritten canon for commenting on student texts" (qtd. in Responding 42). Bizzaro notes:

These comments tend to perform two important tasks. First they respond primarily to textual matters. Second, they tend to encourage a view of revision as text manipulation. Naturally, if misused (or used at the wrong place in the writing process), such comments can easily enable a teacher to appropriate a student's text, since only one text exists, the one the teacher reads and thus rewrites. (Responding 42-43)

In an effort to model for students the critical role he assumes when he asks questions of his own writing, Bizzaro demonstrates in his book what happens when he uses the New Critical approach in reading and evaluating his students' poems. What he discovers, in the end, is that the New Criticism method of evaluation is limiting and less effective. The New Critical emphasis on the text requires him "to use [his] energies to make intertextual comments" (Responding 53). What he finds is that his margin 
comments "asked questions intended to reinforce intertextual comments, and [his] summaries in turn reinforced those questions” (Responding 53). The result of these kinds of comments, however, is that students can simply make the adjustments [he] urges[s] and resubmit the poem as finished” (Responding 54).

He adds, that “This outcome might have been expected given the New Criticism's original goal: to interpret finished texts"; however, he "tended to do much of the work for these students, perhaps in the hope that they would learn from making such changes and apply what they learned in the revision of other poems” (Responding 54). Moreover, he notes that "In an ineffective adaptation of the New Criticism, a teacher might inadvertently require students to write in a narrow range of poetic styles” (Responding 54). The downside to this is that teachers "thereby impos[e], as Petrosky (1989) says, “stylistic limits that act to seal off ... students' writing, to keep it within the boundaries of academic expectations” (qtd. in Responding 54). Although this reading theory proved limiting as a response to students' work, overall, the experience of reading texts from variable approaches gave Bizzaro a better sense of ways in which to return ownership of the poem back to the writer.

\section{* Social Relations: Through a Lacanian Lens}

When a teacher's pedagogy privileges meaning in the isolation of the text, when she situates herself as exemplary reader and authority, and when she values and rewards student dialogue and written work based on her New Critical practice, she influences the social dynamics of the creative writing classroom, and in particular, the relationship between teacher and student. I propose that Jacques Lacan's psychoanalytic theories of the Imaginary and Symbolic orders can assist in explaining the complexities of the 
teacher-student role in the New Critic classroom. Briefly explained, before entrance into language and the Symbolic order, a child becomes fascinated by its own image in a mirror. The baby learns that this image is its own, recognizing that it is a whole entity instead of fragmentary movements (the bits and pieces) and undefined boundaries between self and Other (the mother, specifically). The child situates himself/herself in relation to the image and first knows itself as lacking. The infant forms an illusion of an ego, of a unified conscious self identified by the word "I.” To Lacan, ego, or self, is always on some level a fantasy, an identification with an external image, and not an internal sense of separate whole identity. This stage marks the fundamental narcissism by which the human subject creates fantasy images of both itself and its ideal object of desire. Once a child enters into language and accepts the rules and dictates of society, he or she is able to deal with others. The Symbolic order is bound up with the superego and works in tension with the Real and Imaginary Orders.

The forces and drives that underlie students' writing, reading, and interactions are directly influenced by the realms of the Imaginary, and the Symbolic orders. It helps to understand Lacan's theory of (mis)recognition, the split between the self and the mirrorimage, because we can apply his psychoanalytic model to what happens when there are conflicting types of intentions in the classroom. More specifically, the Imaginary and the Symbolic orders can be seen in the types of relationships that exist between teacher and student in the form of transference and counter-transference. For Lacan, transference is best understood:

As a dynamic structure located partly within a person and partly between people. On the one side is a "divided self," a person . . . who does not understand some 
part of her own action ... On the other side is an authority figure, a person whom the "divided self" supposes to know how to interpret the behavior. The person who feels divided looks to the authority figure for interpretation ... When the figure responds by asking questions or being silent (as analysts are largely supposed to), the divided person tries to respond/interpret the behavior as she thinks the authority figure would. (Brooke 681)

The important relationship then "is largely within the divided person, since it involves a relationship between her conscious self and her projection or current understanding of the knowledge and purpose of the knowing authority” (Brooke 681). To this end, transferring an image of the self onto the analyst, the "divided" person finds in the Symbolic Other (the Subject Supposed to Know); an external means to express his or her inner dialogue. In this manner, according to Robert Brooke who authored "Lacan, Transference, and Writing Instruction, "the analyst serves as a mirror for the person" (681).

In student-teacher transference, the "baffling behavior involved is writing" (Brooke 682) or responding to a written work. The student is "universally assumed not to understand what he has written . . .The writing teacher is fancied . . . to understand writing, to know what writing should look like, how it's supposed to work, what the student’s errors "mean” and how to fix them” (Brooke 682). Comparable to a therapist, in this sense, the writing teacher "is institutionally a version of the Subject Supposed to Know" (682). It is the individual student who places "value" on the "importance of the Subject Supposed to Know" because "[s]omehow he or she must trust that this person really is what the role says she is" (Brooke 683). A student "can always choose not to 
enter transference by refusing to trust" the teacher, and the teacher can "be deceived" by the student's "demand" to know what he should do. After all, how many of our students ask us to just tell them what they should say, what they should do? The biggest "threat," then, according to Brooke and Lacan, is related to "trust” (Brooke 683).

Presumably, most transference relationships allow students to trust the teacher, making learning possible because often a student has an unconscious need that he or she presumes a teacher can fulfill. And often, when a teacher has gained a student's trust, or in Freudian and Lacanian terminology, has elicited a positive transference-the student will look to the teacher as to a parent, someone who "knows" the truth and "knows" what is in the student's best interests even more so than the student. In this manner, the teacher becomes the sole, inviolate authority.

In the New Critic classroom, there is an unhealthy order of transference as the teacher is truly the sole, inviolate authority to the point where her power of privilege [is] so totally unchecked by a second or third party” (Bizzaro Responding 5). The fact that the teacher privileges meaning in the text bears import on her teaching strategies, including how she devises her plan for teaching to the evaluation of student writing. As a result, the teacher exerts complete control, and, to paraphrase Sharon Crowley, "is not only doing most of the writing in the course, but is setting rigorous laws for students to abide by" (qtd. in Bizzaro Responding 5). Crowley notes:

...teachers do most of the writing in composition classes ... Students, on the other hand, spend most of their time reading: they read the teacher to determine what he "wants"; they read the textbooks or anthologies he has assigned to find out what he wants them to know; they read his assignments to determine what he 
wants them to do. When they "write" in response to his assignments, they tell him what they think he wants to see realized in their papers. Almost never do they envision themselves as having something to teach their teachers. (qtd. in

\section{Responding 6)}

While Crowley applies these concerns to the composition class, the New Critical pedagogy can also have immediate concerns for students attempting to reconcile their Imaginary and Symbolic Orders. If we follow Lancanian principles, the student never enters into a contest of trust and the teacher does not question her role as the Subject Supposed to Know. The student cannot work through the writing process and process of learning because the New Critic teacher resists this permitting because she directs and appropriates what goes on in the classroom.

It becomes difficult for students to thrive in a master-teacher-student-apprentice model, one in which many workshop models are based. Haake reminds us that the "Since the first classes were developed at Iowa, teaching creative writing in America has largely conformed to the model of a text-centered workshop where apprentice writers come together to craft poetry, prose, and drama and offer it to peers and the master writer" ("If the Shoe Fits” 80). In this workshop model, the authority of the text meets the teacher as exemplary reader. Case in point: W. D. Snodgrass speaks of his master-teacher Robert Lowell at the Iowa workshop, a "powerful" mentor. When Lowell "did" your poem, said one student:

it was as if a muscle-bound octopus came and sat down on it. Then, deliberately, it would stretch out one tentacle and haul in mythology, a second for sociology, a third for classical literature, others for religion, history, psychology. Meantime, 
you sat there thinking, "This man is as mad as they said: none of this has anything to do with my poor, little poem!” Then he began tying these disciplines, one by one, into your text; you saw that it did have to do, had almost everything to do, with your poem. (qtd. in Snodgrass 127)

Although somewhat theatrical in his dramatic sweep through his student's poem (though this element certainly adds to the mentor's power and mystique), Lowell is perceived by his student(s) as final authority, certainly as master-teacher. Alberta Turner affirms this relationship between teacher as master and student as apprentice when she says, "To the student-poet as artificer the teacher-poets give (or rather offer) advice from their own experience as artificers” (qtd. in Bizzaro “Research and Reflections” 237). Bishop’s scholarship has referenced this dominant teaching model, which continues in undergraduate and graduate courses today, and Ostrom recognizes the perception of writer-teacher as one who "is important, authoritative, powerful" (xiv).

Although Snodgrass' account of Robert Lowell may not have been all that atypical for master-teacher-student-apprentice workshop scenarios at Iowa, Carol Bly suggests that as master-teachers, teachers risk becoming bullies. Beginning writers, Bly says:

give their souls into their work. They are very vulnerable. They believe what teachers tell them. They shouldn't but they do. They honor our (teachers') seniority. Our judgments are probably worth a tenth of what students give us credit for. If we have the least weakness of ego or the least career-climbing corruption or the least inability to reject flattery from people around us, we are at 
risk to bully. When we are tired we might even do a little bullying without noticing. (143)

If not by bullying, then perhaps as master-teachers we hold our apprenticestudents with a powerful hook. Richard Hugo, for example writes in The Triggering Town (1979) about the injurious repercussions of Theodore Roethke’s master-teaching on apprentice-poet David Wagoner in this way: "Roethke, through his fierce love of kinds of verbal music could be overly influential. David Wagoner,” Hugo stipulates, “who was quite young when he studied under Roethke at Penn State, told me once of the long painful time he had breaking Roethke’s hold on him” (29).

\section{* New Criticism Theory: Final Arguments}

In the workshop model, Bizzaro worries that the master-apprentice relationships can lead to "the teacher having near dictatorial control over their students' texts," to teachers deciding, even, a student's failure if she did not make the comments suggested. More often the appropriation is more subtle, but still present, and can and does lead to a "generation of clones—students who sound amazingly like their teachers" ("Wings on the Invisible” 86). While New Critical values are present in our appropriation of students' texts, in our craft-based pedagogy, in our workshop dialogue, many creative writing teachers, as exemplary readers, as final authority, often see their images as far from this prescriptive description. The writing workshop class is not exactly the "banking system of education” in which Paulo Freire's description of teacher as depositor and student as depository fits the creative writing classroom. The hopeful poet or fiction writer "cannot simply sit and wait for the transfer of knowledge from teacher to student-Moses handing down tablets where the truth is etched in stone" (Elliott 113). Also, "Unlike 
professors in any other discipline ... We don't lecture or use the podium. We arrange our desks in a circle and tell our students they can call us by our first names .... many of us . .. would prefer we eliminate grades altogether or establish a pass/fail policy for creative writing classes” (Cantrell 65). In fact, "we are much more comfortable being the cheerleader, the midwife, the coach, or whatever than we are being the authority, the master-writer, the critic, or the judge” (Cantrell 70). Perhaps our New Critical tendencies are, in fact, so deeply fastened in our pedagogy that we do not recognize our role as teacher as final authority.

Lad Tobin insists we must "shock" New Critics in the way we "misread every student text in order to help students say what we think they really mean," so that "when we read we create and recreate, deconstruct and reconstruct.” Tobin suggests:

this sort of generous and deliberate misreading-readings in which we go beyond the words' literal meaning to try and draw out possibilities in a text, to imagine what the text might be trying to become-is at the basis of Shaughnessy's analysis of error, Elbow's believing game, and Bartholomae and Petrosky’s plan to integrate reading and writing ("Reading Students, Reading Ourselves” 79-80). We ask our students to "show" us, rather than "tell” us when they write. We need to follow this practice as well in our teaching. Bizzaro argues that teachers "must spend less time telling our students what they should do when they write and more time showing them who they can be" ("Reading the Creative Writing Course" 234). First, we must be aware of the way we respond to our students' poems and stories, and then "If our reliance on New Criticism shows a discrepancy between what we know we should do and 
what we do in actuality, then," Bizzaro suggests, "we need to explore new and more fruitful models for evaluating student writing” (Responding 40).

\section{The Expressivist Theory}

* Historical Antecedents

As a guiding principle of the expressivist theory, self-expression has its roots in the progressive education movement of the early twentieth century, one which began as a “concrete representation of an idea about the best way to teach literature” (Myers The Elephants Teach 12), and one which, as a form of self-expression, presents in today's creative writing pedagogy. Progressive education's influence, according to James Berlin, “encompasses the best and the worst of the American experience” (Writing Instruction 58). Because there was a dramatic increase in prosperity during the twenties, followed by "the economic catastrophe” of the depression, writing instruction during these years responded in “curious” ways. Subjective-rhetoric, for instance, “celebrated the individual,” and transactional approaches “emphasized the social nature of human experience; both rivaled the current-traditional rhetoric present in the college classroom (Writing Instruction 58). These studies and links of science to human behavior shaped the curriculum of progressive education.

As a result, psychology principles affected the shift from "subject-centered to a child-centered school” (Writing Instruction 59), while sociological maxims influenced perceptions of group behavior. John Dewey attempted to reconcile these two diametric approaches to education-“one psychological and individualistic and the other social and communal” (Berlin Writing Instruction 60). Hughes Mearns, guided by Dewey’s goal toward a transactional rhetoric for a democracy and by his belief "that the aim of all 
education [was] to combine self-development, social harmony, and economic integration” (Berlin 47), shaped an expressivist curriculum, as head of the Lincoln School (also referred to as the "cradle of progressive education”).

At this laboratory school, under the aegis of Teachers College at Columbia University, Mearns conducted a "deliberate experiment” of replacing the subject of English for junior high school students with what he called “creative writing.” Rather than continue with the "over-emphasis on nature poetry" and its complex Romantic and Freudian poetics which looked to nature for metaphoric associations, "greater consideration would be given by teachers to themes more in harmony with the child's probable experience" (Berlin Writing Instruction 78). The "cry was that subjects should not be taught, students should” (Hughes Mearns qtd. in Myers The Elephants Teach 101).

As a literary movement, progressive education stimulated transactional approaches, emphasizing the social nature of human experience, and this led to essays on expressionistic rhetoric. Periodicals such as the 1922 volume of English Journal, soon touted "all writing is art," "writing can be learned but not taught," "the content of knowledge is a product of a private and personal vision," and an emphasis of process over product in the composing transaction (Berlin Rhetoric and Reality 75-76). One such contributor, Allan H. Gilbert of Trinity College, argued that "all honest writing—and no other sort is worth correcting—is the expression of the nature of the student” (Berlin Rhetoric and Reality 76). Like the practices of Mearns and other progressive educators, Gilbert encouraged a nondirective method in the teacher as "gadfly rather than dictator" (Berlin Rhetoric and Reality 76). For instance, teachers could not appropriate students' writing "without bringing about a change to what was limited by their [students'] minds" 
(qtd. in Berlin Rhetoric and Reality 76). Primarily, students were to be encouraged to develop their "own genius."

The charge of instruction was to remove cultural impediments to creative expression. One educator claimed, "[I]n a creative writing class almost any writing is better than no writing” (Myers The Elephants Teach 108). For Mearns, "the best literary education comes with the amplest self-realization of the individual at whatever age he happens to be” (2). This "setting free” of the "creative spirit," takes the form of poetry, a device students had difficulty with when the focus was on topics other than the self.

Because each student was so fundamentally isolated, his only recourse when writing was to delve into himself. "Poetry, an outward expression of instinctive insight," according to Mearns, "must be summoned from the vast deep of our mysterious selves. Therefore, it cannot be taught; indeed, it cannot even be summoned; it may only be permitted ... The new education becomes simply, then, the wise guidance of enormously important native powers” (28). Rather than teach students how a poem works, lessons on craft-based lexis or the critical study of literature and modeling approaches of professional writers, Mearns became concerned that an egalitarian relationship must exist between teacher and student. His pedagogical design employs a "theory of permitting," and the teacher-artist as "an ethical exemplar," a theory of education (28). This notion of the teacher as ethical exemplar is on the opposite end of the teaching spectrum as the New Critical teacher as exemplary reader. While it was important to Mearns that teachers of creative writing were artists so that they might understand the creative process, the process of drawing out a student's creativity required teacher sensitivity and taste. 
The underlying belief was that every student was at the bottom a poet, is clear when he says, "each poet here has his own individual song” (Mearns 45). It was precisely this “individual song," this internal unwritten work that permitted Mearns’ egalitarian pedagogy and allowed him to sidestep the issue of talent in his teaching. What then distinguished one poet from another was not innate, undemocratic talent, but a patience to uncover the poem within. To Mearns and his students, then, the effort to bring these unwritten stories to light of day was not a matter of craft so much as a matter of waiting and attentiveness.

It is not quite like waiting for Carolyn Chute. She finds the discovery of writing more like being in the dark when she admits "[Writing] is sort of like when you've got no electricity and you've gotten up in the middle of the night to find the bathroom, feeling your way along the dark” (qtd. in Donald Murray 112). In his attempt to yoke the individual and the democratic spirit imbued in the new progressive pedagogy, Elmer Edgar E. Stoll (1932) conveyed “art [as] a state of the soul, communicated.” (296-297). Irving Babbitt would say in 1932 that katharsis has moved from the reader, where it properly belongs, to the writer. In the 1930s Faulkner would tell his interviewers that it is "[t]he material itself” that "dictates how it should be written” (qtd. in Donald Murray 112), or as William Stafford has it, "a book has always been something that grew and declared itself” (62). Even later, Joseph Moxley would suggest that "we need to treat all student writing as emerging texts,” as a process of discovery (40).

The "self" was also promulgated in "how-to" books in the expansionist climate after the Second World War. Subsequent decades tended, among other precepts, to discuss the concept of "self," in particular "knowledge acquired outside the 'self', a 
questionable attitude to reading, and continuous stress on self-expression” (Wandor 104). The view of writing as an expression of the self populated in the late sixties and early seventies, with the focus on writing as a form of discovery advocated by such process pedagogues as Donald Murray and Peter Elbow.

As a second guiding principle of the expressivist theory, Romanticism has its roots in the nineteenth century as a movement away from the established social order. Even then, it promoted individualism and subjectivism, feeling over reason, intuition over intellect. Dawson goes back a bit further in his search for the evolution of "creativity" and the "general usage" of the term "creative" to a mid-eighteenth century practice, and “the concept of man's creative power which motivated speculations about original genius, as opposed to imitative talent” (27).This led to a shift away from "the classical learning of poets to their capacity for originality" then on to "the idea of creativity as an expression of individuality and the twentieth century search for the 'genius within'” (27).

There is a common link, Dawson decides, "between nineteenth century poetry and twentieth century education, for the idea of poetic imagination which infused Romantic sensibilities also informed the Creative Writing movement which developed within the American school system in the 1920s” (50). It is here, at this juncture where the selfexpressive theories of "self," "subjectivism," and "discovery" interface with the Romantic sentiments of "genius," "imagination," and "Divine power" under the broader theory of expressivism. The logic behind how these Romantic concepts find their way into the school system can be explained as means to an end. Consider Mearns' philosophy in "a belief in human creative power and its origins in the natural poetic abilities of the child" (50-51) and link this to the poetic sensibilities addressed by 
Wordsworth and Coleridge in Lyrical Ballads to "awaken a sense of wonder at the everyday by retaining and nurturing a childhood enthusiasm for natural surroundings” (qtd. in Dawson 51). Dawson makes the connection for us when he says:

If poetry was the means by which the special qualities of childhood were retained by the original genius, then poetry, or 'creative writing' was the means by which a child's creative potential could be developed before, in Wordsworth's phrase 'Shades of the prison-house begin to close/Upon the growing Boy' (51). In addition to the Romantic conception of poetic genius and Emerson’s democratization of creative power, modern psychology and the latent unconscious creativity believed to be innate in all children, the development of self-expression and romanticism as a creative writing outlet burgeoned in schools during the thirties. However, as an educational movement (its theory of permitting, writing to discover, selfexpression, the rousing of poetic sensibilities) progressive education lost its centrality in the 1940s and 1950s when school reforms called for the learning of more basic skills. The movement rebounded in the 1960s and 1970s as a more radical version, touting free school movement and non-graded classrooms.

Present-day neo-progressivists hope to draw more interest in the fundamental principles of progressive education. While today's school systems are not guided by the principles of expressivism, creative writing, as a field and as a prospering university entity, continues to be invested in principles of self-expression and the sentiments of romanticism. What continues is the belief that "writing ability is fundamentally a matter of individual psychology or selfhood, something certain individuals are born with while others are not” (Mayers (Re)Writing Craft 115). The central tendency for present-day 
teachers in the expressivist camp is to encourage discovery, to help students find their true selves and unique voices.

\section{* Pedagogical Practice}

The pedagogical design of expressivism assigns the highest authority to the writer and her imaginative, psychological, social, and spiritual development and how that development influences individual consciousness. Abrams summaries the expressivist process in this way: “A work of art is essentially the internal made external, resulting from a creative process operating under the impulse of feeling and embodying the combined product of the poet's perceptions, thoughts and feelings” (22). Therefore, the material and the scope of the story or poem are peculiarities/singularities and the activities of the writer's mind. As such, expressivist pedagogy places the artist as the critical element in the composing process with the belief that it is she who not only creates the work, but establishes the criteria by which it is to be judged. Thus, the teacher who privileges meaning on the writer (rather than on the text or reader or other imitable reality) is one who may neglect or discount any reductionist theories that contaminate the purity of writing. Expressionists believe "In its unintelligibility is [creativity’s] splendor” (Boden 14). In fact, Berlin tells us that "Thinking about how specific readers might react to a piece of writing, and trying to gear a piece of writing toward such readers, is folly for expressionists. They believe a truly great piece of writing will find its audience without conscious or specific intent by the writer ("Rhetoric and Ideology" 484-487). Moreover, the nature of expressivist teaching encourages originality (as manifested in the act of discovery) rather than imitation. Abrams’ text The Mirror and the Lamp, from which my taxonomy of pedagogical theories parallels, notes the switch in the nineteenth century 
from the modeling of others to creating original work as a shifting from the mirror to the lamp. As a matter of fact, R. V. Cassill's Writing Fiction compares literature as an imitation of life to literature as "an imitation or representation of the self" (qtd. in Wandor 104) and cautions writers to stay true to their self-discovery. He begins: as soon as we have learned something about our craft we are tempted to turn from concentration on our own experiences to the public world of great events - to write about spies and congressmen. But the first commandment is to go back stubbornly to our own field ... In the long run the reward for this may only be that the writer will discover who he truly is (qtd. in Wandor 104).

\section{Pedagogical Practices: Discovery and Inspiration}

The teacher who favors the inspirational approach of Romanticism "sees creativity as essentially mysterious” (Boden 14). Certainly, Plato, whose philosophical and interpretive challenges included his scholarship on rhetoric and poetry, expresses this view when he defines an artist. He claims "A poet is holy, and never able to compose until he has become inspired, and is beside himself and the reason is no longer in him ... for not by art does he utter these, but by power divine” (qtd. in Boden 14). Brent Royster, who has written a bit about the Romantic myth in the creative writing classroom (2005) and acknowledges he has been trained as a writer, admits:

I've come to relish time spent at the computer, especially when the work I do is impelled (“inspired”) rather than compelled (“forced”)... If I’m working on a poem when such a sensation arises, my judgment about word choices, sounds, connotations and structures seems finely tuned and natural. During such periods, 
I've drafted page after page of work, and have been driven to a frenzied state while pounding keys, pacing, and reading work aloud. ${ }^{3}$

I do not think that I would be far off to suggest that most of us have experienced these fluid writing moments, and we do not likely question their source when they come. Inspiration for Wordsworth came in the form of "an impulse from a vernal wood." Whitman discovered he must "lean and loaf and invite his soul." Others required "external stimulants" to rouse the muse. For Poe it was drugs and alcohol. Coleridge insists “'Kubla Kahn’ was the product of an opium dream.”” Royster describes his personal account of Romantic inspiration as "palpable," "almost addictive,” and "pleasurable;" he is not surprised that such "dramatic, even romantic narratives of the writing process are prevalent.” Psychologist Mihaly Csikszentmihalyi recognizes such a flow state, "in which a person's performance and mood have peaked," and he refers to these periods as "autotelic experiences." ${ }^{5}$ While Royster goes on to discuss inspiration as a "dynamic set of forces coming together" (32), he is here, as a writer, confirming a writer's moments of seemingly inspired words on the page, an axiom teachers in the expressivist camp affirm and infuse into their pedagogies.

Expressivists may believe that they have a primary responsibility as teachers to awaken their students' sleeping muse and to help them discover not only their potential as writers, but who their students are under all the artificial layers of socially-assigned

\footnotetext{
${ }^{3}$ Brent Royster is a contributor to my edited collection: The Writing Workshop Model: Is It Still Working? Ed. Dianne Donnelly. Clevedon: Multilingual Matters Ltd. 2010c. His comment here is from his essay "Facilitating Resistance in the Creative Writing Workshop."

${ }^{4}$ The Inspiration Approach to teaching is further discussed in "New Model for the Creative Writing Classroom,” by Hal Blythe and Charlie Sweet. 311-312.

${ }^{5}$ Royster's comment here is from his essay "Facilitating Resistance in the Creative Writing Workshop." Ed. Dianne Donnelly. Clevedon: Multilingual Matters Ltd. 2010c.
} 
labeling. Such a cathartic process, through writing, through reading, through discussions, can feel rewarding for teachers and illuminating for students. Certainly, the strategy of having students look within themselves for creative material, the perception of writing as a form of self-cultivation, is a property which transcends to the expressivist classroom.

The inner processes at work in Royster's example is a concept that Madison Smart Bell contends is neglected as a teaching approach in creative writing. "The great defect of craft-driven programs," he insists, "is that they ignore the writer's inner process. Creativity, the inner process of imagination, is not discussed" (qtd. in Blythe 311). Even the Iowa Writer's Workshop website—which claims “Though we agree in part with the popular insistence that writing cannot be taught, we exist and proceed on the assumption that talent can be developed, and we see our possibilities and limitations as a school in that light”-privileges inspiration as a driving force of creativity, talent as innate, and creative writing as an individual pursuit.

> Pedagogical Practices: The Expressivist Workshop

One of Mearns' pedagogical terms for creative writing's league with progressive education, is that "the individual speaks out in his own voice" (qtd. in Dawson 56). This tenet would become a prominent expressivist underpinning in the contemporary writing workshops, a space where Myers reports most workshop-based classes "resort to 'subjective expressionism”' (qtd. in Bontley v). Royster advances this concept when he concludes "the creative writing workshop can facilitate the formation of self and voice" through "multimodal, multivocal exploration of text and craft," not by "Romantic illusions of the writer's life” (37). 


\section{Pedagogical Practices: What to do About the Romantic Myth}

Predominant Romantic and inspirational myths view the process of writing as enigmatic and seductive, "intrinsically unpredictable," and paradoxically difficult to define, for "how it happens is indeed puzzling," and yet, "that it happens at all is deeply mysterious” Boden 11). The artist, then, is seen as gifted, imbued with creativity; writing comes easily—needing just a measure of prodding or inspiration to come forth. Such myths that surround the creative process suggest to students that the writing process does not require much work, practice, or revision. Chad Davidson and Gregory Fraser who attempt to dispel the Romantic and inspirational myths that surround, in this case, the writing of poetry, insist that "Believing these myths about artistic creation means accepting the premise that some of us are merely 'hardwired' for creativity and that it cannot be learned” (21).

Burroway offers a version of the inspiration model when she encourages freewriting because "Many writers feel themselves to be an instrument through which, rather than a creator of, and whether you think of this possibility as humble or holy, it is worth finding out what you say when you aren’t monitoring yourself” (qtd. in Leahy 65). When talent is considered natural, when inspiration is our source of creativity and meaning, and when recursive processes are interrupted or ignored because the initial piece was “inspired," and therefore not reducible in any re-envisioning process, the expressivist classroom is reduced to a Romantic model of permitting. A model that “doesn't risk the active self in the writing process" engages the students who think they can already write or those who are "most concerned with self-esteem” (Leahy 61). 
David Galef claims the "aura of the isolated artist" still "shines among the general populace” in our cynical age of spin, marketing, and audience (170). Even "[i]f much of this feeling is misguided," Galef offers, "the enthusiasm of dilettantes [. . . ] nonetheless drives enrollments up” (170). Royster also situates this Romantic portrayal of the writer "wholly dissociated from society," as one, he suggests, who "invests the craft of writing with particular gift and purpose” in the contemporary classroom. Moreover, he sees this same phenomenon within popular creative writing journals such as The Writer's Chronicle and Poets and Writers. He notes how these journals can mystify student writers because they imply creative writing cannot be taught, that talent is inherent, that student writers "need to be individual, gifted, prolific," which leads to "some writers [who] hope to be talented before being taught, before developing discipline, even before becoming writers” (27). These Romantic notions are proliferated by “anecdotes of extraworldly creative prowess," such the rumor that Jack Kerouac wrote On the Road in a matter of weeks, "furiously typed on paper ingeniously taped together to form one long scroll” (27). Anna Leahy extends this Romantic view to students who enter our creative writing classrooms

with what Anne Lamott calls 'the fantasy of the uninitiated' in which 'People tend to look at successful writers ... and think they sit down at their desks every morning feeling like a million dollars, feeling great about who they are and how much talent they have and what a great story they have to tell.' (56)

Leahy notes that "Our students want to be those writers and seek a place where they can foster that desire” (56). Adding to this mindset is "the Romantic model of inspiration," which Leahy explains is one in which "the author is perceived to lack any real effort, or 
any real responsibility for her own poems or stories.” In other words, writing isn't considered "real work" (61). Royster advances this concept when he proposes "the creative writing workshop can facilitate the formation of self and voice” through "multimodal, multivocal exploration of text and craft," not by "Romantic illusions of the writer's life” (37).

Romantic myths can also suggest that there are secrets to the writer's craft, secrets which if revealed "would most surely corrupt [the artistic] process beyond recognition" (Vanderslice 149). One of the questions I asked creative writing teachers in my workshop model survey was in reference to how they kept the workshop alive and robust in their classrooms. One teacher resisted sharing her workshop practices, noting, "I’m not about to reveal my secrets.” As a whole, though, keeping craft secrets seems less of a problem in contemporary creative writing classes. With the process-based model and writers writing about writing, the writing process is exposed in articles, collections, interviews, and public addresses.

Can then, the sensibilities of the Romantic myth ever be a positive influence in our students’ writing? I propose that it can for at least two reasons: first, it values creativity and creative writing. This is enough to motivate students, to give them courage to enter our "creative” writing classrooms. It lets us acknowledge "creativity" as an important and serious business. Creativity requires work, practice, reading-its antithesis is an opposition to labor or the idea that words spring forward on the page as Museblessed. Chad Davidson and Gregory Fraser suggest students might find it helpful to think of poetry [and fiction] writing in terms of sports or dance analogies: 
All the endless free kicks pay off during the game. All the formal dance moves, once internalized, come freely to the dancer performing on stage. One learns in order to unlearn. One internalizes in order to call forth one's knowledge without having to think about it. One naturalizes, embodies, enacts (21).

The authors suggest that part of dispelling Romantic myths is "helping untrained writers to unlearn their preconceptions and biases regarding this very different use of language” (21).

Additionally, to value creativity, as a positive Romantic myth, allows our students to take risks in their writing, to appreciate that the peers in their writing community are taking risks as well. Furthermore, the Romantic myth connects writing to beauty, truth and originality. I took a graduate British literature course in which our professor had us discuss, among many other things, the "beauty" of the literary works that we read over the course of the semester. "We don't take the time to appreciate the beauty in literature anymore," my professor had said. "Our task is too focused on the deconstruction of its meaning.” Our charge becomes, in part, to validate the positive elements of the Romantic myth, whose theory strongly underpins creative writing. Such discussions on the origination of ideas are important in creative writing to weaken other myths such as "talent is inherent and essential, that creative writing is largely or even solely an individual pursuit, and that inspiration, not education drives creativity” (Swander et al 15).

\section{Social Relations: Through a Lacanian Lens}

Some teachers embrace their authority as a means of working with students toward a therapeutic end. For example, Brooke employs the responsive teaching of 
expressivist Peter Elbow and Donald Murray by exploring a version of composition pedagogy as seen through the lens of Lacan's theory. It becomes clear to Brooke "that these kinds of teaching strategies work because they connect some basic psychodynamic processes: the interplay between self and Other, especially when the Other is understood by the writer as the Subject Who Is Supposed to Know” (680).

Brooke's teaching strategy involves a "non-directive" approach that "forces writers to 'figure it out themselves,' to respond to their own text" (680). I adopt this open-ended question approach with much success in my own writing classes, although my motive to date has been to give writing ownership back to students rather than recreate a text of my own making. Brooke likens his process of "projection and response" to Lacan's theory of psychoanalytic transference. He facilitates the transference by remaining fairly silent, as an analyst might, patiently waiting for the student to anticipate what the teacher would say if she were answering Brooke's open-ended questions. For Brooke, then, the writer responds out of her developing sense of what authorities "who know" about texts are likely to say: she responds to her projected ideas of what she thinks the teacher wants. Brooke's teaching strategy also opens space for Real order writing as he introduces confessional and other personal narrative essays in his classroom.

In the same vein as Brooke advocating Real-order expression, first-year composition teacher Carol Deletiner claims in her article "Crossing Lines" that "her students are her comrades” (209). In her class, they “spend a lot of time reading, writing, and talking about pain” (209). Furthermore, Judith Harris, referring to the same notion of Real order, believes "[p]sychoanalytic pedagogy supports the idea that writing can be 
therapeutic and, therefore, more meaningful for the student in the long term than other socio-epistemic pedagogies developed for undergraduate writing courses” (181).

Likewise, Mark Bracher (The Writing Cure, 1999) points to the opportunities for Real order expression in the writing class through "self-reflective student diaries, experiments with confessional writing," as well as [w]riting about literature and other cultural phenomena” (175). He believes these venues can "provide a space for these Realregister forces, if one has one's students explore their own visceral responses. Feelings expressed in a safe and productive way” (175).

The difficult task for most practitioners, one that "many teachers feel threatened by, is providing space for the real—that is, for students to experience, express, and examine their feelings and passions; their desires, revulsions, and enjoyments” (Bracher 175). Opponents of psychological pedagogy recognize this same difficulty and are concerned about the lack of training to handle crises that may be perpetuated by our students' release of unconscious drives and about the constraints of a fifty-minute class, meeting several times a week for one semester. Nancy Welch states "writing teachers have good reason for resisting a construction of the classroom as counseling session and accepting the psychoanalytic concepts of 'transference' and 'counter-transference' as an unquestioned pedagogical good” (46).

She also refers to Tobin's notion that "the dynamics of transference and countertransference between student and teacher are most destructive and inhibiting in the writing class when we fail to acknowledge and deal with them (33). She insists:

it's also because of the destructive powers of transference-the potential misreading, misunderstandings, resentments, potential for abuse, and even 
psychic violence that can come with identifying one's self in another-that I can't join Tobin in saying, "In my writing courses, I want to meddle with my students' emotional life and I want their writing to meddle with mine” (33).

Similarly, while Ann Murphy admits that teaching writing elicits some of the same powerful forces of transference and resistance that psychoanalysis does, she urges that: It may be both foolhardy and dangerous to insist ... that a student probe his feelings about his father, his masculinity, and his grandmother's death, in the interest of provoking a more 'authentic' voice. We have the psychological and institutional power to elicit this matter, but neither the training nor the context to handle it. (179)

She reminds others that "we are serving as teacher/analysts, eliciting these unconscious forces and provoking this encounter with the enormities of language, in an institutional setting which aligns us as well with the less amiable third role in Freud's triad: government official” (175).

In my own classroom, although I know that students draw from their personal experiences (we all do) for their fictional accounts, the difficulty for me arises when they tell me, without any prompting on my part, that their story is "true." Sometimes, the personal experiences they choose to signify make me uncomfortable because I can't know for sure if they are prepared to deal with the sentiments that surface. For example, one of my students writes, "I was a lonely kid. My only true friends were the streaming water, rocks, and earth behind our house.” She tells of her invitation to a party given by the brother of her friend. Her text jumps ahead, noting that "it's a gruesome thing to take something that isn't given ... a horrible thing to take the purity from a child.” Without 
any details, she concludes that "I never liked her brother ... I tried locking myself away inside, protecting what I could hide.” When her parents send her to a therapist, my student asks the doctor "if being with a girl instead of a boy is wrong."

Quite honestly, I'm not sure how to delve into a text like this without misreading the gaps: the reasons why she was a lonely child, the details of what was taken from her, the reason she later recants her question to the therapist when the doctor reacts to her exploration of sexual preference. I'm not sure how to personally respond to bits and fragments of a student's life, or for another matter, if I'm expected to manage, in some small measure, the guilt gnawing away at the psyche of one young driver whose friend is killed in a car accident. There is a part of me that likes to believe that this type of writing is therapeutic, as Judith Harris concludes, but what am I to do once my students' egos are decentered? What are they to do with all of these residual and conflicted feelings that surface in my classroom?

Though I recognize that we draw from life's experiences when we write and that the familiar "discourse of creative writing has been so thoroughly shot through with Romanticism," ((Re)Writing Craft 116), that some teachers readily acknowledge its influence in their pedagogy. The difficult task for others is the threat of "providing space for [Freud's symbolic] real—-that is, for students to experience, express, and examine their feelings and passions; their desires, revulsions, and enjoyments” (Bracher 175). Opponents of a psychological pedagogy that draw on Romantic theory recognize this same difficulty and are concerned with the lack of training in handling crises that may be perpetuated by our students' release of unconscious drives (or "inspirations" to continue the Romantic language) and about the constraints of a class that meets weekly over the 
course of one semester. Nancy Welch states “writing teachers have good reason for resisting a construction of the classroom as counseling session and accepting the psychoanalytic concepts of 'transference' and 'counter-transference' as an unquestioned pedagogical good” (46). I agree with her position, particularly as statistics suggest a significant percentage of our student population suffers from depression and given the fairly recent physical threat in the form of school violence and shootings, it is hard enough, I think, to assume a sentinel role for our university campuses as gatekeepers of our students’ writing lives.

Louise Rosenblatt acknowledges that when students read and write personally, they often reveal some of their "conflict and obsessions," thereby tempting teachers to deal directly with these psychological issues. Although she points out some instances in which students have benefitted from this sort of interaction, she ends up warning teachers against "officious meddling with the emotional life of their students" because "teachers cannot be trusted in this sort of relationship” (qtd in Tobin Reading Student Writing 342).

Teachers present in their creative writing classrooms with their own personal concerns. Rosenblatt agrees that "teachers are themselves laboring under emotional tensions and frustrations” (qtd in Tobin 342), while Murphy reminds us that “composition teachers [and creative writing teachers] themselves are often untenured, part-time faculty — many of them women — whose relationship to their institution is fragile at best” (181). It is unfair for teachers to assume additional responsibilities, to act as "Lacanian analysts, and potentially to endanger their jobs by deconstructing their classrooms, is either naïve or insensitive” (Murphy 181). And yet, Tobin and others believe that "the teaching of writing is about solving problems, personal and public" 
(Reading Student Writing 342). Tobin doesn’t think “we can have it both ways: we cannot create interest and deny tension, celebrate the personal and deny the significance of the personalities involved (“Reading Student Writing” 342).

To the end that I can strengthen my students' identities, I do, by helping them learn how to use the power of language to discover, create, and communicate meaning. Unlike Tobin, however, I do not intend to "meddle" in my students' lives, but I have no doubt that I have done so to some degree. It is hard not to be affected when a student asks if she can leave fifteen minutes early to pick up her birth control pills before the clinic closes, or tells me during office hours that she missed the last three classes because she had an abortion, or when another student writes about his guilt because he should have known his best friend would commit suicide, or another shares the first time she knew she was gay.

Recently, I judged an undergraduate writing competition. One well-written and painfully poignant memoir was about incest, the details very specific, the legalities of publishing such a powerful piece considerable as the case remains in litigation. The essay was eliminated from the contest because of this litigation issue, but the bottom line here is that our students' stories resonate with us whether we try to remain objective or whether we meddle or not. After all, we develop a sense of community in writing classes that only enroll twenty or so students; we place them in small group settings. We make it easy for students to open up.

Whether teachers support self-expression in their classroom or avoid it altogether, the issue of transference and counter-transference cannot be disregarded. How a teacher responds to a student about his or her writing or his or her behavior in class is infused 
with a teacher's own unconscious drives, desires, and identifications, no matter how hard the teacher insists she remains objective. In fact, it is fairly common practice for teachers to instruct students to write their university ID numbers rather than their names on their papers because they are concerned that they will be unduly influenced if they know the writer as they read. Adding to this point, Kruhl wonders what we, as teachers of authority are to do "with a model that ties art to personal well-being" (11). As, perhaps, an opposite to New Criticism's reading and evaluation norms, when the writing is self-expression, "we must accept the relativist notion that any creative work can be judged only with criteria specific to its making” (Kruhl 11). This model (not so uncommon in creative writing classrooms today and quite distanced from New Critical values), renders, by virtue of its relativism, "any classroom authority meaningless and may even eliminate the need for an instructor by eliminating all fixed criteria for judgment” (Kruhl 11).

I agree with Tobin when he claims that we cannot deny the significance of transference in teacher-student relationships. After all, it is impossible not to be affected by our students and impossible for them not to be affected by us. We cannot "focus on the writing process and product as if it existed in a decontextualized situation and relationship" (Reading Student Writing 341). Yes, we may be uncomfortable acknowledging that we assume the role of the Subject Supposed to Know within our students' lives because "unlocking” involves us in both transference and worries about counter-transference. However, since transference and counter-transference involves images of the self and of others and student-teacher relationships, we need to decode more constructively what goes on beneath the surface of our writing instruction. 
Understanding Lacan's theories of the Real, Imaginary, and Symbolic Orders and the dynamics of transference and counter-transference is a good place to begin.

\section{* Expressive Pedagogy: Final Arguments}

Royster tells us that romantic terms such as “creative” and “individual,” and Platonic aims of beauty and truth are seldom questioned in the course of writing creatively. Certainly, it is often ingrained in my students’ consciousness. Like Royster's students, writers in my introductory creative writing class are skeptical when the origin of work is called into question. They speak of inspiration originating from the heart or soul, especially with poetry writing. They want to write in abstractions, reflect in the "self," and express vague emotions; sometime writing long expositions on how a character or persona feels. The problem with inspiration as a Romantic notion is one of ownership. If the writer is merely a medium through which the muse speaks, then who lays claim to the artistic work? Even professional authors are reluctant to deny that indefinite spiritual drive that allows each person to act.

In an effort to investigate alternatives to students’ romantic consciousness, we should examine with our students where ideas come from, what triggers an image, an emotion, a character's actions. I try to ground my students' romantic abstractions in reality, in concrete vivid details, in down-to-earth experiences and research. Bishop does this as well when she asks students to list sources for their creativity— - where they find their inspiration” (Released into Language 64). She tells her students that she gets writing ideas when she goes running, shopping or from reading other writers. Such an assignment forefronts the ways that thoughts enter our minds, the logic and interconnectivity between 
germs of story/poem ideas and formation through metaphors and images, language in general.

Students who enter creative writing classrooms often do so with popular images associated between writing and self-discovery. Kruhl employs useful and variable teaching strategies to minimize this perception. Of particular interest, she "assign[s] readings by writers who discuss issues in question,” and along the same lines, she invite[s] local and faculty writers to class to discuss their writing processes and their reason for writing” (9). Readings and discussions such as these not only lend support to her claims that literary writing is a separate activity from writing, but they also shed light on the writing process as a complicated, recursive practice.

Two final points: first, in considering the degree to which Romantic theory persists, Dawson recollects the survey of $18^{\text {th }}$ century theories that began my discussion. The emphasis he reminds us was on the artists as original genius and the creative power of the imagination. These theories led to how the phrase "creative writing" (conceived by Emerson, named by Mearns), became "associated with a lack of necessity of learning of any kind, with an ease of composition reliant on natural ability rather than the study of precepts, and with a sense of self-expression" (29). He suggests that "This is why when a course of study labels itself creative writing there are going to be complaints that writing cannot be taught, and that a university, a place of higher learning and of work, would seem antipathetical to the very concept of creative power” (29). Expressivist pedagogy advances this classification. Secondly, students in the expressivist classroom miss opportunities to learn others narratives and approaches when the practice of selfexpression and Romanticism are the two dominant and current modes. 


\section{The Mimetic Theory as Imitable Functions}

\section{Historical Antecedents}

Mimesis begins as an explanation of art with the Greek sophists of the fifth century, but even before then, Socrates informs us that this primitive aesthetic theory is evident in "[t]he arts of painting, poetry, music, dancing, and sculpture” (qtd. in Abrams 8). Modes of imitation are expressed in Aristotle's Poetics in "Epic poetry and Tragedy, as also Comedy, Dithyrambic poetry” (qtd. in Abrams 9). The belief that art imitates the “universe” continued long after Aristotle’s Poetics through the eighteenth century when its properties were more narrowly defined by English critics. It was most popular in sixteenth century Italy as critics in their definitions of "art” often included the representation of another work in comparison-as imitation. However, in the eighteenth century, English critics refined the definition of art in relation to a more select and narrowed range of imitable sources. Although imitation pedagogy was interrupted by Romantic concepts of language and the self as original, it still functions today as a pedagogy

\section{* Pedagogical Practice}

The pedagogical design of mimetic or imitable theory privileges the concept that “Art imitates the world of appearance” (Abrams 8). Abrams suggests that this image of art as imitation, while it reveled in "neo-classic aesthetics," did not play a dominant role in most theories. As such, it was more "instrumental toward producing effects upon an audience” (Abrams 11).

One of the reasons why cognitive process theorists and social constructionists challenged the expressivist view in the eighties, was that cognitivists and social 
constuctionists "saw writing as a cognitive activity — that is, as a process of intellection students could learn how to do by imitating the behaviors of good or experienced writers” (Bizzaro "Wings on the Invisible” 81). Imitation or modeling, as a workshop practice is the subject of Nicholas Delbanco's book The Sincerest Form: Writing Fiction by Imitation (2004). While Delbanco does not attach the technique to the cognitive processes of the eighties (in fact, he goes back as far as the cradle for evidence of our mimicry), he does note that "personal expressiveness," in this case, “[m]ay even be a mistake” (xxii), and “[i]n our pursuit of self-expression, we’ve forgotten the old adage that 'There's nothing new under the sun'” (xxiii). While cognivists compared the revision practices of beginning writers to those of more experienced ones, most would agree that our task as workshop teachers often includes pointing out ways in which other more experienced writers have used particular techniques and story lines, and as such, these antecedents function as guides or routes, Delbanco claims, "to authenticity" (xxviii). Imitation is an invention strategy that many creative writing teachers find effective in their classrooms today. It is effectual in the sense that students practice a particular style or learn techniques by mimicry. The downside to such use is twofold: published writing on this basis can add to the homogeneity of literature (Raymond Carver minimalism, Hemingway code of simplicity, Sylvia Plath confessional lyricism), and trying to aspire to "greatness" may lead students to feel inadequate.

The writing prompts which foster creativity such as those from Anne Bernays and Pamela Painter's What If?: Writing Exercises for Fiction Writers (1995) or The Practice of Poetry: Writing Exercises From Poets who Teach, edited by Robin Behn are to some degree imitative approaches in our pedagogy. While mimetic practices are very useful for 
students' practice of various styles and for helping the beginning students who ordinarily might have trouble getting started, as a singular focus, this approach is limiting. One way to supplement this practice is through student and group research and presentations. For example, demonstrations on the different kinds of submissions included in literary journals emphasize critical functions, explore market preferences, and include creativity when exercises which imitate these variable styles—not for entry, but rather for stylistic and experimental purposes—are employed.

Of particular interest to me is the impromptu assignment in which students write a poem (or story) appropriate for the literary journal. As noted by Tim Mayers, this assignment might lead to a workshop of these poems, "not in terms of any general or abstract aesthetic qualities, but rather in light of the specific things the class knows about the journal in question, based on the group project." ${ }^{\prime 6}$ This is not an exercise in publication practices, but one Mayers finds "to be particularly helpful in getting students to think (even if only at a crude and basic level) about how editors, as a potential audience, might be likely to view their work." ${ }^{77}$ While this has important ReaderResponse implications, in its fundamental practice it is based on imitative theory. The premise behind mimetic pedagogy, then, is that students can comprehend writing strategies if they are to copy them. To appreciate how teachers privilege imitation in the creative writing classroom and how this practice impacts teaching, reading, and writing, we might consider Derrida’s practice of reading and rereading. He claims, "It is necessary to read and reread those in whose wake I write, the 'books' in whose margins

\footnotetext{
${ }^{6}$ Tim Mayers is a contributor to my edited collection: The Writing Workshop Model: Is It Still Working? Ed. Dianne Donnelly. Clevedon: Multilingual Matters Ltd.,2010c. His comments are from his essay "Poetry, F(f)iction, and Drama: The Complex Dynamics of Audience in the Writing Workshop." ${ }^{7}$ ibid
} 
and between whose lines I mark out and read a text simultaneously almost identical and entirely other....” (qtd. in Minock). The teacher using mimetic theory underscores the principle that "If you understand the way another's story has been built you can set about building your own.” (Delbanco xv). Most creative writing teachers incorporate exercises in style into their pedagogical practice.

\section{Social Relations: Through a Lacanian Lens}

Lacan's insights lead to a better understanding of the importance and function of imitation in our pedagogy and in the social relations of our creative writing classrooms. In particular, in any dialogue on imitation it is important to keep in mind that "language

is not simply poured into listeners and readers as empty vessels, but translated in a process of rhetorical negotiation with an existing internal language, becoming, in Bakhtinian terms, 'internally persuasive’” (Minock para. 26). To what effect imitation is tied to Lacan's theorization of the mirror stage can once again be explained in relation to a child's initial entrance into language and the Symbolic order and the concept of transference. In brief, Lacan sees the self continuously developed in dialogue with others; conceptually, we nuance the language of others while trying to sort our identities. These unconscious exchanges manifest in the mirror relationship as the divided self looks to the teacher in this case (the temporary embodiment of the unconscious/the mirrored self) for answers or for information.

As such, the implications of Lacan's theory to pedagogy and to imitation are tied to the paradoxes that play out in these exchanges. As teachers, we help students to understand, assimilate, and imitate when we delay the expectation that we are the ones who know. We also, if we accept the process of transference, resist the traditional 
academic response of filling up the empty vessels with consumable knowledge. The supplanting of our own authority "and textual authority encourages students to engage in dialogues with texts, dialogues that are often based on unconscious desires” (Minock para. 23). In her essay, “Toward a Postmodern Pedagogy of Imitation,” Mary Minock refers to these unconscious dialogues as "properly irrational responses," and it is these responses that "inspire in students a great attention to texts, a willingness to read and respond to them over and over again [in Derrida fashion],” and an unpredictably high incidence of imitation” (para. 23).

\section{* Mimetic Theory: Final Arguments}

Mimetic theory has its place in the creative writing classroom. We teach students to draw from the world and to practice the forms and techniques of others so that they can first recognize what is possible before they imitate it as practice and then make it original in its alteration or new construction. We open doors for students, let them look in the mirrors. In the Art of Attention, Ronald Revel speaks of the intimacy that comes from attention. He explains "It is the intimacy of poetry that makes our art such a beautiful recourse ... A poem that begins to see and then continues seeing is not deceived, nor is it deceptive” (8). Rather, "it is an intimacy in which creative writing and creative reading (the poet reads the world with writing) share together continuous presentations of this work ... : ones and ones” (8).

In this way, this is the advantage of mimetic theory, of seeing and continuing to see, as reading the world, as Walt Whitman shares: "you shall not look through my eyes either, nor take things from me/You shall listen to all sides and filter them from your self” (qtd. in Revel 9). 


\section{The Pragmatic Theory as Reader-Response}

\section{* Historical Antecedents}

Reader-Response theory has its roots in the late eighteenth and early nineteenth centuries, before English literature became part of the academy's curricula. Members of literary societies formed on college campuses, measuring one another's responses relative to a piece they had all previously read. Jane P. Tompkins links contemporary readerresponse to classical commentaries on literature when scholars such as "Plato, Aristotle, Horace, and Longinus all discuss[ed] literature primarily in terms of its effects upon an audience” (206). On a more formal basis, Terry Eagleton addresses "reception aesthetics" or "reception theory” as "a fairly novel development” (74). He includes Reader-Response theory as one of three stages that marks the period of modern literature, citing the first as that of Romanticism and the nineteenth century in which there was "a preoccupation with the author" (74). This was followed by "an exclusive concern with the text (New Criticism); and a marked shift of attention to the reader” (74).

With this description, Eagleton contextualizes the history of modern literature in relationship to where meaning lies in the communication transaction. His classification is similar to Berlin's rhetorical triangle representation, Abrams' artistic transaction, and my taxonomy of pedagogical theories. Reader-Response theory is not clearly defined as a theory" of literary criticism, but rather a theory of epistemology because it explains a way that a reader makes knowledge about a text (Anderson 144).

\section{* Pedagogical Practice}

Pragmatic theory as Reader-Response is aimed at the audience, for as Terry Eagleton says, "for literature to happen, the reader is quite as vital as the author" (74). 
This pragmatic theory considers, for Abrams, "the work of art chiefly as a means to an end, an instrument for getting something done” (15). Stanley Fish agrees when he says that meaning "is an experience; it occurs; it does something; it makes us do something." In What a Poem Means, written by John Ciardi, meaning for a reader may begin with intrinsic sensibilities, that resonance that moves us in some way that is very human. Ciardi suggests that in poetry "there is the step beyond: once one has learned to experience the poem as a poem, there inevitably arrives a sense that one is also experiencing himself as a human being” (667).

Fish posits that meaning inheres not in the text but in the reader, or rather the reading community, when he says, "In the procedures I would urge the reader's activities are at the center of attention, where they are regarded not as leading to meaning but to having meaning.” For Fish, there is no stable meaning in a text as its interpretation is variable from reader to reader and reading to reading. In its simplest form, the centrality of the Reader-Response pedagogy then is to teach students how "to conceive a poem [or story] as something made in order to affect requisite responses in its readers” (Abrams 15). I would replace Abrams' use of the word "requisite” (as in "required”) to "deserved” (as in "entitlement") — to accentuate a more positive attitude that the text welcomes a reader's perspective. In fact, Eagleton perceives the text as “no more than a series of 'cues' to the reader, invitations to construct a piece of language into meaning” (76).

Likely, because it is the newest approach, it is also not the one most privileged in pedagogy. It does, however, remove the writer from the lonely garret, recognizing instead, that she is "an agent within a social setting, and within an historical moment" 
(Royster). ${ }^{8}$ This paradigm shift opens a space so that meaning might be placed on the reader in the composing process. Similarly, Stephanie Vanderslice acknowledges the solitariness of writing, and yet, she justly asserts, it is "essential to learning that craft is the transformative understanding that one writes not only for self-expression but also to communicate to reader” (“Workshopping”147).

Moreover, Stephen Earnshaw contends, "it is not easy to navigate through the demands of self," and as such, writers prefer an audience for their material, a reader who has a "sophistication of his or her art, a sophistication that is obviously felt to be lacking when the art is understood biographically” (76). Finally, when meaning no longer lies solely on the black marks on a page, according to some preconceived concept of "good writing," then the text becomes "inexhaustible, infinitely richer than any of its individual realizations because it is capable of different realizations” (Iser 280). It is the interplay of reading (which is a temporal process) of "sequential sentences which act upon each other without referring to an external reality,” that offers meaning (Iser 280).

\section{The Complexities of Reader-Response Theory}

Reader-Response theory is a complex dynamic in the creative writing classroom for the process of reading is always in motion, always transposing. With this is mind, it can be claimed that Nancy Sommers' argument against the linear model of learning in "Revision Strategies of Student Writers and Experienced Adult Writers," also applies to reading - it is not a straightforward linear process. It is, in fact, a revisionist cycle, what Eagleton calls "the hermeneutical circle," a process of "moving from part to whole and

\footnotetext{
${ }^{8}$ Royster's comments here are from his essay "Facilitating Resistance in the Creative Writing Workshop." The Writing Workshop Model: Is It Still Working? Ed. Dianne Donnelly. Clevedon: Multilingual Matters, 2010c.
} 
back to part," and reading loops in this way (77). The reader brings to the work her own biases, beliefs, preconceptions, expectations and assumptions about universal truths (such as genre conventions). These influences interact with the reading of the work. In a sense, it might be said that students are reading themselves in the work—reacting, adjusting, picking up clues, processing, and modifying their perspectives. As a student reads, she inserts herself into the reading, making inferences, searching for what Roman Ingarden calls "a set of 'schematica' or general directions, which the reader must actualize” (qtd. in Eagleton 77). As a result of this process, the reader "fills in the gaps" and "tests out hunches," thus, "drawing on a tacit knowledge of the world in general and of literary conventions” (Eagleton 76).

What our students read in class, whether it be professional stories or their peers' incomplete stories or poems, are full of what Eagleton refers to as “'indeterminacies,' elements which depend for their effect upon the reader's interpretation, and which can be interpreted in a number of different, perhaps mutually conflicting ways” (76-77). To require this kind of reading for our introductory creative writing students is not realistic. For one, the writing workshop model inadequately calls for students to know how to read as a writer and to prepare useful feedback to their peers' drafts. For another, teachers and students would need to make significant shifts from the reading strategies employed with New Critical and Expressivist pedagogy: the two prevailing tropes in the creative writing classroom today.

$>$ How to Bring Reader-Response Theory into the Creative Writing Classroom

Iser's reception theory, based on a liberal humanist ideology, calls for a "flexible and open-minded" reading process. Although as readers, we present with inferences, beliefs, 
and expectations unique to ourselves, Iser requires that we "should be prepared to put our beliefs into question, and allow them to be transformed" (79). How might ReaderResponse pedagogy prepare our students for this transformation? Iser speaks of the “strategies,” which texts put to work, and of the 'repertoires’ of familiar themes and allusions which they contain. Iser contends that "[t]o read at all, we need to be familiar with the literary techniques and conventions which a particular work deploys; we must have some grasp of its 'codes', by which is meant the rules which systematically govern the way it produces its meanings” (qtd. in Polkinghorne 97). For the creative writing class, which is not governed by interpretive criticism, Iser's logic still has relevancy. Writers approach the reading of texts from a writerly perspective, and in doing so, recognize the techniques employed by a writer and its codification in terms of how a story is told that may be said to help shape the way a text is put to work. Learning how to read as a writer, to recognize the choices a writer makes, to appreciate the effects of these craft elements on the readability of the story, and to imagine what might be different, are all necessary and useful skills for beginning writers.

Yet, our current reading practices and our pedagogies limit more varied and sophisticated readings that take into account our students' diversities. While the reading processes of creative writing are measures of our markers of professional difference as a discipline, how might we open spaces in our classrooms and add more depth to our workshops by varying our reading approaches? If different readings are proof that the act of reading is one of creative and active participation rather than passive reception, what pedagogical practices can best help our students to broaden their reader-response awareness and how might they apply new approaches to the way they approach the 
writing process? In addition, since creative writing scholarship is still emerging in the field of audience awareness, how might we integrate composition and literary studies theory into our pedagogical practice? To extend this further, how might we learn from these theoretical applications, refine them for our practices, integrate them with our theories of writerly reading, and form new reading theories—new course development? This dialogue begins to explore some of these questions by pointing to those practices in place.

\section{Teaching Reader-Response Awareness}

Students in introductory creative writing classes have limited to no experience reading as a writer. In fact, the data collected by Colin Irvine, a composition teacher who questions why it is that despite strong pedagogical practices, students remain as poor readers, suggests that perhaps there are underlying physiological and cognitive reasons for our students' reading performance. Our beginning writing students demonstrate some cognitive dysfunction when they cannot follow teachers' instructions to read their peers' work holistically. Despite these instructions, students still tend to comment on more surface issues; they become as Irvine says, "error hunters." 9 Irvine reports the findings of a technologic study of student eye movements conducted by Eric J. Paulson, Jonathan Alexander, and Sonya Armstrong, authors of "Peer Review Re-Viewed: Investigating the Juxtaposition of Composition Students’ Eye Movements and Peer Review Processes.”

\footnotetext{
${ }^{9}$ Colin Irvine is a contributor to my edited collection: The Writing Workshop Model: Is It Still Working? Ed. Dianne Donnelly. Clevedon: Multilingual Matters Ltd., 2010c. His comment here is from his essay "What's Going on in the Workshop Model Now That Suggests it’s Not Working?"
} 
This inquiry and analysis demonstrates that "participants looked at the errors in the essay far more often, and for far longer, than any other word in the essay” (qtd. in Irvine). ${ }^{10}$

To add to this information, Irvine discovers from post-process theorists Thomas Kent and Donald Davidson that writing (in addition to other communication transactions) is "largely paralogic in nature rather than systematic." This study affirms the cognitive reports by Fish and Iser that our students approach the text with prior theories of what it might mean, and as such, "reading involves a series of learned, sophisticated and highly contextual hermeneutic guesses” (Irvine) ${ }^{11}$. What complicates this process, and this brings me to the point I want to make here, is that not only do our students' basic reading skills result from a long history of linear reading practices, but they bring to their reading methods certain assumptions, which for the most part, exist without their conscious awareness. With this is mind, teachers can construct alternative pedagogies that consider and then challenge their students' pre-existing reading skills to help students become more diversified and developed readers.

One such challenge to our students reading practices is to begin by exposing the assumptions, beliefs, and expectations that students bring to their readings. For instance, Larry Anderson begins by addressing two important assumptions to a rhetorical approach to literature. He discusses these assumptions with his students when he introduces Reader-Response theory to his introductory literature class and as a way of setting the stage for a new way of reading. The first assumption is that "there is no such thing as a context-free discourse” (144). Anderson tells his students, "rhetoric has always viewed discourse as a social phenomenon; and literature can certainly be seen as such” (144). His

\footnotetext{
${ }^{10}$ ibid

${ }^{11}$ ibid
} 
pedagogy follows a basic rhetorical principle: "To understand discourse one must understand its context," and this presents "A variety of forces ... always present: historical, sociopolitical, cultural, and situational” (144). His second assumption suggests that there is "no such thing as random discourse," as "[r]hetoric takes all language to be purposive” (144). He uses the traditional communication triangle to outline the transaction of writer, reader, and language.

Although Anderson's pedagogy presents to an introductory literature class, it can very easily be adapted to a creative writing classroom to gain the same results. He distributes a short story to the class (he prefers Washington Irving’s “The Stout Gentleman") and requests that students read the story and write a reaction to it. He requires only two steps for this assignment: students are to interpret the assignment in writing and explain how certain craft elements (plot, characterization, setting, and such) contribute to their reaction. Anderson shares the student responses with the class to demonstrate what kinds of assumptions, expectations, and biases they bring to their readings. It is from this platform that he advances the discussion so that students might see the assumptions underlying the surface of their responses. He asks his students "whether it is possible that the 'point' of the story is to have an effect. Could we not say this about all stories: do not all texts have effects on their readers?” (143). Here is where Anderson comes close to merging what goes on in the creative writing class and what is possible with Reader-Response theory.

Anderson comes close — but there is a difference. Once the architecture of a story or poem is discussed (characterization, conflict, point of view, setting), creative writers do not wonder if the point of the story is to have an effect; rather, because we are reading 
as writers, we consider the writers' choices and how these choices have an effect on our reading. The effect might be related to suspense, credibility, character motivation, complications in plot, increasing stakes, and/or shifts in tone or direction to name a few. At this point, students might engage in questions of "What if?" in their attempt to imagine how a story might be different or can be different at any point. What is missing from this creative writing discussion, that Anderson's pedagogy supplies, is a readerresponse perspective. Such a reading strategy might intensify students' engagement and open spaces for dialogue that links, layers, conflicts, interacts—or any combination of the above — the reading of a story as a writer and the implications of assumptions and biases that students bring to each text that they read. Additionally, there are opportunities to broaden the possibilities for a story construct when we consider the differing and often conflicting reader responses. Anderson's excellent pedagogy can be relevantly applied to the reading studies of creative writing.

\section{$>$ Teaching Reader-Response Strategies}

Making creative writing students more aware of reading response is a critical first step in introducing alternative reading practices. Patrick Bizzaro’s book Responding to Student Poems provides, in addition to useful information on the theories of literary study and the roles of teacher and students, a representation of his reading, commenting, and evaluating of students' poems through several applications. Under the heading of "What Teachers Should Know," Bizzaro addresses the need to “view revision less as the application of certain rules and procedures to a nearly finished text and more as an effort to unfold meaning in a manner that somehow makes possible a similar unfolding for the reader” (Responding 68). Feedback shifts from the normative New Critical evaluation of 
the text to one which "must thus be nonjudgmental and provide the writer with clues as to how the text might better create the envisioned audience” (Bizzaro Responding 68). While the teacher privileges the reader in a Reader-Response classroom, "Interaction and shared authority are at the center of any method of evaluation and reading founded upon reader-response theories” (Bizzaro Responding 69). Students approach revision differently than they would when the meaning and expression is privileged in the text.

Bizzaro discovers that his students’ revisions were more inclined to “the evolving relationship between the writer and reader as they determine what the text will be" than the text itself (Responding 69). He applies Reader-Response criticism to three student poems by emphasizing the reading and not the text as he makes parallel texts, which reflects his reader reactions alongside student poems. Bizzaro admits to the concerted effort in staying true to this method (not reverting back to traditional readings, assessing for audience, generating questions to the author as to how passages might be read). What he discovers in his reading practice, among other findings, is that though he has used a questioning rather than a directive approach, it is difficult to limit himself. On the premise that readers evoke or invoke a particular audience in their writing (per composition theories that propose the author creates a reader as well as a text: Iser 1974, Ong 1975, and Ede and Lunsford 1988), he advises the writer as to how well the audience has been invoked. As such, he performs "as a writerly reader in reconstructing the text" (Responding 71).

What is equally appreciated in this pedagogical model are Bizzaro’s honest comments as he struggles with false starts, shifts in authority, and questions of teaching effectiveness. In the end, he comes to appreciate the shared power and the legitimacy of 
the reader response. Revisions tended to be more extensive and Bizzaro reports that this reading allowed him to provide the author with more commentary. This Reader-Response model gives teachers the courage to make changes to the creative writing classroom so as to try new pedagogical practices.

Finally, while Bizzaro stays true to a Reader-Response model as a single approach effort, there is benefit, I believe, to having students read variable approaches to reading (Feminist, New Criticism, Deconstruction and others) to best appreciate reading strategies as well as to decenter other less useful strategies. A course that teaches the reading and writing of these strategies would be productive for creative writing students.

\section{* Social Relations: Through a Lacanian Lens}

When meaning lies with the reader in the communication transaction, the students' Symbolic order comes into play. If we follow the assumptions of the ReaderResponse theory then we see the reader as the one who projects her self-understanding, her culturally determined assumptions when she interacts with the text. She shapes the text, and as Stanley Fish claims, the text functions as a mirror that provides the reader's reflection. The hermeneutical circle creates for the reader a circuitous route in which the reader seeks constituted representations of herself as much as that is possible. When a teacher's pedagogy privileges meaning in the reader she situates herself as a welcomed reader, one who shares authority with the writer and other model readers.

This pedagogical approach is likely the most symbiotic of the practices discussed for several reasons. First, if we follow Lacan's theory of transference, then the “divided self" which represents the student on one side of the mirror looks to the teacher as the one who supposes to know. The teacher represents, in Lacanian psychology, the other half of 
the divided self—-figuratively, a student's mirrored reflection. In order for there to be a positive transference which enables learning to take place, the student waits for the teacher to provide her with the answers as the student believes the teacher is "suppose[d] to know." The instructor, to best facilitate this positive transference, asks questions as a "model reader" might, also as a therapist might be inclined to do. As a result, the student does not get the quick answer she expects, and thus, must search for answers on her own. Her search brings her to answers and learning takes place. In the end, the student "trusts" the teacher, and transference is positive.

The important relationship then "is largely within the divided person, since it involves a relationship between her conscious self and her projection or current understanding of the knowledge and purpose of the knowing authority” (Brooke 681). To this end, transferring an image of the self onto the analyst, the "divided" person finds in the Symbolic Other (the Subject Supposed to Know); an external means to express his or her inner dialogue. Moreover, it might be conjectured that since Fish perceives the text as a mirror for the reader, that the text, in a sense, reflects the reader's image. I am not certain what Lacan would make of this arrangement, but it seems plausible that there would be implications of "divided self" and identity.

\section{* Reader-Response Theory: Final Arguments}

Jane Tompkins presents an interesting perspective which positions the ReaderResponse theory as one that parallels the formalist reading of New Criticism in which the object of study is the text (201). She argues that "The essential similarity between New Criticism and reader-response criticism is obscured by the great issue that seems to divide them: whether meaning is to be located in the text or in the reader” (206). While both 
critics locate meaning in different places, Thompson's argument rests on the impression (which she deems faulty) that "the specification of meaning is the aim of the critical act" (206). As such, meaning, as the aim of the critical act, "binds [Reader-Response theory and New Criticism] together in opposition to a long history of critical thought in which the specification of meaning is not a central concern” (206).

Her argument comes from a hierarchal assessment of what constitutes a justifiable aim in the critical act. More specifically, when the preferred study of literature is interpretive, literary studies' critics measure other approaches to the study of literature as having less value. In other words, determining where meaning lies (whether in New Criticism or Reader-Response theories) in the composing process is not as significant as the interpretive deconstruction of a text. 


\section{SECTION TWO: THE WRITING WORKSHOP MODEL}

Those of us in creative writing must, if we are to move beyond questions of whether the workshop model works or does not work—or to ask instead more utilitarian questions such as the one Mary Ann Cain aptly interrogates: "What makes it possible for those in the academe to keep asking, 'Does it work?' without any real challenge or inquiry to the question itself, ${ }^{12}$ — come to better visualize what else is possible in this workshop space. Creative writers have answered the challenge generated by some (Ostrom, Ritter, Vanderslice, Bizzaro, Mayers) of whose interests are served by the replication of the workshop model.

Many agree, as Tim Mayers suggests, that as teachers we are implicated in this answer. Such reproduction can be found in:

- “creative writing's investment in the notion that writers are born and not made [which] makes the whole issue of pedagogy suspect from the onset;”

- the identity of authors as writers first, teachers second;

- the replication of the model by tradition—-the "basically unrevised" model as taught by our mentors;

- our "lack of explicit attention to pedagogy ... creative writers [who]consider themselves writers who teach, rather than teachers who write;” and

\footnotetext{
12 Mary Ann Cain is a contributor to my edited collection: The Writing Workshop Model: Is It Still Working? Ed. Dianne Donnelly. Clevedon: Multilingual Matters Ltd., 2010c. Her comment is from her essay ““A Space of Radical Openness’: Re-Visioning the Creative Writing Workshop.”
} 
- our embracing of the Associated Writing Program's (AWP) version of our identity ("Figuring the Future" 8-9).

Randall Albers (Columbia College Chicago) ${ }^{13}$ validates a couple of these points when he proposes that "teachers must totally rethink the way they approach the teaching of writing.” He addresses the time and effort this would take, and suggests "many, many writing teachers are content to do what they were themselves taught.” He submits faculty "would rather spend that time writing their own work than taking on the extra reading, thinking, experimentation, and training that new models would take.” Rationales for reproducing the workshop from program to program and laying claim to its workability often edify or rouse those in the field, usually without much constructive forward movement or change. Rather than idle over the question of why creative writing teachers continue to hold fast to the traditional workshop model or whether creative writing can be taught, we need to ask: What might be gained by flexing the elasticity of the workshop model? How might we add texture and rigor to its applaudable merits? In what ways can markers of professionalism in the workshop model set us apart in our scholarship from composition studies and literary studies?

My inquiry and research of the writing workshop along with my proposal for a more robust and intelligent model are part of an overarching goal to ascend creative writing studies. This study suggests that although the model remains dominant in the discipline's field of practice, there is little agreement as to what constitutes the workshop practice in creative writing classrooms across the nation. My research also reveals that

\footnotetext{
${ }^{13}$ Included in my text are comments/quotes by creative writing teachers who responded to my survey on the workshop model. To best distinguish these responses from other cited scholarship, I have identified the feedback from surveyed creative writing teachers with in-text parentheses that note responders' names and universities.
} 
more and more teachers are in fact exploring new spaces for the workshop model. I propose that there is significant interest in more radical openness and re-envisioning of the workshop model (to frame Mary Ann Cain’s essay title) to warrant a call for further pedagogical inquiry. A study such as this one and those that follow would be helpful to the field of creative writing studies, the profession, and our creative writing students.

\section{A Workshop Survey}

While there exists some MFA and Ph.D. students who may turn a "tin ear" to peer responses after too many workshops taken at the undergraduate and graduate level and while the same students may tend to create stories and/or poems that are workshop-ready (too polished) or suited for workshop approval (too safe) or customized for a teacher’s preference (too similar in style), the writing workshop model for the most part, especially at the undergraduate level as problematic as it may be, is still the heart of the creative writing program and the favorite part of the course.

My recent survey of undergraduate creative writing teachers at programs predominantly across the U.S., my own personal experience as a creative writing teacher, and much scholarship in creative writing pedagogy inform the basis of my analysis of the workshop. Of the survey, my driving questions prompted responses (to name a few) on the utility of the workshop, its effectiveness and value, and its best practices. Respondents considered student motivations, preparedness, and readiness for the workshop model. Creative writing teachers offered ways to keep the workshop fresh and alive or they lamented at such futileness. Still others shared exciting corollaries to the model in the classroom. One hundred and sixty-seven creative writing teachers replied to my inquiry (five more participated in an initial test collection) from a base of 174 
undergraduate creative writing programs (identified for the most part from the Associated Writing Program's database). While teacher response could be anonymous, 105 did identify their comments, and this $62 \%$ represents a total of 70 colleges and universities.

According to the survey results, nearly $51 \%$ of the teachers use a model that is similar to the basic workshop (very broadly sketched here as a forum for sharing and commenting on stories and poems by teacher and student readers; with varying rules of operation, the most prominent being the silence of the author during the peer review process) while $39.2 \%$ practice a variation of the mode of instruction, and only $10 \%$ define their model to be markedly different than the traditional workshop. The model serves as the primary focus or a major component in $80 \%$ of creative writing classes. Students can take the workshop-based course as a creative writing requirement (84.9\%), as an elective (86.1\%), as a writing intensive requirement (35.5\%), or for other reasons (enjoyment, outlet for self-expression, general education requirement, and such 32.5\%), and in some cases, students can participate in a workshop course to satisfy more than one requirement at the same time. A majority of institutions (60\%) do not require prerequisites or a writing sample/portfolio prior to course enrollment, and $24 \%$ of programs call for students to complete a previous semester or two of composition. For the most part, creative writing majors take fifteen or more workshop hours in the course of their study.

Overall, creative writing programs still rely on the tradition of the workshop; surveys by Edward Delaney, David Starkey and Wendy Bishop, and my own survey demonstrate this to be the case. It remains, as Delaney says, "the hub of the wheel." Nancy McCabe (University of Virginia) who has been teaching writing for the past twenty-three years claims what we all know to be true: "students always say on 
evaluations that the workshop portion of the class was the most enjoyable part.” Karl Elder (Lakeland College) concurs, that his class is "almost universally motivated" by the workshop encounter, and this observation has been my experience as well. Perhaps the basis for why the model retains its place at the center of the creative writing classroom is as Phillip Gross says, “a workshop is a very human situation." ${ }^{14}$ Or maybe, when all the spark plugs are firing in sync (or synapses, as the case may be), there is nowhere else in academia where students can "find a rigorous program of study that is also directly personal for them” (Lisa Roney/University of Central Florida).

It might hold true that some of us will follow the logic of polemics put forward in Michelene Wandor's The Author is Not Dead Merely Somewhere Else (2008), Dana Gioia’s Atlantic Monthly essay, “Can Poetry Matter? (1991), Donald Hall’s “Poetry and Ambition” (1988) or its short story counterpart written by John Aldridge "The AssemblyLine Fiction” (1990), and John Barr’s “American Poetry in the New Culture” published in Poetry 2006. In these argumentations, the workshop is either stripped of any rational or purposeful function or the type of writing generated from workshops reportedly has no readership outside the academia. The complaint is that creative writing programs have yet to produce another Mark Twain, Walt Whitman, or Emily Dickinson. What is more, we might find disheartening, the renouncements by those in the field such as poet and critic Allen Tate, who also ran the creative writing program at Princeton. Tate complains about the sameness of teaching modalities, the workshop implied in his argument, noting that "the academically certified Creative Writer goes out to teach Creative Writing, and

\footnotetext{
${ }^{14}$ Phillip Gross is a contributor to my edited collection: The Writing Workshop Model: Is It Still Working? Ed. Dianne Donnelly. Clevedon: Multilingual Matters Ltd., 2010c. His comments are from his essay "Small Worlds: What Works in Workshops If And When They Do."
} 
produces other Creative Writers who are not writers, but who produce still other Creative Writers who are not writers” (181). Similarly, Kay Boyle, though a teacher for sixteen years at San Francisco State creative writing programs, suggests “All creative-writing programs ought to be abolished by law" (qtd. in Menand). Some may be familiar with R.V. Cassill's response at a Boston convention, ironically, on the fifteenth anniversary of the Associated Writers Program to disband the very organization he founded in 1967. In this address, Cassill derided the complacency of writers, the corruptness of the academic system, and the poisoning by departments and institutions. It was time for writers, he insisted, to get out of the university.

It is hard to dismiss, offhandedly, such cancellations of support by those with respectable histories as Cassill's. He is writer, critic, author of the popular textbook Writing Fiction, teacher at Brown University, and editor of The Norton Anthology of Short Fiction. Still, despite apologias that shake the workshop at its core, some of us may murmur from a position sans theory, sans standards, sans empirical data, "like Galileo at his inquisition,” like Philip Gross of Glamorgan University: “Eppur si Muove. And yet it moves."

\section{Defining the Workshop Model}

When one speaks of the pedagogy or the discipline of creative writing, the workshop is implied in the address. The model might be defined as "competent but uncompelling" (Myers The Elephants Teach 118) or as a place where we "teach craft and discourage self-indulgent junk” (Toni Graham, OK State). Philip Roth contends the workshop serves three objectives: "to give young writers an audience, a sense of community, and an acceptable social category—students” (qtd. in Grimes 4-5). Our goals 
for our undergraduates may be lofty as we wish to "enhance students' understanding of the meaning of art in their lives” (Karl Elder/Lakeland College) or far-reaching as we strive to create deeper, closer, more responsible and creative thinkers, readers, and writers” (Linda Russ Spaar, University of Virginia). Michelene Wandor likens what we do in the workshop model to the "academic practice of peer-reviewing (in journals and publishing)" (124). Peter Harris (Colby College) finds the space “a wonderful place where people’s lives open up,” where they "begin to own their own voices.” The pedagogy introduces vocabulary necessary for the discussion of texts. It also foregrounds writing as process.

For most, the operation of the model often depends on course level and teacher design. I can report that some teachers approach the workshop with a heavy reading list such as the instructor whose workshop syllabus requires students to read ten books over the course of the semester or the one who assigns long, difficult novels. There are those who view the workshop as a course in craft, a study in how to read poetry, how to identify elements of fiction, how to appreciate the choices writers make, how to imagine ways in which these choices might have been different; how to, as Martin Cockroft of Waynesburg University suggests "reform student ideas about what is poetry, what is possible in the form, and how it can/ought to be written.” In still other classes, the students' work is the center of the course; the workshop functions as the single pedagogy. Some teachers support the practice of free-writing, others prefer invention strategies such as exercises and writing prompts to generate story and poem seeds. For the instructors at Columbia Chicago College, the model differs from the traditional one in that theirs is a process-based story workshop, one that uses "classic, storytelling forms, along with skills 
of conceptualizing, abstracting, critical thinking, and imaginative problem-solving” to supplement basic skills (Randall Albers). Most would agree with Sue Roe who claims "Workshops are fundamental - launch pads rather than flights, rehearsal strategies rather than the exigencies of polished and finessed performance." ${ }^{, 15}$ We might also agree with Maurice Guevara that its design can be "sin of all sins—unimaginative.”

\section{A Study of the Workshop Model}

Before undertaking a defense of the writing workshop it is important to outline a more global assertion on behalf of creative writing as an academic discipline. Briefly restated, in order for creative writing to advance as an academic discipline in its own right, it must undergo an inquiry into its field, much like composition studies did in the middle to late twentieth century. This field of inquiry, a factor critical to the development of creative writing studies, necessarily explores the pedagogical problems and paradoxes of the discipline. Such internal complexities are typically the impetus that sets a “programmatic revolution” (Mayers “One Simple Word”) in motion, of which creative writing studies is situated in its early phase. Kelly Ritter and Stephanie Vanderslice remind us that "a field whose teaching practices and theories are relatively unexamined runs the risk of being dominated by an ever more unwieldy body of knowledge and practices, some of which have likely outgrown their usefulness or been misapplied” (“Introduction” xv).

The workshop, as the default model of pedagogy in creative writing classrooms, has been, Bizzaro says, our "model of instruction [for] over a hundred years" ("Research

\footnotetext{
${ }^{15}$ Sue Roe is a contributor to my edited collection: The Writing Workshop Model: Is It Still Working? Ed. Dianne Donnelly. Clevedon: Multilingual Matters Ltd., 2010c. Her comments are from her essay "Introducing Masterclasses."
} 
and Reflections” 296), and as Peter Vandenberg infers, our practice “is ripe for annexation” (“Integrated” 7). Consider that AWP’s 2008 Guide to Writing Programs points to a significant rise in creative writing programs. The 79 undergraduate and graduate creative writing programs recorded in 1975 pales to the reported present figure of 822. Of this number, more than 300 are at the graduate level (37 award the Ph.D.), and thousands of students are enrolled nationally (Healey, Menand). Consider that every program, according to Virginia’s Christopher Tilghman, “devotes 50 percent of its time to the workshop” (qtd. in Delaney). Given these staggering statistics, the workshop’s universality, its application at all levels to vitally diverse populations, its differing teacher foci, and its reportedly mixed results, in the words of Ostrom, "all of us could probably benefit from taking a hard look at precisely how ‘the workshop’ functions in our classrooms” (xix-xx). Such an inquiry asks us to consider at a microcosmic level:

What are our guidelines, and what assumptions underlie them? How explicitly do we probe the criteria for assessing work-in-progress? What is our role in workshops and group work, and how productive has this role been? What other roles might we experiment with? What else should go on in a workshop besides the workshop? To what extent are we "playing the old tapes" of workshops we took? What do we know about group dynamics, and what should we know? Who gets silenced in our workshops and why? How often do we/should we revise our workshop methods? When are the conversations in our workshops most productive and why? What might be gained by dismantling the workshop model altogether and starting from scratch?” (Ostrom xix-xx) 
On a more macrocosmic grade, if creative writing studies is to operate as a more distinct academic discipline, then scholarship at a curricular level should as Katherine Haake suggests "seek to move beyond our preoccupation with the writer or the text to the role of creative writing as an academic discipline inside a profession that includes, but is not limited to, the production and teaching of imaginative writing” (qtd. in Mayers "One Simple Word" 218). This begins with establishing "markers of professional difference" (Ritter "Professional Writers" 208) to include ways in which the field of creative writing is set apart in its scholarship from composition studies and literary studies. These are significant undertakings, and yet, as Bizzaro "envisions there may be a great many teachers of creative writing like himself" interested in discussing and debating pedagogy (“Should I Write this Essay? 287). I wish to join that discussion and debate by continuing the field's inquiry and offering not a dismantling of the workshop model or even a simple re-tooling (which would not address more systemic issues), but rather a more enlightened view of the model as an intelligent and robust pedagogy, one we might advance with our emergent field of creative writing studies.

Dawson’s question: “Is the pedagogical process merely guided by idiosyncrasies of each teacher, the practicing writer able to pass on knowledge by virtue of his or her innate talent and secret knowledge of the craft? (qtd. in Ritter and Vanderslice "Introduction" xiii) is more than rhetorical, and it has merit when we consider that the workshop model offers no real standards of measurement. Bizzaro reminds us that we have practiced this "basically unrevised" century-old method "without giving it proper scrutiny” ("Research and Reflecting” 295). Sharing stories and poems, reading from a writerly perspective, providing helpful feedback, re-envisioning works-in-progress, are at 
least some of the functions of the traditional workshop model. Its practice has become so deeply-ingrained in our pedagogy that it continues without question. Or if it is questioned, in the sense that many of us are uneasy with varying degrees of a workshop's artificiality, ethical disparities, multiversity, idleness, singularity, program design, authority, evaluation, absence of theory, and/or its range of student readiness, preparedness, and motivation; we are at a loss as to how to fix it.

If what seems to be a melting pot approach to the model boils down to a little of this and a lot of that, a community crock pot of flavors, it is no wonder that, at times, we are unsure of just what it is we taste in this covered dish—-this workshop. And we wonder, how might it sustain us?

For instance, we may suggest that as untrained creative writers, we are teaching "by the seat of our pants," our workshops presumably "unstructured and friendly” (Leahy 20). This relaxed- we're-just-chatting consciousness surfaces regardless of how much planning goes into the class. Others could suggest we operate our workshops in a vacuum, with a separatist view that defers outside reference; certainly, AWP's mission statement supports this position. The majority opinion is that we practice the workshop model as our primary pedagogy, sometimes emulating our own mentors because these are the methods from which we have learned. Or perhaps, the workshop "has remained," as Haake says, "as close to a home as we are ever going to come in the academy." ${ }^{, 16}$ Even

\footnotetext{
${ }^{16}$ Katherine Haake is a contributor to my edited collection: The Writing Workshop Model: Is It Still Working? Ed. Dianne Donnelly. Clevedon: Multilingual Matters Ltd.,2010c. Her comments are from her essay "Re-envisioning the Workshop: Hybrid Classrooms, Hybrid Texts.”
} 
with this thought, the one thing Haake and many of us can say with any certainty about the workshop remains, "that's not it, that's still not it."17

To illustrate this patchwork of practices, we could consider some workshop praxes and teacher perspectives. For example, if one teacher supports, encourages even, personal self-discovery (and recovery?) and another endorses the objectification of the text, excluding all outside factors; and the instructor in the neighboring academy focuses mostly on writerly techniques found within the current Best American Short Stories with the last fifteen minutes dedicated to writing activities, and if a creative writing teacher in Boise, Idaho sanctions the bulk of classroom time to the critique of students' texts, and if the instructor who teaches inner city students refuses to abide by the author gag rule of the traditional workshop because her students' voices have been silenced long enough, then how can the writing workshop be contained within the same pedagogical model? How in fact can it not be paradoxical in nature or contradictory in its aims? Michelene Wandor addresses such antipathetic purposes when she says:

If creative writing is training professional writers (those who already have 'talent'), then the great-writers approach privileges the text over the writer; if students are taught that creative writing expresses the self (writing as therapy), then the person is privileged over the writing. The first overvalues the art, the second overvalues the person, and together they confuse the object of the work and its objectives. (128)

${ }^{17}$ Katherine Haake, "Re-envisioning the Workshop: Hybrid Classrooms, Hybrid Texts.” 
To add to this, there are inconsistent issues related to an egalitarian relationship when both teacher and student assume the role of "writer." For instance, Tim Mayers references the pronged "Elitist versus democratic" scenario: democratic in the sense that "newcomers might make significant contributions" to literature and elitist in "identifying in the end only a select few students who might be worthy of the label 'real writer"' ("Figuring the Future" 4). Additionally, the "theoretical egalitarian responses of the peer friendly" workshop create an addling for our students when the postscript to their default response of praise contradicts that of the teacher (known as a "tutor" in the United Kingdom) who has ultimate authority as evaluator of students' work upon completion of the course (Wandor 127). These "built-in tensions" are reflected in Siobhan Holland's collective response of some of the delegates at the 2001 creative writing conference at the Bath Spa University. Holland argues "It is not fair to students to find their work praised in workshops and criticised in assessment feedback" (qtd. in Wandor 127). What is more, an ethical dilemma presents when we are faced with the decision to silence the author and her valued intentions and processes versus justifying this traditional silence as a necessary function of minimizing the writer's defense and maximizing her processing of the workshop response. Complicating these paradoxes are the ethics of exposing personal experience in the workshop and the standard of measurements for such writing reflection. Finally, though the list of ambiguities may go on, the traditional workshop may move along the “consensus” principles of Kenneth Bruffee’s collaborative learning theory. It may also butt against “dissensus” as argued by those like John Trimbur.

Granted, the workshop is a process, and as such, its "plasticity" conforms to individual manipulation, and its response depends to some degree on the dynamics and 
preparedness of each particular class. However, if we continue to place such emphasis on the workshop process in our classrooms, if we name it our practice, our signature pedagogy, if we assign it curricular substance for fulfillment of a degree and usher our students out into the workforce and community with diploma in hand; then should we not consider how we manage that which defines the heart of our course?

More importantly, given such variances within our pedagogy, how can the workshop be properly scrutinized? If we were in fact to examine it in such regard, how might we determine what happens in the workshop and why? To ask the enveloping question then: how are we to evaluate if the writing workshop model still works? By extension, as it is implicated in the workability of the model, when many question whether creative writing can be taught, and if so how is it taught, and who can teach itquestions, by the way, which have been asked long before the new compositionists embodied a constructivist view that "genius," "imagination," and "power” were not given but obtainable-is it enough, then, when someone like Mark Winegardner of Florida State counters with “You can’t teach every piano player to be Thelonious Monk, but no piano teacher seems tortured by the question of whether piano can be taught”? (qtd. in Healey). Is in enough to say as John Barth did in a 1985 article in the Times Book Review titled "Writing: Can it Be Taught?," that "emphatically it can, mainly on the ground that it so emphatically is”? (qtd. in Menand, my emphasis). Where might one begin this ontological study? The answers to probing questions such as these are, as Shirley Geoklin Lim notes in her essay “The Strangeness of Creative Writing," "so nuanced, constrained, interrogated, and indeterminable as to raise more questions” (157). Indeed, I say. 
Part of the difficulty in even defining the workshop, let alone reconceptualizing it as a rigorous and intelligent pedagogy, relates to the elasticity of the model—its ability to morph into variable shapes, to stretch in so many ways, and as such, it is easy, like Saran wrap, to take it for granted. My goal is not to dismiss variances of the workshop model, but rather, I want to explore current practices of creative writing's signature pedagogy as part of an overarching inquiry into the field with a secondary goal to ascend creative writing studies as a distinct discipline independent in its own scholarship.

\section{How Our Workshop History Informs Our Praxes}

Prior to the conception of the Iowa-based academic workshop model, writing colonies gathered outside of institutions in such places as Nashville, Iowa City, and Greenwich Village as a pre-war rebellion against restrictive university curriculums. These writing clubs created spaces where students and faculty could share their work and receive criticism. In addition, writers such as "Frost, Sandburg, Dreiser, Mencken, Stephen Crane, Sinclair Lewis, and Hemingway held jobs as cub reporters, learning about factual narrative and detailed observation, a training that influenced the form of the modern novel” (Adams 90-1). These influences are worth mention because by the 1920s, much of this off-campus tradition moved onto campus and along with it, came its writers, who were given, more often than not, favorable positions that accounted for their first priority: their writing life. For example, historian Katherine Adams in A History of Professional Writing Instruction in American Colleges notes that a writer-in-residence position offered to playwright Percy MacKaye at Miami University of Ohio in 1920 also included "building him a much-publicized studio and requiring him to perform few academic duties” (93). The same relaxed instructional responsibilities held true for 
Robert Frost as poet-in-residence at the University of Michigan during 1921-22 (Adams 93), and many more examples followed. Today, the great writers' approach still occurs at many of the top programs. These writers "teach infrequently (one class in a year or year and a half seems typical) because their published works are believed to do more than their teaching for the program's image. This is because writing programs must contend with the authorial 'star system'” (qtd. in Delaney). Such hiring expenses and star system adulations, cycle the university perception (which then cycle such beliefs at the program, student, and community level) that only notable writers who are well-published with prestigious presses can teach creative writers.

Even before the onset of postwar second-generation teachers and the "elephant machine” replication of the workshop pedagogy—a metaphorical vehicle for the production of other writers and other workshops as referenced in Myers' The Elephants Teach — writers brought a less-than-academic focus to the creative writing classroom. Their emphasis was on student manuscripts, not on required readings, or craft discussions, or creative exercises and assignments as they are in current conventions. Pulitzer Prize poets such as Robert Frost and Richard Wilbur would never have considered creative practice or writing prompts in their workshop settings. In fact Wilbur insists “I don't want to turn my students into clever executors of formal problems. I want them to start the way any kind of poet starts, with the matter, with the urge ...” (qtd. in Garrett 94). The preferred style of these writer-teachers was similar to critique sessions like those the Fugitives held in Nashville (Adams 93). Some continue this argument today when they say that the contemporary workshop model has little value or basis for authentic learning. Grant Matthew Jenkins (University of Tulsa), for instance, steers clear 
of the artificiality of the workshop model. Instead, he attempts to recreate for his students the life and work of poets like himself and others. He states:

I don't sit around with my poet friends and critique their work. Instead, we read seminal works about relevant issues...collaborate on projects, host readings, give each other poems (as gifts but sometimes for comment), buy each other's books, solicit manuscripts, invite each other to readings, etc. This experiential mode gives students a much better view of the life of a poet than the arbitrary and artificial workshop model.

Similarly, one teacher, responding to my survey, agrees that "learning” to "improve your writing" cannot "be communicated in a classroom; or, for that matter, between two writers, no matter how well-intentioned.” S/he urges that "learning how to write in a voice that's your own isn't found that way, and, despite the forests of rubbish written on the subject, there isn’t a good writer alive who won't tell you the same thing.” This instructor also advises, "It's living you have to do more of, not workshopping, in order to become a writer.”

To return to the workshop history: prior to the war, early orchestration of the academic workshop began in Harvard's advanced creative composition classes followed by a Verse Making course at Iowa in 1897 and a drama graduate workshop course at Harvard from 1906-1925. Norman Foerster, director of the Iowa School of Letters from 1930 to 1944, was successful in implementing the creative dissertation in the Ph.D. curricula, a program meant to include a creative and critical study for all Englishmajoring students. The "workshop" launched in 1936 under the direction of William Schramm as did the awarding of the MFA degree in creative writing. In seceding 
Schramm and Foerster, Paul Engle dropped the critical component of the creative writing study and focused instead on the studio-based workshop model in the 1940s and 1950s, the same model which would, in effect, become the archetype for creative writing courses. In 1949, an undergraduate workshop-based creative writing program was offered as an English major. Because the method was intended for the teaching of graduate students, it would soon prove troubling for instructors who imported it into their undergraduate classes.

Creative writing's original goal to teach writing for its own sake changed with the university’s expansion of its role in society and its institutional sanctuary for the arts. It is here where creative writing essentially splits from literary studies in terms of its influence on a writer's education in criticism, and according to Myers, creative writing becomes subject to patronage and growth within the institution. The postwar expansion encouraged an influx of returning veterans onto college campuses (Louis Menand in a recent New Yorker article reports this number to be greater than two million), and more specifically, into writing workshops by way of the G.I. Bill. The Bill stipulated that tuition assistance could only be applied to degree or certificate programs, and, this directive was the impetus for the development of degree-granting creative writing programs.

This student demographic was less interested in studying the Classics or the British literary canon, demanding instead a more relevant study of literature (T.S. Eliot, W.B. Yeats, Faulkner, Fitzgerald). At this point, universities (aside from its purist literature professors) were more amenable to new courses and modern literature. The Iowa workshop took on a militaristic atmosphere, one that simulated the boot camp 
environment familiar to this predominantly male population. As such, workshop critiques were brutal, derisive, gruff—delivered for the purpose of shaping the "talented" writer and his work for the hard-core reception of editors and publishers. Although I do not intend to be inclusive, for the most part, workshop atmospheres today range from this similar battleful mode—-that drive "our need for absolution," and our students to "taste something fetid at the back of their mouths which won't dissolve no matter how many times they spit” (Domina 27) — to a workshop ethos that is much more polite- to an expressive theory of permitting which is analogous to those theories underpinning progressive education, to Romantic outlets for self-discovery and stalwarts for inspiration, to ignoring the author in our objectifications of the text, to an audienceinvoked/evoked reception, to something entirely different or a combination of the above.

Creative writing's new postwar goal became the production of teachers, an ambition clearly evidenced by the proliferation of workshop-based programs founded mostly by Iowa Workshop graduates in the sixties. "Between 1960 and 1969, enrollments doubled," Menand tells us, and "more professors were hired than had been hired in the entire previous three hundred and twenty-five years.” This coincides with Sharon O’Dair's account in “Stars, Tenure, and the Death of Ambition” that, in general, "life was far less rigorous and competitive” for graduate students and junior English department faculty during the fifties and sixties. George Levine points to his own hiring experience as an example by noting, "We were less troubled ... at the very moment when English and higher education were experiencing their most rapid and rich expansions ever” (45). It was not unusual, he continues, for most of his colleagues to receive "at least three job offers” (45). Today, more that 2,000 graduate students compete for the approximately 
100 tenure-track faculty jobs in creative writing (reported in Menand). In the sixties, colleges and universities became patrons of writers' careers, and the NEA, established in 1965, would add to this patronage, allocating funds to writers in the university, to literary publishers, and to venues for readings and residencies.

As alumni of the workshop-based programs received publication notoriety, universities, in turn, received endowments from their prestige, which, in turn, drew student interest, increased enrollment and opportunities for further expansion.

Professionalization through the AWP led to curriculum guidelines and support of the MFA degree as the appropriate credential for the teacher of creative writing. The workshop model was considered as the preferred venue of study. Our twenty-first century scenario is quite different in that many hiring colleges and universities, offering tenuretrack positions often sidestep the MFA graduate in their preference for the Ph.D.-degreed applicant.

With the graduation of veterans in the early 1950s, there came a change, George Garret remarks, "from the hard experience of the veterans ... to the younger students who lacked this same maturity" (50). In addition, a shift "from content, in terms of importance, to form” occurred (50). Garret reports that students were now reading The Catcher in the Rye and Lord of the Flies. Garrett who experienced this transition firsthand, speaks of the mounting dissent between literary studies and creative writing as the "Beat Movement," formed by "mildly disgruntled academics," began to balk at theory and "fight over the canon" (50). For the poets, literary study had "no point of contact with concerns of most working poets," and the critics discarded the workshops' production of poems and stories as "pseudo-lit” (Garrett 50). This adds to the split between creative 
writing and criticism and the isolationism and marginalization of creative writers and creative writing programs.

In going forward from this point, I am not prepared to offer a full analysis of the variant views of writing processes that impact the workshop in our current practices, but what follows are some of the more significant approaches and their consequential effects on today's workshop praxes. In the sixties and seventies, expressivist views placed the writer at the center of the rhetorical triangle, promoting a sense of the writer, a presence of "voice" in student writing. This practice continues today as many creative writing teachers place the writer at the center of the workshop, fostering the discovery of a student's voice. Expressivists had no use for theorists or anything that might divert the attention from students or teaching. We see this atheoretical stance in our contemporary workshop-based classrooms as creative writing teachers form the "disproportionate share of those who retreat from theory” (Ostrom xii).

Cognitive process theorists and social constructionists challenged the expressivist view in the eighties, cognitivists first with their study of writing processes. Bizzaro reminds us that "Those who argue for the influence of culture on the development of individual identity—social constructionists or social epistemics—argue that there is no such thing as an autonomous self" ("Wings on the Invisible" 81). "As a result," he notes, "teaching that was intended to produce voice was off target, wrong in its assumptions about writers, who they are and what they do" ("Wings on the Invisible" 81). In the eighties, the teacher who supports expressivism in the classroom was felt to play a passive role, failing to provide structure, conventions, and strategies. Expressivist rhetoric, and this includes the rhetoric in poetry and fiction, according to James Berlin, 
leader of the anti-expressivist campaign, hopes to promote "individualism," but it ignores economic, social, and political conditions, and can marginalize people who resist—-thus empowering them through isolation. Bizzaro suggests that "Creative writers and teachers of creative writing did not know (and many still do not know) that they were the ones being spoken to and about” (“Wings on the Invisible” 81). While the workshop goal of helping students' find their own voice continues both in the traditional sense of selfexpression and in new ways as it relates to challenging assumptions and master narratives, Greg Light offers an enlightening “conception of learning” as it relates to voice, challenging the description of voice as coming from the personal self. Rather, he suggests that “voice is better understood in terms of the writer's conception of the practice of writing.” In this context “voice is not 'authentic' or 'inauthentic' so much as 'integrated' or 'detached'. As such it is not simply a function of the writer but of the socio-cultural situation in which the writer is writing” (13).

To continue, there are other historical markers that still affect the workshop model. Ostrom contends that those influenced by postmodern theory "appear to cut the writer loose from all moorings, sanctioning an anything-goes classroom” (xv). He refers to these groupings as "elite guilds who rush ahead of the novice theorist, wagging fingers. Novices are sure they can never catch up, learn the code, and be accepted” (xv). Certainly, New Criticism, though not chronologically presented in this timeline, continues to enforce a principle of the "close reading” of students' texts to determine the choices a writer has made, or as Phillip Roth contends "the executed result of the author's intentions” (qtd. in Grimes 15). Roth decides that "when a student enters a Workshop seminar room, any hope of being rescued by the abstractions of theory vanishes the 
moment discussions begin” (qtd. in Grimes 15). He notes that the workshop leaders, having "jettisoned genius and ignored literary theory" in the interest of "the nurture and love of literature are consequently reduced to the teaching of craft (qtd. in Grimes 15). And yet craft, the "[t]echniques or formal strategies of composition,” William Faulkner said at the University of Virginia in 1957, are the “'tools' in a writer's workshop” (qtd. in Guevara).

Today, some believe that the workshop has "shift[ed] in focus from the text as autonomous object to the text as a construction of the reader" (Ramjerdi 10). Centering the reader in a rhetorical axiology (a social conception of writing), creates a whole new set of considerations, that Jan Ramjerdi reports "were suppressed in a formalist perspective" (10). With the "elevation and redefinition of the role of the reader from a neutral observer to an active participant," the workshop is said to take on a more dynamic atmosphere. (Ramjerdi 11). When the text is no longer isolated, "its boundaries are no longer clearly there;" therefore, "political and ideological issues ... emerge” (Ramjerdi 11). The argument here is that more is at stake in this workshop setting as there are issues of audience to consider—personal preferences, prejudices and such—or depending on the specifics of the classroom, "audience” may imply a discourse community which considers not personal priorities, but the expectations that compositionist Patricia Bizzell informs us, are "share[d] by the virtue of belonging to that particular community" (218). More is at stake, Ramjerdi concludes, because there is no longer an "object of study that filters, directs, constrains, and distances response” (14-15).

This history does not suggest that workshop teachers overtly subscribe to one axiology over another or that there are not overlapping approaches. In fact, in many 
cases, alternate workshop practices and approaches exist, some of which are discussed below. This historical account does, however, shed some light on workshop approaches and attitudes as influenced by university needs, writers’ practices, and cultural relativism, not to mention how what we do changes with each generation. The past events demonstrate to some extent, the ways in which literary study has dominated creative writing and how the theory of composition and rhetoric has often informed the theory of creative writing. Peter Vandenberg rightly includes the training of creative writers as composition teachers in this intersection, and I might add that the number of creative writing teachers who also teach composition as part of their course load has been rising since Joseph Moxley urged educators to "be careful not to confuse the single cell for the organism” (27), and Wendy Bishop addressed her writer-teacher/teacher-writing perspective on blurring the boundaries between composition and creative writing in the late eighties. Although there is much more that is relevant to the history of the writing workshop, and by extension, the field of creative writing, reproaches regarding the workshop’s practice-based pedagogy, its bureaucratization, its bred of sameness and questionable theoretical and intellectual value, and its suggested apathetic interest in reform, are pressing concerns that make championing the workshop as the profession's signature pedagogy no small task.

\section{Perceptions and Practice}

\section{* Our Students}

If it were possible to construct our student profile, we would need to consider the vast diversity of all who enroll in our workshop classes, their values and traditions, their motivations, and their preferred method for learning. Not to consider such variables 
might generate stereotypes and assumptions. However, though as educators, we cannot assemble such a character sketch; it is impossible really, outrageous even to envision, we can appraise the wide range of sociological and cultural research and studies that issue collective perspectives on forces that bear influence on the students we teach in higher education, factors that impact our students' interest in creative writing, their ability to learn and respond to our modes of teaching. Teachers can assess their students' motivations for signing up for their workshops. They can and should draw on these conclusions and their usefulness as it relates to the (re)construction of their workshop design.

Today, we teach the Google Generation. These "Tech-savvy 'Millennials,'” as Scott Carlson describes them in his The Chronicle of Higher Education article entitled “The Net Generation Goes to College," "have lots of gadgets, like to multitask, and expect to control what, when, and how they learn.” Our students think differently; their attention is scattered, their concentration diffused. We are no longer of the mindset that "the 100 billion or so neurons inside our skulls are largely fixed by the time we reach adulthood" (Carlson). Our students have begun to take on the qualities of "our intellectual technologies" - their brains are "adapting . . . at a biological level," says writer Nicholas Carr . In his 2008 The Atlantic article “Is Google Making Us Stupid?” Carr complains that "Immersing myself in a book or a lengthy article used to be easy. My mind would get caught up in the narrative ... and I'd spend hours strolling through long stretches of prose.” No longer is that possible, Carr admits. "Now my concentration often starts to drift after two or three pages," he notes; "I get fidgety, lose a thread, begin looking for something else to do.” For Carr, "the deep reading that used to come naturally has 
become a struggle." These "troubles" are not dissimilar to the experiences of his friends and acquaintances who are, mostly "literary types." Kathryn Tyler, author of "The Tethered Generation” specifies that individuals born after 1978 tend to have difficulty thinking for themselves without the tethered advice from parents or significant others who are just a text or speed dial away. They struggle with patience, with detail-oriented tasks such as those required for writing and proofreading, and also with attention to social conventions and understanding what it means to focus and work hard.

My students and I have talked about their digital generation and their "supposed" self-absorption. One student, I'll call Jake, adds one word to the above descriptions that characterize his generation-isolation. He says, "The condition of humanity in which the digital generation exists is one of profound isolation.” Jake speaks of a "closed bubble," an "impenetrable wall of loneliness," one which "no light can pass through." ${ }^{18}$ Another insists "The notion that any individual whose entire existence can be uploaded and stored quite easily on a three inch hard drive could establish a meaningful relationship with any human being is so absurd as to be laughable,” though he is serious. Jake's workshop partner adds that "the digital generation is not concerned with the world at large; their only concern is studying and analyzing their own personal existence.” She concludes that the loss of barriers, the loss of trials, the loss of ambition and curiosity ("after all, what is curiosity when all the answers are given") have created a culture fueled by selfabsorption.

\footnotetext{
${ }^{18}$ Student comments that refer to the Net generation were generated from my classroom discussions about how writers in the New Millennium read, write, and learn; and how these students think teachers should/could vary teaching methodologies to reflect the Net generation's needs and special proclivities with new media and technology designs.
} 
This perception runs parallel to the one which situates our students as selfgratifiers with inflated egos, liberated from oppressed influences, and immersed in an American culture of disposability and commodification. The emphasis on feelings, a fundamental absolute of progressive education persists as a dominant postmodern philosophy in our educational system. As a result, some students come to us with Romantic notions of writing their poems and stories in one long, uninterrupted stream of consciousness. They have ideations of talent—-they've been writing their whole life. Mark Wallace (CA State University, San Marcos), a respondent of my workshop survey, has seen some of these preconceptions play out in his classroom. He notes, "Students often come into my courses with high expectations about their futures as writers and are sometimes shocked to discover how much time and effort it takes to write well.” Additionally, Monica Berlin (Knox College) contends "students often misunderstand what our job there is." She observes, "They often come into workshop expecting we will disregard all notions of graciousness, and in doing so they often do not take the work on its own terms.”

Problems created by lack of experience are sometimes compounded by a lack of motivation and a lack of talent. One instructor admits “I don’t want to spend time workshopping sloppy, incomplete, last minute efforts.” Lorna Jackson (University of Victoria) asserts "students are still reluctant to commit themselves to a schedule of practice," and Martin Cockroft (Waynesburg University) adds “students tend to undervalue the $90 \%$ of the time spent reading and talking about OTHER students' poems and stories.” Because of this perception, he contends "a few students put very little effort into prepping for workshop (i.e. they write few comments, have lost the poems for that 
day, or have little of substance to say).” For Gaylene Perry (Deakin University, Melbourne, Au.), lack of effort translates to students "not reading drafts in time for class or the workshopping student not supplying a draft in time." She considers this "to be a new problem for us, perhaps partly due to university pressure to let more students enroll in our program. In the past," she submits, "the classes were smaller, the skill levels higher, and the commitment and preparedness much greater.”

While I am aware that these comments may generalize students' lack of effort, it is also clear (as some workshop survey responders specify) that a complicated history buttresses students' engagement with their coursework. It is a history that significantly precedes the day students sign up for creative writing courses or the day they enter creative writing classrooms. Concerns of program design and class size, open admission policies, and a long well-documented history by the NEA of poor reading skills and comprehension at the college-level coupled with fewer opportunities for the reading of literature in college shadows our students’ profile. Although there are many more influences, certainly the focus of this section on the Net Generation and all that it bears is a major contributing agent.

What motivates students to seek out creative writing workshop classes may be because they want "freedom from an oppressive curriculum that demands too much rote critical thinking, dry textual analysis, and academic prose strangled by thesis statements and Strunk \& White correctness” (Healey 32). Catherine Cole agrees, citing a panel of researchers who note that "society's emphasis on success, instant gratification, the retail/consumer model of education" as well as "student-centered approaches to learning, lead students to look for easy answers and to count on high grades, to avoid difficult 
work and to develop inflated perceptions of their abilities” (7). Edmund Hansen and James Stevens implicate our students" "low tolerance for challenge,” their "risk averse” posture in our classrooms as products of "educational consumerism and an institutional focus on assessment” (qtd. in C. Coles 7).

Others sit in our workshop for reasons still valid in Stephen Minot’s 1997 assessment of student motives, some which involve therapy and a childish love of language. They may enroll in our workshops, according to Gregory Light’s study, for an opportunity to write in a structure that provides "an interactive writing environment with experts/tutors and peers” (4). While they may find a place in the circles of desks creative writing teachers construct for community sake, it may be because they assume their workshops will be fun, engaging, and easy. I would second the response of teachers who note how their students are surprised by how much hard work goes into the practice of writing and how vigorous this coursework can be. But more often, students today recognize, as one of my student writers says, “Adulation is earned through talent and ability; claims which could be made in the future, but right now the digital generation has not earned that right.”

These are my undergraduate writing students_-business majors, nursing students, marine biologists, those undecided. A few may come unprepared to class; many come with little or no reading experience. How are creative writing educators to connect with students who are preoccupied with a virtual rather than a physical world, students who are more likely to skip lectures and less likely to go to the library and check out a book? Are our writing students among the average college graduates who have "spent less than 5,000 hours of their lives reading, but over 10,000 hours playing video games (not to 
mention 20,000 hours of watching TV)," as Marc Prensky claims in "Digital Natives, Digital Immigrants"? We do know that our students are among the majority who want technology at the ready. "The more portable the better," Carlson notes. After all, "they are able to juggle a conversation on Instant Messenger, a Web-surfing session, and an iTunes playlist while reading Twelfth Night for homework.” Are creative writing teachers prepared to embrace and prepare for changes that suit these Googlers- to construct workshops online, craft lectures on podcasts, which can then be downloaded to students' iPods, becoming portable, rewindable, even pauseable? Should they be?

While this generation may depend on the "tethering" that Kathryn Tyler addresses in her article "The Tethered Generation," to feel secure in its decision-making, it is also a population which works well in group environments. Tyler contends Millennials are familiar with diversity. Perhaps the physicality of our small class size attracts students to our workshops. They are a creative bunch; experts at multitasking, at thinking out of the box — and their creativity — the "buzzword of the business world"—has real market value claims Steve Healey in his essay “The Rise of Creative Writing \& The New Value of Creativity.” Healey reports that business recruiters are presently visiting top arts graduate schools looking for candidates for their corporations. This is because, per Daniel H. Pink, author of "The MFA is the New MBA," published in Harvard Business Review, "the basic financial skills learned in the MBA program are quickly becoming obsolete ... The tasks that remain ... increasingly involve creativity” (Pink qtd. in Healey 34).

Businesses, looking to distinguish their products and services "in today’s overstocked, materially abundant marketplace” are seeking alternatives, creativity, ways "to make their 
offerings transcendent—physically and emotionally compelling” (Pink qtd. in Healey 34).

Creative writing students are deeply immersed in the digital world and a part of a historical moment Thomas L. Friedman, author of the bestseller, The World is Flat: A Brief History of the Twenty-First Century, coins “The New Age of Creativity.” Friedman connects communications technology and the occasion for people interested in "authoring their own content,” particularly, Healey adds, “in easily manipulated digital format” (34). Creative writing students can make this “leap,” Healy accurately suggests, from the new authors of the digital networks to the new authors of the Creative Writing workshops” (35) with better pedagogical planning in our workshop-based classrooms.

Much has been written about the holistic purpose of creative writing and the writing workshop and its noble ability to make our students more rounded citizens. These are echoes of the egalitarian principles of Deweyan education, which advance the “democratization of creative power” (reiterations of Emerson). Healey cites the Romantic mission statement of AWP, Jane Ciabattari’s Poets \& Writers essay “Workshop: A Revolution of Sensibility,” and D. W. Fenza’s defense of creative writing in the academy in "Creative Writing \& its Discontents” as proselytizing these views. AWP adopts the artist as "outsider, set apart from the standardized triteness of institutions” (Healey 32); Ciabattari refers to the “willed discipline through which students learn to shape and order their perceptions of an ever more complicated world around them” (para. 3); and Fenza strengthens creative writing's otherness when he says:

Like other lessons of creative writing - creativity, empathy, persuasiveness, expression, and aesthetic discernment - the artistic experience of the will's 
efficacy may seem too rarefied a goal for a practical age that prefers to quantify

success in patents, cures, sales units, and dollars. (para. 57).

Healey thinks not, and I agree with him. While poems and stories are valued products of the workshop, there is more to be learned through the model's process, more "front loading" as Henley calls it, pedagogy "with interventions in the writing process before it begins and while it's happening, instead of the more traditional back-loading—that is, intervening after a written product already exists” (38).

Creative writing teachers miss opportunities to design more vigor in their writing workshops, when they lag behind as a field, Healey suggests, a field which also falters in the "development of a reflexive theoretical framework that would make it more aware of its real social value and its real social effects, and this lag has encouraged further lag in revisions of its teaching methods” (38). Creative writing students may be ahead of educators in the discipline in terms of "thinking out of the box" if teachers consider that as part of an institutionalized field, they generally continue to think of themselves as still "inside the box."

\section{* Our Critics}

As creative writing teachers we may be insulated by our marginalized (sometimes self-imposed) home within English departments, but we are not cocooned to complaints about the model's effectiveness by critics who do not sit in our workshop circles or at our tables of writers. Complaints about the lack of intelligence in the workshop design come by way of faculty tensions or exclusions from department decisions or overt or obscure charges in journal articles and/or editorials, and possibly at professional conference sessions. Creative writers are not compliant with the department's mission or held to the 
same scholarly standards that dominate the profession as a whole. In fact, creative writers often make further distinctions between the department profession and their profession. Their poems and stories, also known as their "hallmarks for success" which may be published in respectable but not always nationally-recognized journals and presses, are treated like flimsy, onion-skinned tissue paper. Their conferences are sometimes tabled as artsy. Even their professional organization fails to re-envision their discipline, its teachers, its mode of instruction-its workshop.

This kind of criticism and divide has a long history despite the continued contribution that creative writing programs bring to the English department. My intent in laying out these interdepartmental issues is not meant to aggravate what Ben Siegel refers to as "bruised sensitivities" between creative writing and literary studies; derisions which “appear most bitter and open” (Siegel 7). On the contrary, I suggest that an emerging creative writing studies can stand alongside literary studies and composition studies with its value-added scholarship, its renewed workshop pedagogy (complete with markers of professional difference), and hybrid models that include more specialized course offerings.

\section{* Our Teachers}

Creative writing teachers make efforts to monitor the pulse of the workshop as Karl Elder (Lakeland College) does, gauging the needs of his students by offering “models of strong work that will appeal to their unique sensibilities.” Likewise, my workshop survey indicates that creative writing teachers try to engage with students as individuals rather than abstractions. This instructor "finds their issues and challenges" and in this pursuit, s/he discovers "who they are, their passions and go from there." 
Similarly, survey responder Robert Boswell (New Mexico State U) considers the individuality of his students by affirming "that every student is taught in every class, not just the student whose story is being discussed.” To personalize his workshop course, Keith Kumasen Abbott (Naropa) makes adjustments based on student responses to his first week survey, while Jane Hilberry (Colorado College) dismantles her workshop by teaching "on a model of improvisation, each course and each class different, depending on what the students bring to the course.”

Some creative writing teachers are responding to the "shifting nature of students' readings in new media, film, and digitized images, music/texts” (Cole 7) by adding digital writing workshops. The University of Massachusetts Amherst, for example, transitions students to write in the new digital age by offering courses like "Telling it Straight, Telling it Slant, Telling it Digital.” George Mason University offers an introduction to digital writing in the genres as part of its creative writing concentration program. Janet McCann (Texas A \& M) has a "section on hypertext poetry and using computers in poetry,” and Valerie Martinez (College at Santa Fe) includes in her course, “a study of cyberpoetics.” Judith Baumel (Adelphi University) uses “wikis, blogs, and Moodle to teach the workshops," and one teacher "encourages the use of graphics and the material nature of what they are making" when they construct and "distribute their own books.” What else is possible in the creative writing workshop-based classroom? How might we insert digitalized writing to a creative revision of say, Macbeth? Most have witnessed comedic versions of Shakespeare's Romeo and Juliet (Shakespeare in Love) in the theater; how would a scene from Macbeth, for example, play out in today's techno lingo? 


\section{* Our Workshop Pedagogy}

In the workshop chronicle above, I address ways in which creative writing's history confines and complicates its practice. The structure of creative writing in terms of its praxes and principles and of the workshop-to the degree that this method of instruction is for many teachers, the primary pedagogy of creative writing - finds itself divaricated. Just what are creative writing teachers doing in the workshop model? Some workshop teachers advance the Romantic perceptions of student writers. Ostrom contends we might locate "some of the [current] resistance to conceptualizing teaching back to resilient Romantic theory (Blake, Wordsworth, Coleridge, Keats, Emerson, Whitman, Ginsberg)” where "Pedagogy and theory become incidental at best in the egotistically sublime pedagogy of the self” (xv). Here, defined in Romantic terms, the writer “has no particular use for teachers or workshops,” for “'he’ was born with authority, with authorizing talent, with genius, with a potency, with a 'repetition in the finite mind’ (as Coleridge would have it) 'of the infinite I Am.”' Given this Romantic belief, “[h]e is godlike-Dionysian, Promethean, mercurial. He is gifted and blessed; he’s got what it takes” (xv). The workshop teacher who advances these notions or who is unaware of their pitfalls faces challenges in the workshop dealing with authority and revision practices.

Maurice Kilwein Guevara (“Out of the Ashtray: Revivifying Creative Writing Classes”) questions teaching practices rooted in such Romantic notions of the imagination as “sacred” and “intangible” and to "tamper with it is taboo.” He laments workshop practices that do little to exercise what we as teachers desire to promote in our students: “originality, imagination, and creativity.” Other instructors may be guided by 
the sensibilities of humanistic practices of the cultural and intellectual call for a renewal of academy and culture initiated by Irving Babbitt and Norman Foester. The humanistic workshop teacher promotes the early academic goals of writing for its own sake, for the overall improvement of students' writing inside and outside academia. These workshopbased classrooms are less interested in more complicated programmatic goals that might help establish writers for teaching, publication, or other possible creative career development.

Most often critiqued is the workshop practice that promotes expressivist practices that are based on principles of self-expression and inspiration. Other workshop models include feminist pedagogies, which tend to decenter models of inspiration and traditional master-apprentice type workshop models. Feminist pedagogy influences such teachers as Mary Ann Cain, Nancy Welch, Katherine Haake—craft critics who promote less formal structures and more "dismantling [of] authority." Reader-response theories in the workshop model are likely the least practiced approach, while New Criticism in its close reading practices of professional stories and student texts is a workshop praxis which informs the ways many of us come to understand and interpret exemplary texts and student manuscripts. Despite the fact that many say New Criticism is no longer a viable approach to the study of literature, it remains steadfast over the sovereignty of the poem [and fiction] so that it prevails more unflinchingly in the workshop than anywhere else. Here, it not only "survives and is prospering," but it also "seems to be powerless only because its power is so pervasive that we are ordinarily not even aware of it" (Dawson 105). As an operational pedagogy in the workshop model, it focuses too much on the text as final authority and the teacher as exemplary reader. 
As addressed earlier, presenting students with a multi-faceted approach to reading and writing offers them more writing options and practice. Patrick Bizzaro's book Responding to Student Poems (1993) not only addresses various methods for teachers to read and evaluate students' poems, but he also considers how these methods mirror "the range of possible relationships between student and teacher" (xv). As such, we might become more aware of the authority dynamics in the classroom, the dialectical relationships that exist in our workshops. Gayle Elliott asks us not to see our role in the workshop as "the teacher-of-the-students and the students-of-the-teacher," but rather as teacher-student with students-teachers . . . a communal” model where "the students generate the 'texts' for the course," "engender the tenor and scope of the criticism” (114). Peter Elbow “encourages instructors to surrender the trappings of traditional teacherly authority and act as a member of the class' 'writing community'” (qtd. in Kuhl). Lad Tobin insists we must "shock" New Critics in the way we "misread every student text in order to help students say what we think they really mean," so that "when we read we create and recreate, deconstruct and reconstruct." Tobin suggests "this sort of generous and deliberate misreading — readings in which we go beyond the words' literal meaning to try and draw out possibilities in a text, to imagine what the text might be trying to become- that is at the basis of Shaughnessy's analysis of error, Elbow's believing game, and Bartholomae and Petrosky’s plan to integrate reading and writing” ("Reading Students, Reading Ourselves” 79-80).

In workshops, teachers ask students to "show" rather than "tell" when they write. Perhaps workshop instructors need to follow this practice as well in their teaching. Bizzaro argues that teachers "must spend less time telling our students what they should 
do when they write and more time showing them who they can be” ("Reading the Creative Writing Course” 234). First, we must be aware of the way we respond to our students' poems and stories, and then "If our reliance on New Criticism shows a discrepancy between what we know we should do and what we do in actuality, then,” Bizzaro justly suggests, “we need to explore new and more fruitful models for evaluating student writing” (Responding 40).

Finally, composition's rhetorical strategies bear a strong influence on our workshop model. Early scholarship presents the ways in which composition and creative writing might share writing strategies beginning with Wendy Bishop, forged ahead by Joseph Moxley, and later, as supported by Tim Mayers. As a teacher of creative writing and composition studies, I admit to the ways in which composition's rhetorical practices have influenced my workshop dynamics and how creative writing techniques have added depth to first-year composing and persuasion. Writing teachers who are composition instructors and those who engage in creative writing scholarship through publications and/or conferences often talk about how writing out long passages of criticism helps to strengthen their creative works and how description and imagery, for example in stories and poems, aids in adding more depth to scholarship.

I welcome these intersecting influences for the discipline of creative writing. What the workshop model needs now is a rigorous inquiry into its practices, a more thorough understanding of how its history impacts our pedagogies, a study on what motivates our students, how they learn, and how we might open the workshop space to other alternatives — to more program designs. We are prime, not for annexation, as 
Vandenberg suggests, but for more independence through the development of creative writing studies.

\section{* Flexing the Workshop Shape or Opening the Space to Alternatives}

The success of the writing workshop and our students' "success” in the workshop model are relative in terms of standards of measurement because of many contributing factors. In some cases, student publication is still the primary institutional aim, and there is pressure to produce results to sustain program visibility and enrollment, even at the undergraduate level. This more global objective may be contrary for the teacher who uses the workshop as a platform for students to acquire and practice fundamentals, for more risk-taking activities and experimentation, and for opportunities to emphasize process and explore how a story or poem unfolds.

On the other hand, department goals may disclaim a teacher's expertise and privilege a workshop space in which student feedback carries more weight than a teacher's technical knowledge. In many institutions, program design is in the hands of administration and guided by bottom line costs and profit margins. The success of the workshop is largely contingent on class size, particularly at the introductory level. Ideally, a workshop class could be well-managed with ten students. Martin Cockroft (Waynesburg University) has seventeen students in his introductory class; some have eighteen or more. Given the increased class size, Karen Holmberg (Oregon State) attests, "if we were to workshop all poems in the class, we would only have time to write 3 poems a term." Lorna Jackson (University of Victoria) admits that "as a fiction teacher, at certain times of the semester" she is "unable to read the volume of work in a reasonable work week.” Furthermore, oversize classes can lead to students spending excessive 
amounts of time "reading the works of student writers rather than those of more accomplished writers” (Deanna Kern Ludwin/Colorado State). Course workload and the mix of majors and non-majors in workshop courses is another issue for teachers like Lex Runciman (Linfield College), who notes, "We struggle to meet student demand, and recent assessment feedback from our creative writing majors tells us they wish we had more 'majors only' courses.”

Some suggest entry requirements for enrolling in a creative writing class, particularly an upper level class, would lead to more authentic learning opportunities and more serious student commitment. There are more colleges and institutions that offer creative writing classes without a major or minor than there are BFA or minor tracts or associate degree programs. Bishop and Starkey suggest the "workshop has led to an unprecedented democratization of imaginative writing in America" (Keywords in Creative Writing 198) In fact, they conclude, "now that nearly every American high school and community college offers at least one creative writing class, access to basic instruction in the art is widely available” (198). Given the recent expanse of the field that Kelly Ritter and Stephanie Vanderslice address in their introduction to Can it Really Be Taught?: Resisting Lore in Creative Writing Pedagogy, such a proliferation of program development should give us pause to rethink creative writing's pedagogy to include the workshop model by "reassessing specific patterns and practices” (xvii). Such rapid program development might also serve to further dilute the significance of a creative writing degree. Imagine, some teachers ask, that anyone can declare himself or herself a creative writing major or that anyone can take a creative writing course with little or no experience. The experience of such indiscrimination, according to one unnamed 
instructor, leads to a class "filled with a lot of disinterested, unengaged, untalented students. Not just untalented, s/he notes, but students who actually have significant writing problems; students who need to retake comp[osition], even.”

In fact, the survey suggests that many students can take creative writing to satisfy an elective, and/or to satisfy a creative writing program requirement and/or a writing intensive requirement. To this claim, Juliet Davis (University of Tampa) responds, “This should not be the case." She grants that "one of our biggest challenges is the fact that students can take creative writing to satisfy both a writing intensive requirement and a humanities requirement.” For $60 \%$ of the programs surveyed, students are not required to take a pre-requisite to an introductory creative writing course.

There are many influences that complicate the workshop space that range from the teacher's appropriation of student work and/or the presumption of style to the more global call for us to attend to the poor reading and comprehension skills of our students as reported in the latest NEA report. We are now being asked to "focus our attention and resources on an activity both fundamental and irreplaceable for democracy” (Dana Gioia qtd. in Burriesci 2). My point in emphasizing factors that bear influence on the workshop model is twofold: first, as Minot suggests teachers should "draw on a full range of tastes and address particular student motives for coming to the creative writing classroom” (35), and second, teachers must reconsider their program design, addressing what one teachers in my survey calls "one of the narrowest educations ... especially if most of its courses are run with the traditional workshop model.”

Students' motives girdle my second point which begins with the advancement of two possible workshop trajectories at the undergraduate level. The first path functions as 
a series of courses under the general education tract for the appreciation of literature through writing and one that centers on a degree program situated for the advancement of writing (and reading) for its own sake (creative writing's early pedagogical goal). Coursework at the general education level might include "The Craft of Fiction” (or poetry or drama), “The Writing Process,” "Reading as a Writer,” "Form and Technique,” “Narration and Description”; perhaps, genre writing to include fantasy, science-fiction, digital options, romance, writing to discover; nonfiction studies in memoir, creative essays, nature and travel writing. A course that addresses the lore of creative writing would be illuminating. Considering some of the courses noted above, I see the workshop setting for this track in any number of ways: as a pairing of partners, a small network, a larger writing community, a one-on-one student-teacher conference. The workshop would provide a place for students to experiment, take risks, develop skills, share work, and advance creative and critical thinking.

This program track might also incorporate more panoramic goals to include, among others, an outward attention to public spheres. I see this offering as one open to all undergraduates; perhaps, even as a course option that is required of first-year students as suggested decades ago by Wendy Bishop and advanced by Kevin Clark in "Study as Practice: On Creative Writing \& the English Curriculum” (1999) for the purpose of satisfying "rigorous standards" set by English departments. This option considers the popularity and growth of creative writing and the workshop model while understanding that the goals of this path are noble in their encompassing nature.

The second baccalaureate program track considers the intermediate and advanced creative writer, one whose placement in the program is dependent on a sample of student 
work. While not excluding some of the coursework outlined above, the curriculum for this track should be more robust and inclusive. At this level students should understand and apply variable critical approaches to reading and writing. With a secondary goal toward flexing the elasticity of the workshop, students might be exposed to other performative arts in an effort to broaden their expanse of writing. I am not thinking of an appreciation of art (or music or drama) in this regard, or an approach that suggests less rigor, but rather one which introduces more outlets for expression, more venues for creativity, more activity and demonstration, and more synthesis, analysis, process, production. This might mean a sharing of workshops between the arts; perhaps, a dialogue that is acted by drama students, action that is produced on stage, and/or poems expressed in music, painting, sculpture, dance-more rigor. Hans Ostrom, in his introduction to Colors of a Different Horse, wonders how creative writing might be linked to "the street.” He asks, "Who among us is already inviting rap, hip-hop, performance poetry, and other so-called popular sources of compositional improvisation into our workshop?” (xxii). Although not all instructors agree with the kind of performative art that Ostrom addresses, nor are all teachers interested in employing technological techniques in their classrooms, but there are many creative writing teachers who have initiated some movement in other creative arts disciplines. For example, Gaylene Perry (Deakon U) speaks of “dance studio sessions or visual arts life drawing classes," where students can "practice” their work. Donald Platt (Purdue) has partnered with a visual arts class, "visiting their studio for 1-2 class sessions and writing poems from their work. In turn," he says, "we gave them poems that were not inspired by art, and the artists used them to generate drawings and paintings.” 
Similarly, Lisa Russ Spaar (University of Virginia) team-teaches “a poetry/printmaking workshop in which students collaborate (the printmakers write poems, the poets print, and they work together to produce low and high-end books.” Mekeel McBride (University of New Hampshire) asks students "to invent or make a musical instrument, then write a poem and accompany the poem with the instrument.” She notes, "People have used Volvo car engines, crystal glasses filled with water, etc." McBride claims this exercise "teaches [creative writers] to listen to sound in a whole different way.” In Martin Cockroft's (Waynesburg University) workshop class, students listen to recordings of poets reading. He has shown them "YouTube videos of slam poets and animated poems (i.e. Billy Collins and others).” Cockroft also introduces his class to useful websites such as "Poetry Daily, the Penn Sounds poetry archive, online journals, and writers' blogs." Another teacher plans to establish a web page that she will "seed" with an opening sentence. She'll permits students "to add or delete anything at any time and see what we have at semester's end.”

Film clips are used by Deanna Kern Ludwin (Colorado State) to "illustrate dialogue and the use of metaphor." She adds "Il Postino is great for this." At the threeyear MFA program at the University of North Carolina at Wilmington, Philip Gerard notes, that students "write dialogue, and then see it performed by actors in a black-box theater on campus ... They watch films to learn how to build scenes better.” Keith Kumasen Abbott (Naropa) also uses media—-“drama and documentary—usually in the opening 8 weeks — but very sparingly in terms of length.” He never uses an entire film during a workshop, and will also introduce "artists and musicians and their art or music to discuss organizational principles.” I use film to demonstrate dialogue techniques- 
dramatic and comedic clips in films such as Before the Sunset to show how dialogue delves into relationship issues, or a snippet of Princess Bride as an example of a dialogue that takes a serious situation and deals with it in a comedic fashion, or a preview of Doubt to accentuate how dialogue can convey conflict, urgency, power. We always follow these clips with discussion and writing — prompts that allow us (always I experiment with my students) to practice our craft in new ways. Film as a venue can also illuminate scene development and the credibility of details, setting, and atmosphere.

This program course might include more interdisciplinary activity—perhaps a literary studies course that embraces creative projects or a theory course that experiments with the construction of writing. Creative attention to workshop development should also include student and group research and presentations. For example, demonstrations on the different kinds of submissions included in literary journals emphasize critical functions, explore market preferences, and include creativity when exercises which imitate these variable styles—not for entry, but rather for stylistic and experimental purposes—are employed. At this level, working collaboratively in small groups, my creative writing students are empowered to choose stories, facilitate discussions, and design exercises to demonstrate and practice processes in such a way that is different than what students do in literature and composition. We might intersect with ways in which social and cultural hierarchies and contrasting ideologies impact our roles as writer and reader. Deweyan principles of "doing” are advanced here, not to mention a shifting of master-apprentice assumptions. Moreover, these are the type of activities which Haake refers to as linking with the world, and Argie Manolis refers to "outside of academia," the engagement that occurs beyond the classroom defined as "teacher, writers whose work is 
studied, peers, and student author” (149). Deanna Kern Ludwin (Colorado State), for example, takes her class on field trips such as "campus art galleries to stimulate writing." This concept is not unfamiliar to Julie Carr (University of Colorado Boulder) whose class writes “on location together.” Carr suggests that in her class, “It’s never just 'write a poem.' There are always things to try.” Additionally, a workshop course that includes what our students might do with a creative writing degree would be well-attended—one that offers multiple perspectives, visiting lecturers-real practical exposure. In both baccalaureate tracks we should not forget "that our aim should be to foster more dedicated writers” (65), a goal Brent Royster claims we often lose as we engage in other pursuits.

Coordinated carefully, a program that includes a series of mini-lectures on relevant topics might interest a large number of students, could defray costs, and might be managed over shorter six to eight week semesters. Workshop breakout sessions might follow these lectures to advance writing and discussion relevant to lecture topics. With such variability, rigor, and relativity, there would be no need to abolish the workshop for undergraduate students as Eve Shelnutt suggests.

At the MFA level, the same course direction might exist, with pedagogical differences. For example, splitting the MFA track into two paths opens possibilities for the writer who is interested in advancing her writing. The other track might include writers who are also interested in the pedagogy of creative writing, the pedagogy of creative writing studies, the pedagogy of composition, the interdisciplinary approach to teaching creative composing practices. A complimentary or overlapping track might include a concentration on creativity in the marketplace. Think of the exciting 
coursework, internships, and relevancy to such a program design with conscious departures from traditional models. Right now, creative writing certificates and concentrations are provided in some universities for the business major. Why not apply this practice as part of the MFA career track, perhaps inviting corporate recruiters to classes as well as creative writing staff team teaching with communications and business faculty? Craft critics Tim Mayers and David Starkey, in particular, advocate for splitting of the MFA into two directions. Finally, the workshop at the Ph.D. level might be more variable than the tired "shopping" of "works" to include more critical exigency, teacher training, relative coursework that considers Bizzaro’s suggestions: "Research in Creative Writing," "Pedagogy of Creative Writing," and "Professional Issues in Creative Writing” as a means of "connect[ing] research skills typically stressed in English departments with skills stressed in creative-writing instruction” ("Research and Reflections” 301).

Rather than pitching a one-stop workshop, or pitting creativity against criticism, or constructing a crustacean shell as Haake admits to doing around her practice, "stubbornly insist[ing] that we commit ourselves ... to an examination of what happens in the writing moment to let writing take place," we might get more creative and purposeful with our workshop design to better serve our students, our profession, and our field.

* Our Lore

Perceptions of creative writing are perpetuated by its lore—a topic, which binds the essays in Kelly Ritter and Stephanie Vanderslice's edited collection Can it Really Be Taught?: Resisting Lore in Creative Writing Pedagogy (2007). Lore is defined by Stephen North, as "the accumulated body of traditions, practices, and beliefs . . . that 
influence how writing is done, learned and taught” (qtd. in Ritter and Vanderslice “Introduction” xiii). Moreover, North ascribes “anything” to the component of lore, insisting that "Once somebody says [something] has worked or is working or might work, it is part of lore.” His more disquieting feature concerns our discussion about the questionable effectiveness of the workshop, in that "while anything can become a part of lore, nothing can be dropped from it either. There is simply no mechanism for it” (qtd. in Ritter and Vanderslice "Teaching Lore” 107-108).

Consequently, the century-old workshop model, a pedagogy which has been "basically unrevised" and sustained as "lore," has governed the workshop-based creative writing classroom, regardless of its usefulness or application. In fact, my survey results as well as Delaney’s report notes the range of variability of the workshop’s appliance. Delaney notes, depending on whom one is asking, "workshops are always useful, sometimes useful, or never useful.” Regardless of the verdict, the workshop is critically a part of creative writing's lore, and as such, North informs, cannot be withdrawn or altered. While North claims we can "argue for the value" of what others "hold in ... low esteem” (qtd. in Ritter and Vanderslice “Teaching Lore” 108), this "stand requires that practitioners first reflect on, examine, and challenge their own institutionally inherited practices in the interest of rendering them more robust” (Ritter and Vanderslice “Teaching Lore” 108). While I attempt to challenge such practices, to vivify and render them more robust, it is nonetheless difficult to intercept and reverse the lore of the workshop model and the commodification of popular images of writing and writers, which draw some of our students to our workshops. 
Such lore manifests in popular magazines and inspirational guides such as The Artist's Way, The Vein of Gold, and Simple Abundance or commercial handbooks that infer anyone can be a writer. For example, in a collection from The Washington Post Book World popular novelist Mary Higgins Clark in an essay, titled “Touched by an Angel," addresses a question often asked in interviews as to when she decided to become a writer. Her response perpetuates the lore that writing cannot be taught but rather that talent is innate, blessed, in fact, by one’s fabled patroness. Clark claims, "I firmly believe that mythical godmothers make appearances at our cradles, and bestow their gifts” (35). One envisions Clark's godmother, wand in hand, standing at her cradle, bestowing such a gift, whispering, "You will be a storyteller”" (35). Other authors suggest young writers might learn to write if only they listen to their muse. This same message is conveyed in films. The Muse, for example, depicts a screenwriter's use of a real-life muse to inspire his creativity.

Other movies sustain the lore of the writer in ways that romanticize his lonely, troubled life in the garret (Finding Forrester, As Good as it Gets, Big Bad Love, Bullets on Broadway) or that display some manner of a once-prolific-but-now-writer-blocked teacher who is either infused or tortured by the genius of his/her student (Alex \& Emma, Barton Fink, Deathtrap, Deconstructing Harry, Starting Out in the Evening) or that portray the deranged writer fan (Misery) or the alcoholic writer (Barfly). Francine Prose's novel Blue Angel continues the middle-aged, writer-blocked creative writing professor tale. This one trysts with his talented female student, who, coincidently writes, flaunts even, her life-as-art musings in his workshop. In the end, the student gets a book deal, and the writer-teacher is told by his editor to give up fiction and pen a memoir about 
substance abuse. Popular images of the writer that count Carrie from Sex and the City and the industry of self-help writing books, including Oprah's role in advocating writing as self-discovery are the subject of Nancy Kruhl’s essay “Therapeutic vs. Literary Writing.” When students are "so heavily invested in the popular mythologies dealing with writing and creativity," Kruhl notes, she finds it challenging to make "meaningful” connections with her students. As long as popular imaging continues to mystify and/or stereotype the writing and writing process, "instructors of creative writing workshops will increasingly face challenges to their authority”(Kruhl 61). When students are influenced by the lore of creative writing and the expected ease of the writing process, Kruhl notes that, for students, there is little "value of any writing process that incorporates criticism, revision, and audience expectations” (61).

Lore is even visible in website advertisements for creative writing programs, even for the notable top-ranked "rigorous" programs. For example, to study creative writing at Columbia University’s School of Art means to “explore the deep artistic power of language,” at Florida State University, one can enjoy its "Southern charm, where the roads are lined with live oaks and the world's best oysters are shucked fresh from the Gulf.” At NYU, students attend workshops and "gather informally, seeking out quiet corners in which to read and write;” Michener Center for Writers is located on a rolling landscape of limestone bluffs, springs, rivers, and lakes.” Decidedly, the heart of the program at Chatham University lies in its nature, environmental and travel writing. Students travel to such places as Costa Rica, New Zealand, Greece, India and "generate creative work about the experience.” 
They offer "rich opportunities for reflection and meditation.” At Iowa, teachers "work in large offices where their classes and workshops also meet, like one-room schoolhouses.” Students, like those in Christopher Tilghman's class in Virginia, meet in their teachers' living rooms” (qtd. in Delaney). The advertisements cater to the artistic centering, the quiet serene settings, and the atmospheres which might inspire beauty, creativity, inspiration rather than rigor and hard work. Edward J. Delaney, in a 2007 Atlantic Monthly article titled "Where Great Writers are Made," reports his assessment of America's top graduate writing programs—noting these are the places students who "are infected with the fever of the emerging artist” attend. Many students, he says, are "driven by the implied example of other notable writers who have emerged from one or another program.” The lore, Delaney suggests, is that “A single faculty-member writer who’s having a notable success often seems to trump a legion of others quietly publishing work that is respected but not widely celebrated."

Program design often plays into the lore of the easy workshop-based creative writing course. Leahy bemoans the perception of students who think her class will be an easy “A,” and Michael Cunningham bolsters this mythos when he says that at Brooklyn, "unless you simply don’t give a shit, you'll get an A" (qtd. in Delaney). This anti-critical acumen is repeated elsewhere. In the main, Delaney reports, "professors and program directors characterize their programs as places where writers can find some sanctuary from judgment,” or as Columbia's Ben Marcus suggests, at least a setting "without a lot of hostility to work around.” New York University’s program director, Chuck Wachtel sees it less as "teaching students" as much as "helping them learn.” This sense of helping is forwarded by James Alan McPherson (Iowa's eminence gris) who "likens [the 
workshop] to the Midwestern concept of 'neighboring,' of one crossing the road to help another with a crop.” These non-threatening "neighboring” methods of instruction support the lore that the workshop is an easy conversation, a "talk fest," one that lacks structure, such risks that James Wilkinson warns us are consequences of our open discussion formats (qtd. in Leahy 20).

Adding to this lore is creative writing's absence from the history as a contributor to the ascendancy of English studies. Such invisibility diminishes the concreteness of our discipline, advancing us instead as mysterious, veiled tenants of the English departments that house us. Creative writing is also excluded from the list of addresses for English in the PMLA Directory. Lin reports that while such programs as American Sign Language, Eurasian studies, classics and archaeology, ethic studies, women studies,” among others are listed in the directory, the program listing for creative writing is missing from the directory (153). Conversely, creative writing job postings are included in the MLA Job Information List. Lin justly concludes that "by a strange contradiction, creative writing functions visibly as a significant part of the employed profession but remains invisible as part of the discipline” (153).

David Madden signals instructors’ culpability in perpetuating lore when he claims he is "distressed to hear many teachers of writing cater to the romantic preconception of the public and of students when they deny that writing (a mysterious process) can be taught, then go on to claim to achieve far more impossible goals—such as changing a student’s life” (qtd. in Ritter and Vanderslice "Introduction” xvi). It is no wonder then that teachers like Susan Carol Hauser (Bemidji State) observe that our "students start writing because they are called to it or driven to it," and "They stay because they come to 
understand and love it.” The first may be perpetuated by the lore of becoming a writer, the latter, we hope, is secondary to a rigorous workshop environment that emphasizes the process of writing and the rewards of its practice.

Perhaps more urgent than the lore that impacts our students and program or the critics' complaints are the voices we find familiar. Perhaps they belong to our creative writing colleagues, or perhaps we hear our own sentiments echoed in a recent article, on a listserv, at a conference session, or in our thoughts as we sit before/among our expecting students, their works-in-progress in hand —-the voice asks for something more from the workshop—something else—something better than They come to us—this is the best we can do.

\section{Developing Markers of Professional Difference}

Most creative writing teachers are decidedly tepid on the workshop as a traditional pedagogical tool. Yet, as Bizzaro concludes the model continues because of its tradition rather than any inquiry or study which has proved its effectiveness ("Research and Refelections” 296). This is the lore of the workshop model, the reason why Guevara says so "many creative writing workshops seem to drag on like a sled being pulled through a bog of wet snow by a team of faithful dogs"-creative writing teachers are those sledgedogs, and unless they want to continue their mushing, they must actively discover their professional markers and ways in which their model can improve. If creative writers are to revolutionize their discipline then they must rethink their workshop components, inquire as to the model's effectiveness, revise segments that constitute its rigor and purpose, define how the ways they teach their students to read, write, respond, 
and revise are different than those functions in literary studies and composition studies. Finally, the workshop practice must embrace new theories.

\section{* The Case for Reading and its Distinguishing Markers}

The 2008 NEA Report “To Read or Not to Read” results are even more dismal than the 2004 study which depicted Americans as reading fiction, poetry, and drama at a significant lower rate than they were ten or twenty years earlier. Our college students continue to perform poorly in the latest report, with sixty-five percent reading for pleasure less than an hour per week or not at all. Students readily argue against this charge, claiming there is little time for pleasure reading given the competitive nature of the school system. A corollary item reported in the NEA summary concerns students' distraction by technology. The results suggest "new media are displacing the intellectual engagement of reading with mere entertainment” (Burriesci 2). There is nothing new in this notation since students candidly admit their attentions are limited, they bore easily, and they have trouble narrowing their focus. They know how to twitter, wiki, and blogengage in virtual social activity on Facebook, show emotions using symbols in text, snap Kodak moments on their cell phones, have YouTube bookmarked on their computers, and know all the sources from which to download movies and songs on their laptops, on their iPods, and on their Apple iPhones. They do all of their research on the Internet, and while teachers would like to think they are using the library’s virtual database, Googlers prefer to-Google. They cannot discern the credibility of their sources, and their circuitous route to unsubstantiated knowledge takes them further and further through a deeply-potholed maze of opinions and nuances. The recently retired NEA Chairman Dana Gioia (the same Gioia who objects to what he calls creative writing's appropriation 
of poetry from the public) anticipates a defense for those who might conclude online reading has replaced the hard/softcopy book, when he says the NEA summary "is not an elegy for the bygone days of print culture, but instead a call to action ... it has enormous consequences for literature and the other arts” (qtd. in Burriesci 2).

Some of this lack of reading readiness for our workshop model can be attributed to a culture which seems to have, as one creative writing teacher reports, respect "for just about anything other than literary culture." Given the new performative modes of literature, John Meredith Hill (University of Scranton) longs for the tactile pleasure of a book in one’s hands, noting that these performative modes "engage some of our students, in ways that curling up with a thin volume in a corner of the student union while smoking a French or English cigarette (or something) and wearing an intense look was popular among 60s/70s student poets.”

Couple the NEA findings with the manner in which students read "texts" in literary studies classes today, and it becomes clear that our students do not bring the necessary reading acumen to the workshop's round-table discussion. This critical approach to the study of literature proved problematic for Novelist Francine Prose when her passion for reading prompted her interest in graduate school. Here she thought she would continue her reading of literature; however, her experience served as a warning for what was to come in the decade or so after she dropped out of the program. "That was when," she says, "literary academia split into warring camps of deconstructionists, Marxists, feminists, and so forth, all battling for the right to tell students that they were reading "texts" in which ideas and politics triumphed what the writer actually wrote." Perhaps, because we experience writing as performance, our fluid form resists such 
shaping. Sue Roe suggests that "because we know that an imaginative piece of writing might be informed as richly by painting, music, dance or theatre as by an in-depth knowledge of literature we have always been reluctant to hook the study of creative writing in a rigid or inflexible way to the study of English literature."19

Gary Hawkins (Warren-Wilson) speaks for many of the creative writing teachers surveyed who contend the workshop model "works best when students are also enrolled in an array of literature (reading) courses, so that they get a sense of the literary traditions from which they’ve sprung, and from which they may want to eventually depart.” Although Hawkins specifies that these should be reading courses, the fact remains that literature courses today focus less on the reading of novels and poems and more on what Maurice Manning (Indiana U, Bloomington) refers to as "literary theory and pseudopolitical tracts," which he notes results in work that is "often boring, self-evident, and poorly written." The unfortunate realization, Manning observes, is "when students come to our workshop, we know what they've missed: a basic understanding of the history and tradition of English-language literature.” Leslie Adrienne Miller (University of St. Thomas) concurs when she says "as the discipline of English has moved away from New Critical methods and close reading, it has become more difficult to teach workshops because students do not come into the course with basic analytical skills—which renders the workshop method fairly ineffectual.” Miller finds that more of her time is spent teaching what used to be taught in general literature courses, which, she decides considerably interferes with the time she would dedicate to workshopping.

${ }^{19}$ Sue Roe, “Introducing Masterclasses” 
The workshop model which is predicated on critical reading acumen and response skills, often thrusts students into these roles before they know how to perform them. Or as Stephanie Vanderslice suggests "throwing students like this into the traditional workshop cold is like holding a minnows' swimming lesson in the deep end of the pool” (“Workshopping” 147). Rather than go into depth about how a story works, the workshop has a history of nitpicking, with students focusing on what they "like” or "don't like.” Such personal preferences draw the attention away from the work and towards the reader. More appropriately, “good writers,” R. V. Cassill insists, “are interested in something more than the application of successful literary formulas, and so they must study texts in addition to principles” (qtd. in Myers “The Lessons”).

Along the same lines, B. W. Jorgensen (Brigham Young University) judges that "almost no students have a vocabulary for talking about syntax, which seems to be partly why they don’t perceive sentences very clearly.” Jorgensen urges, “You have to teach them to read like writers, you have to teach them that a sentence is something that can be felt and thought about.”

Whatever the agency behind our students' lack of reading readiness, the workshop model must cultivate the student as literary reader. There is certainly enough substantive information in this section to more than suggest that our students will not be well-read when they enter workshop classes; perhaps, except, in popular genres or as one teacher laments, their "reading by choice only Anne Rice.” Students' lack of reading history and the lack of literature (reading) courses create an additional load for teachers in the design of their workshop class. Indeed, some teachers, like Lisa Lewis (Oklahoma State), settle the problem of this theory focus in English studies by providing “a more literary 
sensibility” for her workshop students.” T. R. Hummer (Arizona State University) adds to this position when he says, “creative writing instructors have to make heroic efforts to make sure their students read enough, and don’t assume they can write without reading.” Manning provides another way to reduce this “additional load,” by suggesting we offer courses that intensify reading skills such as a course called "Reading for Writers," one designed for creative writing students that might stress "cross genres and literary periods.” Requiring such a course, Manning claims, would then "add rigor, to a degree, in creative writing.”

Vanderslice adds to this argument when she reminds us that students also need "reacquainting ... with the responsibilities of the writing life" ("Workshopping" 152). "These students," she insists, "need to be introduced to the universe of literary reading and encouraged, perhaps directed, to develop extensive reading lists of authors who might enlarge their sense of the world and their own work" ("Workshopping” 152). Assuredly, they need to know how to read as writers, not as literary or composition scholars, whose reading practices differ from ours. Vanderslice suggests that we prepare our students “to continually ask 'why?', to try to get inside the head of the author and 'workshop' what they are reading in the same way they might do with a student text” ("Workshopping” 152). Creative writers consider the text from the inside, taking into account the effect authors' choices have on a story or poem, to imagine what else a story might be, to conjecture, constructing theories driven by questions of “What if?'. This, Vanderslice tells us, informs "the heuristic nature of creative writing to construct for the reader, and for the writer, a hypothesis” (“Workshopping” 152). 
Such a practice of reading differs from the interpretive function of reading in literary studies, where the interest lies in determining the source of literary texts, the deconstruction of the text (and other more specialized objects of study), which supersedes how a story is constructed. R. V. Cassill clarifies our readerly distinction from the determinism of literary studies and the rhetorical modality of composition rhetoric when he insists that "[a]bove all [creative writers] are interested in how texts are made—-how the parts fit together to form a whole-which means they are committed to the view that a text might have been made otherwise than it is" (qtd. in Myers “The Lesson”). The story or poem reads as it does because the author has chosen his or her form from a number of other options. A writer's literary study is situated in this understanding that the writer chooses the story or poetic form.

Students must bear some of the responsibility of expanding their reading range by adding to the bibliographies and reading lists we provide, by seeking out suggested stories, poems, and references that might provoke some avenue yet developed in their writing. Finally, a scaffolding of writerly-reading courses should be part of the creative writing course design, beginning with basic reading skills to more intensive reading courses that supplement the workshop model. These protocols further establish the scholar of creative writing as a discipline markedly different than literary studies and composition studies.

\section{* The Case for Writing and its Distinguishing Markers}

Creative writers learn to write by reading and by writing. We know that reading as a writer is a cognitive process that allows readers to actively process and then manipulate the workings of a text in a manner that is distinct from other kinds of 
readings. Francine Prose considers the manner in which works of art trigger thinking from an aesthetic or philosophical perspective. She suggests the reading of a text "can suggest some new method, some fresh approach to fiction," but she adds that "the relationship between reading and writing is rarely so clear-cut,” relating it to something more active, "like watching someone dance and then secretly, in your own room, trying out a few steps” (9).

That the workshop model should demonstrate this link between reading and writing is clear. At the very least, creative writing practice has its roots in early Emersonian construction (as the primary means of literature in the making), compositional practices of invention and modeling, and the practice of writing within genres as classified by literary studies. The discipline's writing practice is epistemologically different than those of composition studies and literary studies in that creative writing emphasizes writerly processes, not rhetorical persuasion or philosophical discussions of goals and methods of particular literary camps. Creative writers do not begin with a thesis, a main controlling idea that serves as the contract between writer and reader. Creative writers do not submit rhetoric modes of persuasion that anticipate the pathos, ethos, and logos appeals of our readers. Rarely do creative writers consider opposing views and refutations or contextualize their positions in the larger conversation. They do not organize their stories and poems to resemble the structure of a scholarly essay or argument. Their narration is not laden with the lexicon of academics. Instead, their poems are often fragments, images. In fact, their narrators may be unreliable, the point of view of their stories and poems may be shifting, objective, subjective, omniscient—-their diction, perhaps, limited to the confines of a first-person persona. 
Rather, and I speak as a fiction writer, we step inside our characters’ minds, showing, perhaps, unique perspectives on ordinary lives. Our characters are flawed, raw, rounded - their lives complicated, convoluted; perhaps, sympathetic — their motives are defined by their movement, dialogue, interactions, the choices they make, the things they ignore. They will change, perhaps ever so subtly through the course of their actions. "Our fiction,” as Robert Butler says, “is the form of human yearning” (34). We begin in medias res, with an unstable ground situation; perhaps a trigger shifts a story’s direction.

Creative writers withhold information (or competently control its delivery), diverting off the beaten path if they choose so they may show readers the dust that gathers in the cuff of their character's pants and the grease that collects on the cushy pads of her palms. Maybe she fails to wrench the corrosive lug nuts from her flat tire but succeeds, instead, in ignoring the cell phone that sounds her baby's recorded laugh.

Rather than making direct references and connections, readers of creative writing will look for the links, the clues writers drop along the way. Our endings may surprise, rather than summarize, or they may speak to the beginnings of stories or poems. Writers may create atmosphere with their setting - maybe motive, metaphor, believability. They will mix up their narratives_-blocks of exposition, summary, direct dialogue, scene breaks_-perhaps they will flash forward or backward in time.

The distinction between writing taught and practiced in a creative writing workshop class and writing performed in a composition class has more to do with the compositional practices creative writers must unlearn as they write their poems and stories. Creative writers may have drawn from the composing practices of composition and literary study pedagogies, but clearly, their writing processes are significantly 
different and marked by their own cognitive theories of writing. What remains is the need for more versatility and experimentation in the workshop writing practice and more studies of its markers of professional differences.

\section{* The Case for Responding and its Distinguished Markers}

Before addressing student response and distinguishing markers in the creative writing workshop, it is useful to consider what risks and dynamics are at play during the peer review process to the text, the writer, the reader, the teacher. If we are to approach the text as verbal icon in the true fashion of New Criticism, then the text exists in isolation, as "words on the paper," never as an incomplete work, but rather, according to Edward White, as a finished product "in general in order to be criticized” (qtd. in Bizzaro Responding 236). Additionally, a New Critical approach becomes complicated because whenever a text is objectified and perceived as final authority, the reading of student work and the workshop dialogue traditionally silences the author, both in the overt discussion of his or her piece and also as it relates to the possible biographical coincidence of the writer to the speaker of a poem or a fictional character in a story. In other words, no authorial intent or biographical nature on social or cultural contextualization embraces or implicates the author. New Criticism's singularly focused reading of the student text does not "grant to the student possible intentions or insights not yet present on the page” (Edward White qtd. in Responding 53).

This approach assumes that students can isolate the words on the page and any interactions with a piece from a social or cultural perspective bears no import on their reading or the usefulness of their feedback. However, Haake reminds us that workshops are not filled with homogenous groups of writers, and this understanding complicates the 
traditional workshop model's narrow reading that is focused on craft and technique. Moreover, the traditional workshop space rarely includes room to challenge master narratives or much maneuverability for the constructs by students which may respond to prevailing literary conventions. A consideration of Mary Louise Pratt’s perceptivity in "Arts in the Contact Zone," offers teachers some options in the ways they view and teach within their writing communities to include the way they manage the response component of the workshop model.

In her description of a particular course, one that attracted a diverse body of students, Pratt explains "how the classroom functioned not like a class of homogenous community or a horizontal alliance, but rather like a contact zone.” Texts at play had historical relationships, and she responds that everyone had a range of stakes in the discourse. This theory has significant implications for the workshop space-a space which also functions as a contact zone. When teachers open the workshop space, flex it so-to-speak; then everyone has a stake in the responses of the workshop discussion. There is more movement away from the current limiting workshop response of what works and what does not according to the personal taste of a particular reader.

Indeed, if we consider, as Pratt does that "literate arts of the contact zone include: “authoethnography, transculturation, critique, collaboration, bilingualism, mediation, imaginary dialogue, parody, and vernacular expression,” and that the dangers of writing in the contact zone might create: "Miscomprehension, incomprehension, dead letters, unread masterpieces, absolute heterogeneity of meaning,” then we can better understand that much more is at risk in workshop classes than either composition studies or literary studies when the student text opens to more than just craft. Jan Ramjerdi clarifies that 
"What we are willing to call a response, literary scholars would call an initial personal response which then requires a standing back” (14-15). Without such critical distancing, he notes, "the use of a critical lens turns the text into an object of academic study rather than a nebulous encounter, a blur really, of personal and ideological texts, yours and mine (Hence, more is at stake)" (Ramjerdi14-15).

Healey addresses the need to "front-load" workshops with "interventions in the writing process before it begins and while it is happening," instead of the current practice of "hammering out literary verdicts like a jury" (38). Jenkins agrees that when it comes to the workshop setting, the problem lies with "the competitive, grand-standing nature of the firing-line where the student who is up for critique just absorbs comments from others, who may have ulterior motives for comments." When students are not taught "how to put [comments] into practice," one instructor comments, “the workshop can feel just like 'voting' on TV or a focus group.”

Karen Holmberg (Oregon State) wonders if putting "the writer before the class as a teaching tool” may not be "ethically problematic.” In addition, the model assumes, as one instructor says, that 'the work under discussion needs 'fixing,' like a car brought into the shop for repairs, when, depending on the students' level of seriousness and experience, such an approach may not really be helpful.” However, a number of teachers appreciate how the writer under review in the workshop model prepares students for the kind of feedback and revision practices expected in the community and workforce. Here, the attention is on the purpose of criticism and revising as a means of responsible improvement. J. T. Bushnell (University of Oregon), for example, acknowledges that "having a story workshopped is uncomfortable for an author," and as a result, "more and 
more writers seem to be responding to this discomfort by rejecting the system that produces it." His point is that "writers who reject the workshop experience are the writers who make little or no progress with their work and their vocation.” Bushnell is not alone in this argument. Another surveyed instructor, for instance, concurs that "even unhealthy dynamics offer teaching moments. It's all about process.” S/he reminds us that "student writers of all stripes, from business to science, must learn to show their work around with an eye toward improvement. Civil, sane, and substantive conversations about written work," this teacher insists, "are essential for a healthy society.”

To continue this line of thought, although the "pure" workshop, one that "presumes everyone in the workshop has the ability to read well and to edit in a manner which will help any given individual grow,” is "humanly impossible,” states Thom Brucie (Brewton-Parker College), “a classroom is still a classroom,” and “its efficacy lies in the opportunity to make mistakes and learn from them in an orderly manner, within a short time frame, utilizing a 'mentor' to facilitate student learning as much as possible from any given experience.” A well-managed workshop, he contends, "presents this classroom experience as one that is "better than any individual using a singular experience and vast amounts of time in search for answers for problems and vast amounts of time in search of improvement.” Sometimes teachers (and subsequently our students) feel the pressure of this “efficacy,” of "this classroom experience,” of this "well-managed workshop” when they try to cram as much as possible in a single semester with noble intentions to improve our students’ work.

Donald Platt (Purdue), however, believes that the “'soul’ can easily be sacrificed on the altar of technique.” Peter Harris (Colby College) coincides with this view, 
concluding, if "Workshops privilege clarity,” then, perhaps, “[Emily] Dickinson would flunk.” Furthermore, Arielle Greenburg (Columbia College Chicago) rightly suggests that conflicting feedback by "students—or the professor!—can lead the poet astray or confuse them” because students do not know how to use the workshop comments. For this reason, although I personally do not find this to be an issue, students might "validate what is most mediocre or honeyed in the writing, and students may ignore the teacher's criticism because it requires too much work" (Allison Cummings/ So. New Hampshire University). At its worst, one suggests, "the proliferation of comments serve to dilute student work—certain students try to write the bland story that everyone will kind of think is okay but nobody will love." McCabe agrees that "students can be too easily satisfied with the adulation of their peers and not work to make their work as strong as it could be.” To add further confusion, the opposite may hold true in that students learn to disregard their peers' comments if they run contrary to the writer's intentions or they dismiss all comments but the teacher's as exemplary reader of their work, the one who assigns it, finally, a grade. This notion gives Martin Cockroft (Waynesburg University) pause to speculate "if Rilke was right: Critical response to creative work results in 'happy misunderstandings,' rather than clarity, increased range, or aesthetic growth.” He reminds us that Donald Hall wrote that "our contemporary poetry will be remembered for its mediocrity and lack of ambition.” He wonders if the workshop model, the way it "helps churn out the same ‘workshop’ writing—a poem mill, doesn’t contribute to this.”

It is clearly this derisive naming of what is wrong with a piece, the focus on the end product (though revision is intended) and the inconstancy of a reader's agency that ascribes such negativity to the workshop model. There is so much room for improvement 
in this process. For starters, the beginning creative writer who is still exploring the "writerly" and "readerly" processes of creative writing cannot be expected to evaluate a body of work with any critical acumen. This ability requires not only the diligence of study and practice, but much reading experience and an ability to approach a body of work from a consonant perspective. This is certainly not an endorsement to abolish the workshop at this level, as students can still benefit from, at the very least, having an audience for their work. Rather, it is a caveat that too early immersion into a workshop process can lead to unhelpful critiques, premature inflation of writing ability, or an early censor of a still-burgeoning piece.

Even at the MFA and Ph.D. level the workshop can create a good deal of guarding and gainsaying. This causes Philip Gerard to be decidedly tepid on regarding the traditional workshop as the ultimate pedagogical tool. What he says is an argument echoed by many in the field, but it is worth trumpeting the horn one more time: "It can be a lot of people sitting around,” he insists, “saying 'I liked this but I didn't like that,' and it can do more harm than good by creating a lot of defensiveness” (qtd. in Menand).

Student responses such as these are not only not helpful to the writer or the piece or to the collective learning experience of the class, but they remain superficial and do not help creative writers to distinguish markers of professional difference in the ways creative writing students respond to written work differently than composition studies and literary studies.

I am in agreement with those who advocate for another version of the workshop, one that does not privilege identity as defined or voice as singular or workshop writing as finite. Let me emphasize that such a workshop is possible. There are new spaces to 
construct for the workshop model: spaces that "dismantle authority" and consider what more the model can offer. Katherine Haake tells us when she first recognized the repetitive cadence in her voice, "to hear [herself] tell the same stories, say the same things” (“Dismantling Authority” 99). Her aim became "to disorient students sufficiently so as to force them into a new space for writing” ("Dismantling Authority” 100). As a result, she developed topics-based writing seminars and hybrid workshops, "products of intensive scholarly rigor and careful planning” (“Dismantling Authority” 101).

Yet, there is still more to be done. Light's provocative new understanding of students' conceptions of voice and Healey's advice that we question the authenticity of voice are markers that must give us pause to reconsider our thinking and our practice. This is not to suggest that ideologies will not be challenged or that writers will not acquiesce to the majority rule in creative writing workshops. Rather, Healey suggests that instead of competition, that "we learn through collaboration, as members of a group that collectively encounters a series of writing tasks and critical activities, that studies past and present models, all with judgment suspended” (38). This is not composition’s version of collaborative theory in which consensus risks individualization, but rather, one I perceive as open dialogue, one in which the process of writing is our driving compulsion. In an environment in which the variable ways that writers might approach a text and the variable ways that writers might be influenced in their writing, are interesting points of departure from old traditions of what is working followed quickly by what needs fixing. Moreover, discussions get interesting when a written piece (professional- or studentgenerated) rubs against students’ ideology. These are useful opportunities for expanded discussions, intriguing encounters to discuss processes of writing. 
Eugene Garber adds to this argument when he talks about the limits of discussion that go so far, that “don’t really get to the profound cultural, epistemological, maybe even ontological works that appear to be representational but don't represent correctly (i.e. rerepresent the master narratives) (17)." He believes that conversations that head in this direction "will be the most energetic because people will see that the counters and structures of master narratives are really being challenged” (17). Let me clarify that I am not interested in turning the creative writing workshop into a forum for social or political agendas—definitely not. But there are refreshing opportunities for the discipline to shift the workshop tenor from its current default mode of finding fault to addressing the writerly process of how a piece works (or does not).

Tim Mayers shares an anecdote regarding an undergraduate workshopping of his poem and how it was revised based on that experience. His motivation for the retelling is to wonder what might have happened instead. For the most part, the workshop discussion focused on the elements of craft—overall it was more of an editing, rather than revision focus. "Perhaps, the most interesting avenues of discussion about the poem," Mayers shares, "were implied in the professor's seemingly off-the-cuff remarks before we moved on to the next poem” ((Re)Writing Craft 141). Mayers recalls the professor pausing, with a glance back to his poem before offering to Mayers that on his first read, he "half expected to hear a jazz saxophone in the background," supposing that "some people might think of this kind of poem as high art” ((Re)Writing Craft 141). Because Mayers' workshop space was closed off to discussions such as what kinds of imagery and topoi might have been generated by the professor's association, Mayers’ revision was limited to simple technique. In this respect, then, we can envision how our writing community 
“can help students better understand how language is a social force, and how their writing practice functions in a social context” (Healey 38).

\section{The Case for Theory}

David Starkey contends many people have much at stake in the maintenance of the status quo. To this end, Ostrom suggests, teachers tend to rely on validation through performance and testimony, rather than consider theories that underpin their pedagogy. Traditional writing workshops are a bit threadbare; their theories leave no room for pedagogy. Ostrom warns "Most probably, those who retreat from theory and pedagogy are likely to fall back on the workshop in its simplest form.” This means "going over" poems and stories in a big circle, holding forth from time to time, pretending to have read the materials carefully, breaking up squabbles like a hall monitor, marking time” (Ostrom xiv). Ostrom reminds us that an aversion to theory is in a sense, still a theory.

Peter Vandenberg has another perspective. He laments that:

it is a sad fact that when we complain about 'theory,' we are almost always complaining about something else-nominalization, bald professionalism, myopia, professional turf-grabs, arrogance, elitism, and so on. We are rarely complaining about a particular set of provisional concepts, definitions, and propositions that, by specifying relations among variables, function to explain and predict phenomena. .. As an institutionalized practice, the production and circulation of theory in textual form functions to empower some and disempower others. (“After Words 107)

In the end, he considers, "It is not theory, then, that threatens, but a particular, institutionalized version of theory-as-practice” (“After Words” 107). Vandenberg’s 
perspective on the misguided dismissal of theory by creative writers is an interesting one. Whether creative writers really intend to dismiss the "authority of a particular institutional practice" or overtly intend to dismiss theory or a combination of both, the practices still "deny creative writing and its practitioners critical tools and a self-reflexive ethos” (“After Words” 107).

I argue for a more rigorous and intelligent workshop model, one with definitive markers of professional difference from composition studies and literary studies. Behind these distinct practices which set creative writing apart from other disciplines are the theoretical underpinnings in the way our students write, read, and respond in our workshop-based classrooms. Inquiries and research into the practice of the workshop model will help to explore distinguishable markers, will lead to a more useful and robust workshop, and will continue to advance creative writing studies as a scholarly discipline. “Theory,” Ostrom reminds us, "can result in new creative products, in honorable teaching practices, in classroom events that electrify pedagogy, in intellectual refurbishment" (xix). Peter Vandenberg, for example imagines the "application of contemporary genre theory to the circumstances of a given workshop” (“After Words” 109). Such imaginings open spaces in and around the workshop model.

Rather than deny or resist theory, we should embrace that which can only open possibilities to expand not only our teaching, but our students' appreciation and understanding of the workshop model and the development of creative writing studies in the academy. Ostrom says it best when he concludes:

By talking with, through, around, beside theory, [the creative writing teacher] becomes better grounded in her own institutional history—less defensive, 
combative, or ill at ease. She will be more easy, familiar, and supportive with students, more likely to invite them into her own evolving doubts and beliefs about reading, writing, and literary conventions. If she approaches theory on her own terms, she will be more likely to change the institution, to shift paradigms, to dismantle the ancient hierarchies that even the most avant-garde critical theories seem, subtextually, to preserve. Best of all, she can still have "differences” with her colleagues and his ideas—and even with herself. She hasn't sold out or gone over to the other side, assuming the bifurcation still seems necessary to her. (xix) Indeed, she has evolved—as must the workshop model she teaches.

\section{* The Workshop Model: Final Arguments}

The writing workshop stays the same when workshop teachers continue to produce "their own interpretations of creative writing classroom lore in a field that as a whole rejects notions of itself as an academic discipline” (Ritter and Vanderslice "Introduction" xi). Most of us do not want to replicate the tired workshop model, despite Starkey's claim that much is at stake for some in maintaining the status quo. John Hopkins program director Jean McGarry warns "If workshops are only about selfexpression, then you have literary bums floating in and out” (qtd. in Delaney). Teachers who promote rigor and inventiveness in the workshop model stretch the model's flexibility—and in doing so, they also shape, for the better, our pedagogy, our students, and our profession as an intelligent model set apart in his distinctiveness from composition studies and literary studies. 


\section{SECTION THREE: THE ACADEMIC HOME OF CREATIVE WRITING STUDIES}

Perhaps the first objective in determining the academic home of creative writing studies would be one of purpose. Earlier, I position creative writing at a crossroads along with creative writing studies. In my discussion of the workshop model, I speculate on the trajectories of both disciplines and recommend course development, program designs, and curricular tracks at the undergraduate and graduate levels. In this section, I argue for the academic home for creative writing studies. It should be noted, however, that as I consider the space for creative writing studies in the academy, the academic residence of the discipline of creative writing (perhaps in a more dimensional form) becomes a natural part of the discussion. This crossover occurs primarily because creative writing has a history and relationship with the institution and with the disciplines of English studies and because creative writing studies is an emergent field.

I submit that given the value-added service that creative writing provides to the academy, there are a number of location options for the discipline of creative writing, one of which is to remain within the English department as a viable and growing program for students whose first priority is to write (rather than teach). At the very least, as I explore placement options for creative writing studies as my primary aim in this argument, there arises many opportunities for creative writing to add more dimension to its field. As creative writing studies stands at the crossroads, it does so with what I suggest is a keener 
vantage point. Its orientation permits a far-reaching view of where the discipline of creative writing has been, and as best as the practitioners of creative writing studies can judge from the topography below, what might lie ahead for their students, their profession, and their field.

Why, if creative writing is such a popular program housed mostly in English departments, one which draws student enrollment and financial support to the university, do we need to consider the academic home of creative writing studies? Could creative writing studies not just set up its scholarly operations from the current home base of creative writing? Further, to draw creative writing into this discussion and to assert an academic home for creative writing studies means drudging up considerable unrest. We must grapple with the voices of contention from literary critics who appreciate what our student numbers mean to their own discipline, not the least of which is more students reading literature. Then there are the concerns of compositionists who identify with our underdog status and the constructivist aims in our writing classes. But any talk of an academic home for creative writing studies also means some heel digging from our own creative writing teachers, many of whom retreat from theory, who dislike much delving into their practices and pedagogy; who, perhaps, want to keep the mystery and lore in and around the process of writing, and who, generally, resist reform. Why provoke such a discussion? After all, an argument can be made that creative writing now represents one of the three major "power blocks" in the English department, along with literary studies and composition studies. Creative writing's rising course and program enrollments certainly suggest it has arrived as an academic discipline. As long as these numbers 
climb, creative writing could invariably carry on its operations, its workshop-centered classrooms.

In a sense, creative writing’s academic home has been a point in question since Emerson pledged for a democratization of creative power and a desire to study creative writing within American universities. It took fifty years for Emerson’s vision of creative writing in the academy to take place; however construed it was (in its purity) as an opposition to philology’s scientific study of literature. Conceived later as a pedagogy, creative writing operated as a studio-based model at the University of Iowa, then its writers and poets soon attended the same faculty meeting as did literary critics and composition scholars. Richard Hugo’s reasoning seems cogent when he says, “The English department seemed a logical place for creative writing perhaps because it was already involved with other writing, critical and expository . . . and the assumption that reading and writing was closely related” (54).

Although creative writing programs continue to develop and student enrollment steadily rises, the discipline remains anomalous within English studies as a deviant from the scholarly norm. Shirley Geok-lin Lim speaks of the "major oddness of creative writing” (154), how its forms of poetry, fiction, and drama shape "the chief substance of what is studied and taught," how it is largely absent from the history of literary studies despite its pivotal role, and how it is "hardly visible as a disciplinary component of the profession” (154). Creative writing programs "have seldom received the scrutiny of outsiders or been required to account for themselves to the same extent as programs like composition and American studies” (Lim 156). Lim asks “How does the modern research university incorporate or contain creative writing?” (151). 
Today, creative writing graduates compete for many of the same jobs as their rhetoric and composition and literary studies counterparts. Mixed course loads that include the teaching of creative writing, creative nonfiction, modern literature, and composition coursework are the norm. Theory-based Ph.D. creative writing candidates, in particular, present with more multi-faceted attractiveness than ever before. These candidates join with MFA graduates; both groups have received little to no teacher preparation in creative writing. As a result, creative writing graduates join the majority of faculty in their field who do not know their history or theories that underpin their pedagogy. They are less likely to inquire or research or publish scholarship on topics related to their field, and they are inclined to follow the tradition of the workshop model.

I argue for a different kind of space for creative writing studies, an academic home that occupies more substance for the discipline, more equal-but-separate-standing with its colleagues in literary studies and composition studies, more distinction for its students. My research question asks: What space will give creative writing studies more meaning for the academy, for its profession, and for its student body so that it might fully avail itself of the qualities needed for a best representation as a scholarly field?

\section{Control of Space, Domain, and Power}

Foucault argues that "space is fundamental in any form of communal life; space is fundamental in any exercise of power” (qtd. in Porter and Sullivan 389). With this in mind, relations of power, knowledge, and space become entwined, unavoidable. Foucault also tells us that space is a vital part of the battle for control, of which power can be productive and negative. Territorial disputes ordinarily ensue in this struggle because of competing ideologies and the subsequent control of space, domain, and power. We see 
these power dynamics play out in what has been a mostly hegemonic English department in which literary studies has occupied the terrain, and thus the power. In the seventies and eighties, in particular, not only did literary studies have a poor view of the intellectual contribution of creative writing faculty, but teachers of creative writing (mostly MFA graduates) often held a dim view of their own desire to participate in the writing of literary criticism and/or the study/practice of theory. Certainly, as creative writing and literary studies situated under one umbrella, friction ensued. Creative writers were not taken seriously then, and even, today, with the rise of Ph.D. creative writing programs some literature professors continue to perceive such programs and their creative dissertation as anti-intellectual.

While space can be a theater of operation for such power dynamics, Foucault also posits space as a space of freedom, as unconstrained by barriers. It is within this idealized space of freedom that I wish to springboard my argument that creative writing studies must secure its academic home and its separate-but-equal position to that of literary studies and composition studies within the department of English.

\section{The Academic Home of Creative Writing Studies}

Here, I explore the fronts which have come forward in their architectural plan for creative writing and creative writing studies - either with an offer to coexist within English studies or as a separatist consortium apart from the department of English. In the end, I argue against these offers. I petition, instead, for an academic home for creative writing studies that stands on more equitable ground, that promotes the visibility (rather than the isolation) of its practitioners, that incorporates graduate career training to include teacher preparation, that articulates its research agenda and academic forums, and that 
permits its practitioners to claim creative writing studies as a research area. While exploring its academic home, my argument promotes creative writing studies as a convincing professional body of knowledge.

\section{* Creative Writing Studies and Literary Studies}

In her 2006 president's column of the MLA Newsletter, Marjorie Perloff speculates on the growing number of Ph.D. creative writing programs and what such a rise in development will mean for literary studies. She concludes that Ph.D. creative writing graduates will be asked to teach, in addition to creative writing classes, a modern literature course or two. Conjointly, this candidate will be expected to have some "knowledge of early literary periods, genres and conventions as well as of the present," (4) if one considers the traditional required curriculum of a graduate students' literature coursework. Since logic presents that Ph.D.-level creative writing faculty will incorporate theories of reading as well as "the study of rhetoric — the how of writing rather than the what" (4), in their pedagogical approaches to teaching, these practices correlate, for those in literary studies, as more engagement by students in the reading of literature. For Perloff and others, what unites Ph.D. creative writing graduates (not all of which will teach in the academy) is "love for the field of human interest" - the field of literature— "a field without which creative writing could not exist and which, conversely, may currently have no other place to go" (4).

The above explanation is necessary to appreciate the ties (whether positive or not) that bind creative writing to literary studies. In this case, the perception exists for those like Perloff that creative writing requires literature as a means of teaching its students, and "literature," or more specifically, the reading of literature has always been considered 
a hierarchal function of literary studies. On the other hand, this insight also suggests, with a hint of fatalism, that the important new work in the field of creative writing studies combined with the noticeable decline of twentieth-century literature, may mean that the discipline of literary studies may have "no other place to go" than to creative writing. It seems clear that literary studies would desire to maintain propriety over creative writing because "creative writing was perceived by many to belong with literature and the reception of texts” (O’Neil 31). The antecedent of such a view that creative writing's role is to acquaint students to literature can be found in the early twentieth century laboratory school where Hugh Mearns’ students were introduced to literature as a means of permitting their experimentation with it.

Along the same lines as Perloff, Paul Dawson buttresses the partnership between creative writing and literary studies. He redefines a role for creative writing in his formation of literary studies in what he refers to as "the New Humanities." While Dawson's view vilifies Perloff's dramatization of the struggles between writers and critics over the integrity of literature or the importance of aesthetic value, he nonetheless sees the common ground and common goal between creative writing and literary studies as one based on a vision of social agency rather than a theory of generic form or of the creative process.

Dawson, personally attuned to the potential offered by Australian creative writing programs in the post-Theory environment of the "New Humanities," collapses the writer and critic into the figure of the public intellectual— - the exemplary figure of the New Humanities” (201). Dawson outlines the various forms of literary authority assumed by the writer and shows how this authority has positioned the writer (185), and he seeks 
another purpose for creative writing "beyond its 'official' purpose of employing and training writers" (192). There must be, Dawson argues "a function specific to the university," that would "contribute to the domain of knowledge of cultural intellectuals within the academy by the provision of a literary education” (192). As such, rather than continue "the teaching of writing literature alongside the teaching of writing criticism," Dawson argues for a particular "mode of literary research within the academy," one which would entail "literary and critical writing as complementary practices" (178-179).

While I support the role of the creative writer as public intellectual and appreciate the benefits of joining forces in the best interest of serving the academy, Dawson's view limits other avenues which creative writing studies might pursue if it were to more appropriately direct its own pursuits. For example, the use of social media in creative writing studies is one such path that might obscure traditional literature readings by virtue of its immediacy and technology. If we are to become a place where students can generate ideas, try out these new ideas, and continue a quest for human expression, then we might also collaborate with others in the fields of media and technology to explore options of digital writing and digital teaching. These kinds of forward-thinking vehicles of creation might very well go against the grain of literary studies’ more traditional modes of instruction.

To add to my argument against such an academic home for creative writing studies, it is not certain how such a partnership (or collapse) might affect decisionmaking or shape the program development for creative writers at the undergraduate and graduate level. Who speaks for the goals and direction of creative writing programs and the development of creative writing studies and their students in such a "partnership"? 
How does the "New Humanities" offer markers of professional difference for our field? Taking on a collective academic identity under the umbrella of "New Humanities" steers us away from our approaching identity as writers and artists and teachers and scholars. Such uncertainty adds to a familiar unease concerning the dominance of literary studies over the discipline of creative writing. Furthermore, it seems doubtful that this new academic home might incorporate a negotiation between the ways in which texts are interpreted and literature is studied, a fundamental difference between literary studies and creative writing and creative writing studies. As such, refiguring a new discipline in this space seems implausible given the unlikely shift in the current structural model of English studies. Moreover, collapsing the creative writer and the literary critic, as Dawson suggests, can be accomplished in the same person, without the consociation of literary studies — in the field of creative writing studies, we call this person a craft critic.

\section{* Creative Writing Studies and Cultural Studies}

The argument for locating creative writing studies within the cultural studies program is tied to the idea of an all-round aesthetic education for our students. Such an aesthetic education proves problematic in an English department in which literary studies splinters into a variety of movements, most centered on the ideological or historical analysis of a text, and in which creative writing focuses mostly on writerly processes and the production of a well-formed piece of work. The debate for an academic home for creative writing studies within cultural studies predicates that a union between creative writing studies and cultural studies is the answer to the known divide between creative writing and literary studies. Such a divide is more than territorial if the methodology for approaching writing within an arts curriculum encourages what Peter Howarth refers to 
as “double-think in its students” (41). In other words, students “code-switch” depending on the class they are in, and this reflects the split within the academy between those who theorize (critics) and those who produce poems and stories (writers).

Rather than encourage such a split, proponents believe that making creative writing or creative writing studies part of a cultural studies program will narrow the gap between creative freedom and historical criticism. Students would, perhaps, resist the traditional critical evaluation of a work and instead reflect upon the felt experience of reading and/or writing a particular form. Coursework might include literary theory, medieval literature, and sociolinguistics along with parallel seminars in which creative readings guide discussions of cultural categories that resist or oblige those which students encounter in their reading and/or writing. Such integration with cultural studies leads Kevin Brophy to conclude this synthesis is critical "if creative writing students are to maintain a level of sophistication and security important to resisting rigidity in their approaches to writing” (203). In addition to advancing a more aesthetic education for our students, the rationale behind linking creative writing studies with cultural studies is to reconcile the kind of split thinking traditional English studies curricula promote for students engaged in both literary studies criticism and creative writing.

I would not dispute any programmatic depth that added a series of practical cultural studies courses and seminar discussions as a means of facilitating students' experience of creative writing studies to the social contexts of literary criticism. Undergraduate and graduate programs should, of course, involve students in a course of study that introduces them to a score of possibilities. However, I could not appreciate the 
development of creative writing studies as an academic discipline to this end, as a means of limiting creative writing studies in this singular focus.

\section{* Independent Writing Programs}

The academic home for creative writing studies' in an independent writing program assumes a unique configuration of space and issues quite different from what, for the discipline of creative writing, remains on the fringes of the English department. This space would not be a part of an English studies department, but rather it would stand apart as a newly-formed disciplinary space devoted exclusively to writing.

Notwithstanding the need to negotiate many more bureaucratic and operational issues such as funding, staffing, curriculum, and questions of how such an independent writing program would gain acceptance within the existing structures of universities.

There is much to consider in terms of the measurable sense of community within independent writing programs if we are to consider the "new kinds of collaborations," opportunities for "radical challenges in writing instruction, for rearticulations of disciplinary boundaries” that emerge in this context (Crow and O’Neill 8). The discipline of creative writing is not alone in its adjuvant status in the English department. Despite its intellectual claim to share with the hard sciences, composition studies has long been referred to as a service field, the work-horses of the department. The problems of composition are said to be "deeply rooted in the traditions of English departments and in the field's history with them” (Grow and O’Neill). As a result, compositionists have long imagined professional lives separate from an English department as suggested by Maxine Hairston's 1985 CCCC presidential address in which she calls for the field's intellectual independence. Hairston rallies compositionists to "establish [their] psychological and 
intellectual independence from literary critics who are at the center of power in most English departments” (qtd. in Grow and O’Neill 2).

Creative writing shares with composition studies a communed history of subordination by literary studies along with a shared interest in writing practices and writing theories. This history, in part, attracts the attention of creative writing studies. After all, many of creative writing's practices have some foundational basis in early composition pedagogy, and it would be difficult not to become enmeshed in whatever political agendas may surface in untangling from the embattled field from whence both fields derive.

A space such as the one created by Daniel Royer and Roger Gilles within the department of academic, creative, and professional writing at Grand Valley State University, might mean "twice as many writing courses” for creative writing students, a curriculum model approaching "that of art and design, where studio courses outnumber content courses—but where 'content' naturally informs each and every studio course” (32-33). For creative writing students it is a space that is not about literature or writing so much as a location for "theories about writing and the teaching of writing and theories of reading” (33). It means cross-fertilization possibilities such as merges with media studies_-team taught classes by composition specialists, poets, fictionists, technical communication specialists, and media scholars. Bridging such a divide has research implications for the ways students think, read, study, learn, and write in such an integrated, yet collaborative model.

Although there are interesting and innovative gains for creative writing studies in this space constructed as an independent writing program, what becomes lost, 
coincidentally, relates to the autonomous gains we might experience as an independent academic discipline, and it is this independence that bears more weight than what a united writing community such as the one described here might court. In addition, our “divorce” from English studies (if the concept of a marriage can be loosely applied to this relational context), may leave us uncertain, wondering if another relationship so soon is not "simply shacking up with another 'oppressor'” (Grow and O’Neill 3). Rather, we might imagine how we can profit from aligning with such a venture. For instance, what new courses could be developed that would incorporate team-teaching opportunities as well as cross-fertilization with those in the fields of composition, professional writing, and technical communications so as to add more depth and relativism to a creative writing studies program design.

\section{* Creative Writing Studies and Composition Studies}

A less circumscribed version of the independent writing program is one that incorporates a number of spatial properties for creative writing studies aligned with composition in a number of ways: as an intersection between the two fields, a minor or major program track, a concentration within disciplinary studies, or a blending or blurring of discipline lines. Among the first to suggest a natural relationship between creative writing and composition are Joseph Moxley and Wendy Bishop. In “Tearing Down the Walls: Engaging the Imagination,” Moxley writes that “engaging students’ imaginations,” a process he sees as the primary purpose of our instruction, "requires an interdisciplinary approach, one which brings together creative writing, literature, criticism, and composition” (25). In “Crossing Lines: On Creative Composition and Composing Creative Writing,” Bishop asserts that "We need to be crossing the line 
between composition and creative writing far more often than we do" (181). Anthony Petrosky (“Imagining the Past and Teaching Essay and Poetry Writing”) notes that, despite surface differences, the processes of poetry and essay writing are productively similar," and Marie Ponset and Rosemary Deen (Beat Not the Poor Desk: Writing—What to Teach, How to Teach It, and Why) agree that there is "no essential difference between writing a poem and writing an essay” (qtd. In Bishop 190).

If we believe as Ponset and Deen do that "all students of writing are creative, that they are always writing literature, and that writing processes have basic commonalities” (qtd. in Bishop 190), then what lessons can each discipline learn from the other? Hans Ostrom tells us in the introduction of Colors of a Different Horse that there are those who believe "(so-called) imaginative writing has a greater role to play in (so-called) basic and first-year writing” (xxi). In addition, Ted Lardner poses that creative writing has “important lessons to learn from composition in reference to process, pedagogy, and epistemology” (72). Whether students are writing a rhetorical analysis for composition class or developing a story for a creative writing course, both processes combine some elements of creating and composing. In addition, "both are grounded in some degree of reality, and both involve some use of the imagination. Both kinds of writing include the subjectivity of the writer” (Miller 43). Each requires planning, drafting, and recursive processes and employs "a reader-response theory [which] persuades that meaning does not reside solely in the text, inserted once and for all by authorial agency” (Bishop 191). "Meaning," as Bishop contends, "is constructed by authors in conjunction with a reading and a reader" (191). She asks us to consider "that for years we may have been reading a wealth of 'imaginative' and 'creative' essays even when we have assigned them and 
evaluated them as non-fiction work." In addition, Bishop claims that "it is also possible then to visualize the infinity of shaped 'family stories' and 'true experiences' that comprise the beginning composition of generations of creative writing students” (192). A crossover between composition and creative writing studies seems reasonable to me; however, as Bishop contends "the old, limiting distinctions ... were given primacy because they helped keep our selves and our academic territories well and safely sorted" (192). These "limiting distinctions" continue to be major stumbling blocks to the intersection of composition and creative writing studies.

Although creative writing and composition were considered one and the same in the early years of Harvard English education, their bifurcated tracts since then are one indication why their intersection remains incomplete today. To begin, the protraction of their degree-tracks differ. Creative writing, once perceived as an arts studio degree, developed MFA programs while compositionists formed Ph.D. studies in rhetoric. Consequently, Peter Vandenberg reports "As creative writing was defining itself against the research ethos, rhetoric and composition, following literary studies, was buying into it” (“Integrated" 8). Compositionists became very focused on writing processes and pedagogical approaches and expressed some relative interest in creative writing. Moxley, for example, published Creative Writing in America (1989), which is said to be "the seminal work about creative writing informed by composition pedagogy” (Vandenberg “Integrated” 8). Bishop responds to how Moxley’s composition pedagogy might inform creative writing. She suggests:

that knowledge in that field will redefine our understanding of creativity as "the natural consequence of learning, involvement, and commitment.” Moxley 
discusses language studies and composing research; he looks at the scientific method, hemispheric brain research, and writing productivity. In doing so, he claims that it is possible to develop theories of teaching creative writing, and he begins to map out the resources for developing a theory-based pedagogy. ("Rev. of Creative Writing in America" 426)

After the release of Creative Writing in America, Katherine Haake recalls her anticipation that NCTE, the publisher of Moxley's collection, would roll out a whole series of texts on creative writing pedagogies. This production did not transpire, but if it had, one wonders if such attention to pedagogy and practice might have stimulated more interest in such an intersection; certainly, such a study would have advanced the emergence of creative writing studies. Moxley’s book was followed by Colors of a Different Horse (1994), edited by Bishop and Ostrom, and once again, contributions, in particular Ostrom's introduction and a section on "Rethinking, (Re)Vision, and Collaboration" attempted, in part, to consider the intersection between creative writing and composition.

Peter Vandenberg adds to the list of the above pedagogues interested in overlapping the interstitial spaces between composition and creative writing studies by including David Starkey's perspective in Teaching Writing Creatively. Starkey endorses what he calls a "polyculturalist" approach to writing instruction constructed by "teacher theorists who, over the years, have actively cross-pollinated areas of writing that had once been isolated from each other" (qtd. in Vandenberg "Integrated" 9). Then there is Tim Mayers, poet and compositionist, who makes a plausible case in (Re)Writing Craft: Composition, Creative Writing, and the Future of English Studies (2005) for a hybridized field of inquiry which joins composition and creative writing as "writing studies" (114). 
One of the mitigating factors behind such a conjoining is a need to offset "literary studies as the rightful center of English studies” (133). Mayers proposes that this shift in infrastructure is possible through "a concerted effort to alter one of the fundamental dynamics of the disciplines at large” (133). At the very least, he notes, "compositionists and creative writers will have to put aside their very significant professional differences long enough to realize that working together ... they can accomplish more than they can by working separately" (133). Mayers maps out the necessary groundwork for such a structural change which requires, among many other adjustments, converging composition and creative writing practices within three of the core undergraduate courses: first-year composition, introduction to creative writing, and the writing about literature course.

Vandenberg informs us that “A clear sign of a field's maturation and stability is the move to claim influence for one's own scholarship discourse on that of another field" ("Integrated" 9). Most of the movement towards an intersection or union between the discipline of creative writing (or creative writing studies) and composition studies has been executed by compositionists or those writer-teachers who find it difficult to shift their personas when they enter their creative writing and composition classrooms. Add to the mix, the increasingly generous space in journals like CCC and College English (which devoted an entire issue to creative writing in 2003) for essays on creative writing pedagogy and/or reflections of the field's composition influence. Combine this direction with the rise of creative writing sessions at the College Composition and Communication Conventions since 1996. It becomes apparent to Vandenberg and to me, that "Clearly, composition has claimed creative writing as a correlative" ("Integrated" 10). It is 
questionable if creative writers are attentive to composition's dialogue about creative writing, and if they were, there is no movement to suggest their interest in such a space.

As someone whose feet are in both fields, I endorse the blurring of lines between creative writing studies and composition studies. And to that point, it is difficult not to consider overlapping properties given the functional interdisciplinary of more and more teachers today. In my own case, my higher education includes creative writing and rhetoric and composition, my writing practices include fiction and scholarly publications and presentations, my teaching pedagogy is informed by both disciplines, and my research methods mix observation and experiential skills with bibliographic and pedagogical scholarship. I represent a fused model of a collective identity, one that influences my students, my colleagues, and my field to the degree that I can, but the shifts in structural models that Mayers argues for, such determinant programmatic directions and praxes, are beyond the capabilities of such an intersection. A merger remains abstract because the fields stay entrenched in their own histories, conferences, professional organizations, practices, and program development.

Creative writers, for the most part, are suspicious of composition's theoretical advances. Kelly Ritter, another writer and teacher of creative writing and composition, points to the structure of graduate degrees offered to its creative writing students as one reason for this withdrawal. She asserts that both MFA and Ph.D. programs in creative writing "by design encourage writers to become islands adrift professionally and intellectually from their larger English departments” (“Professional Writers” 209).

As a field, many creative writing teachers are resistant to a discourse that includes theory and pedagogy, and Ritter suggests the lack of training in these areas explains why 
creative writers are less interested in the research of ways in which creative writers read, write, and teach. The AWP, as creative writing's professional organization, compounds this problem when it disregards an endorsement of graduate training in the preparation of teaching. If we are products of our training as Judith Harris suggests when she notes, "In prioritizing the writing skills that will best prove students' proficiency, teachers tend to perpetuate biases that are embedded in their own training and predilections," then it is no wonder that creative writers take on, what Ritter refers to as "collective academic identities.” In the field of creative writing, we see ourselves as “'writers' and 'artists' as opposed to 'teachers' or 'scholars”, ("Professional Writers” 210). Composition’s teaching training versus creative writing's lack of such training, would ultimately leave such a space conflicted over how student writers might be taught.

The academic home provided for creative writing studies and/or creative writing by composition studies is one in which creative writers remain suspect. I return to Moxley, who makes two excellent points: first, that "the general segregation of creative writing from literature and composition corrodes the development of a literacy culture,” and second, that "our passion for specialization within writing departments has caused us to divide and subdivide (potentially) consolidating processes of discovering and shaping meaning” (25). Foucault's concept of space seems reasonable here, for as he relates space, knowledge and power as that which is necessarily related, he notes "it is somewhat arbitrary to try to dissociate the effective practice of freedom by people, the practice of social relations, and the spatial distributions in which they find themselves. If they are separated, they become impossible to understand” (qtd. in Elden and Crampton 9). 
Perhaps the current "spatial distributions" of creative writing studies and composition have bearing on our inability to intersect and this "separation of sorts" impedes our understanding of one another. Perhaps, "spatiality occurs as an integral part of a larger concern—as a tool analysis rather than merely an object of it” (qtd. in Elden 9), and if that is the case, then there is work for creative writing to do in its field, in redefining its space, power, knowledge. For the time being, the segregation and division that Moxley refers to remain as a mostly theoretical binary between creative writing studies and composition. That is, until creative writing studies can become better situated as a research field and as an academic curricular entity.

\section{* The Academic Home for Creative Writing Studies}

It is in this space, the space Foucault reserves as a space of freedom that I argue for the academic home of creative writing studies. Defined by Tim Mayers in a special panel 2008 MLA presentation and in a recent College English article, creative writing studies is "a still-emerging enterprise that has been set in motion by some of the problems and internal contradictions of creative writing"; and as such, it "is a field of scholarly inquiry and research” (“One Simple Word” 218). As a scholarly field of inquiry and research, creative writing studies is not a new concept; in fact, Wendy Bishop can be said to have pioneered its beginnings with her spatialization of creative writing and composition as an intersection. Also, in the United Kingdom, in particular, creative writing — unencumbered by the history that confines the traditional United States' discipline - has partnered with criticism, research, and scholarship from the start. Recently, in the U.S. there have been more assertive proclamations for a new academic 
home for creative writing studies in the twenty-first century, particularly from craft critics Kelly Ritter, Patrick Bizzaro, Katherine Haake, and Tim Mayers.

I return to Foucault's concept of space as a space of freedom, as unconstrained by barriers. Foucault adds, "Such is the power of language: that which is woven of space elicits space, gives itself space through an originary opening and removes space to take it back into language” (qtd. in Elden and Crampton 7)—such language exists in academic home of creative writing studies-in the power, the knowledge and the space of creative writing studies. This academic home situates the practitioners and scholars of creative writing studies shoulder-to-shoulder with its colleagues in composition studies and literary studies. I have argued for the establishment of creative writing studies, outlined the steps to advance its emergence, added to the development with my own inquiry and research into the field, and proffered its academic home. If creative writing studies is to become pedagogically and programmatically sound, productive and meaningful to the academy, its profession, its creative economy, and, critically, to its student body—it must continue its necessary field of inquiry, scholarship, and research as well as advocate for its own identity at the public and institutional level. 


\section{CONCLUSION: THE LEGITIMACY OF CREATIVE WRITING STUDIES}

My overarching goal in this study is to provide academic legitimacy to the discipline of creative writing studies and to add to this legitimacy through my contributions to the field's inquiry and research. To best accomplish this objective it is important to explore the discipline’s history; more specifically, to understand how the grounding of creative writing's practice informs not only its pedagogies and the theories which underpin its practices, but also its isolation from the central curriculum and its binary opposition with academic critics. With regards to the latter, Hans Ostrom tells us that creative writers often feel underappreciated. They are "aggrieved," he says, "always waiting to arrive,” and "even scorned, by those in 'literature' and challenged by those in composition and cultural studies” (xiii). The smallness of creative writers in the scope of the dysfunctional family it calls English studies, “only exacerbates elitism, inbreeding, suspicion, and unproductive conflict” (Ostrom xiii).

Figuratively, along the same lines, it is hard not to connect with Eve Shelnutt's view of creative writing teachers "huddled in tight circles reminiscent of Conestoga wagons under attack," and “as second-class citizens in English departments” (11). She claims our students come to accept their "proper place” "in the intellectual ghettos of English departments,” and learn “they were never meant, heaven forbid, to become creative writers and thinkers too" (emphasis mine, 12). Scholars criticize the study of creative writing, the classes that convey "an immoral disregard for great literary 
monuments," the writing processes which are "too intuitive and naïve at best,” and “irrational and ignorant at worst” (Fenza para. 39). Creative writing classrooms are "occasions for self-indulgence, confessional exhibitionism," and "hardly the stuff for the rigors of an academic discipline” (Fenza para. 39). Those who teach creative writing complain of disparate hiring practices, of perceptions that the area of creative writing is soft and trivial, only a fun activity, anti-intellectual, and "touchy-feely."

Some of the skepticism between creative writers and those in literary studies are located in the way the discipline is defined, the lore and perception both from within the academy and from the popular images of writing and writers. Even such basic principles as "whether we write the writing or the writing writes us," are wrangled with issues of ownership, authority, and practice (What Our Speech Disrupts Haake 53).

There was a time in the early twentieth century when creative writing and literary studies partnered. When poets, in particular, entered the university and joined literary critics in an unlikely partisan group to fight against the scientific study of literature. Poets became critics, defining, in part, the study of literature from a New Critical view. Even Norman Foerster, who designed the Iowa School of letters, intended for creativity and criticism to be allies in his university curriculum for writers. The discipline, however, became less dually-aligned with creative writing and criticism when Paul Engle dropped the academic track at Iowa and focused instead on the studio method, the workshop prototype practiced in classrooms today. Since the sixties, the "mystique of professionalism” has given rise to creative writing teachers disregarding the discipline of criticism to become, according to Myers’ charge: “a national staff of writers who teach writers who go on to teach, and to hope for tenure and promotion” (qtd. in Lim163). This 
sustains, Lim reports, “the debilitating segregation of writing from criticism and scholarship, of technique from theory” (163).

The workshop model provides a useful pedagogical example of a practice in which the separation of writing from criticism and technique from theory is apparent. As discussed, the century-old workshop has been "basically unrevised” because there has not, until recently, been any "rigorous inquiry," which "offers testimony to its excellence” (Bizzaro “Research and Reflection” 296). As part of my course to add to the theoretical and academic scholarship of creative writing studies, I explore such a “rigorous inquiry” to the model and find, as a result, exciting opportunities to flex its elasticity and complement and complicate its practice.

With an understanding of creative writing's history, even one as brief as I mention here and throughout my discourse, it is not difficult to trace the path that led to creative writing's isolationist location within English studies, nor is it difficult to trace the evolution of some of the interdepartmental disputes and note where and when creative writing as a discipline partnered with criticism and where it separated from the practice of criticism. What is important to also address in the discipline's history is the selfmarginalization by some creative writing teachers who resist inquiry and research into their pedagogies, who retreat from theories that underpin their classroom planning and practices, and who replicate the basic workshop model and other methods that idle.

Moreover, self-marginalization in creative writing is also very much connected to "the absence of teacher training and pedagogical reform in the face of the lore that perpetuates the traditions and customs of the field” (Ritter and Vanderslice "Introduction” xiii). This is the lore of the lonely writer in the garret; of long, unbroken 
passages of inspired writing; of casual classrooms and clustered conversations, of easy "A's" and cool, eccentric teachers. This is the lore of teaching creative writing, which "is systemic, pervasive, and rooted in creative writing's isolated academic status, at once frustrating and comforting to the writers and organizations who perpetuate it” (Ritter and Vanderslice "Introduction" xiii). One of the more critical ambitions of creative writing studies is the training of its graduates in teacher preparation. David Radavich proposes that "advanced degrees in creative writing cannot generate the job prospects available even to graduates of more traditional doctoral programs" and that "there is no profession for which an MFA or $\mathrm{PhD}$ in creative writing provides direct training” (110). There is an urgent need for such training not only to better position creative writing graduates in the marketplace, but also so to best prepare instructors who can teach the new skills formulated through the field's inquiries, research, and discoveries. This training (and then practice) equates to what amounts to a significant professional paradigm shift as more creative writers welcome inquiries into their field and willingly participate in the scholarship and new identity of their discipline.

As long as there are such vast differences in epistemological studies and pedagogical approaches between the disciplines of English studies, tensions will remain, and faculty will question why and how creative writing is still a tenant in the English department that houses it. However, a discipline such as creative writing studies which explores the pedagogy and theory of its field, establishes its own scholarship, identifies its own markers of professional difference, trains its graduates in teacher preparation, develops new courses and venues for passing new skills on to its students, may bridge some of the widened gap that has occurred over the embattled territory of what many 
consider to be a mostly hegemonic English department. Creative writing studies moves beyond its opposition to criticism so as to develop its own scholarship and identity. As an academic discipline, it may not eliminate interdepartmental tensions, but there is hope that because some points of creative writing studies overlap with both literary studies and composition studies that the emergent discipline will create more positive movement in redefining the structure of English studies.

Moreover, Mayers considers the fate of creative writing in a dysfunctional English department. He notes that should there be a split between composition studies and literary studies (for example, composition studies joins an independent writing program), then "creative writers may be placed in undesirable positions," as they are “compelled to choose between two imperfect options” (“One Simple Word” 227). Mayers' scenario is further "validation for the importance of creative writing studies—a field of inquiry that will provide creative writers in academia with the intellectual tools to answer tough questions and face tough choices” (“One Simple Word” 227).

As an academic discipline in its own right, creative writing studies negotiates, accommodates, and identifies critical theories. It identifies and negotiates critical theories as it challenges traditional practices such as I have done through my inquiry and research into the workshop model and the discipline's major pedagogical theories. It accommodates critical theory as it considers what it draws epistemologically from composition studies and literary studies and then applies, modifies, or develops discipline-specific critical writing and reading practices in the creative writing classroom and writing workshop. The vision for practitioners of creative writing studies situates the writer and the discipline within a broader theoretical base. Part of the imperative in 
creative writing studies is the constant questioning and challenging of existing practices. We are that much closer to accepting creative writing studies than we were a decade ago. As the discipline aims for a more diversified body of knowledge, it also rethinks its signature pedagogy, dominant teaching strategies, and its perspectives on theory and scholarship. It becomes more expansive, flexible, collaborative, enriched, and independent. As creative writing studies becomes better situated as a research field and as an academic curricular entity, it will soon receive the attention it deserves. As it does, creative writing studies will add more meaning to the academy, its profession, and its diverse student body. 


\section{BIBLIOGRAPHY}

Abrams, M. H. The Mirror and the Lamp. London: Oxford UP. 1953.

Adams, Katherine H. A History of Professional Writing Instruction in American Colleges. Dallas: So. Methodist UP. 1993.

Anderson, Larry. "Using Reader-Response Theory in the Introductory Literature Classroom.” College Literature 18.2 (Jun. 1991): 141-145.

Beach, Richard. A Teacher's Introduction to Reader-Response Theories. Urbana: NCTE, 1993.

Berlin, James E. “Contemporary Composition: The Major Pedagogical Theories.” The Writing Teacher's Sourcebook. Oxford: Oxford UP, 1981. 9-21.

---. Writing Instruction in American Colleges, 1900-1985. Carbondale: So. Illinois UP, 1987.

---. Rhetoric \& Ideology.” College English 50.5 (Sep, 1988): 477-494.

---.Rhetoric and Reality. Carbondale: So. Illinois UP, 1987.

Bishop, Wendy. "Crossing the Lines: On Creative Composition and Composing Creative Writing." Colors of a Different Horse: Rethinking Creative Writing Theory and Pedagogy. Urbana: NCTE, 1994. 181-197.

---. “On Being in the Same Boat.” AWP Chronicle. (March/April), 1992.

---. Released Into Language: Options for Teaching Creative Writing. Urbana: NCTE, 1990.

---. “Rev. of Creative Writing in America.” JAC 10.2, 1992.

--- and Hans Ostrom. Colors of a Different Horse. Urbana: NCTE, 1994.

--- and David Starkey. Keywords in Creative Writing. Logan: Utah State UP, 2006. 
Bizzaro, Patrick. "Reading the Creative Writing Course: The Teachers' Many Selves.” Colors of a Different Horse. Eds. Wendy Bishop and Hans Ostrom. Urbana: NCTE, 1994. 234-247.

---. "Research and Reflections: The Special Case of Creative Writing.” College English 66.3 (Jan. 2004): 294-309.

---. Responding to Student Poems. Urbana: NCTE, 1993.

---. "Should I Write the Essay or Finish a Poem? Teaching Writing Creatively.” CCC 49.2 (1998): 285-297.

--- and Michael McClanahan. "Putting Wings on the Invisible: Voice, Authorship and the Authentic Self." Can it Really be Taught? Ed. Kelly Ritter and Stephanie Vanderslice. Portsmouth: Boytin Cook, 2007. 77-90.

Bizzell, Patricia. "Cognition, Convention, and Certainty: What We Need to Know About Writing.” Journal of Rhetorical History 3 (1982): 213-243.

Blythe, Hal and Charlie Sweet. "The New Writing Community: A New Model for the Creative Writing Classroom.” Pedagogy 8.2 (2008): 305-325.

Boden, Margaret A. The Creative Mind: Myths and Mechanisms. London: Routledge, 2004.

Bontley, Thomas. "Creative Writing in the Academy.” Sewanee Review 115.1 (Winter 1007): iii-v.

Bracher, Mark. The Writer Cure. Carbondale: Southern Illinois UP, 1999.

Brook, Robert. "Lacan, Transference, and Writing Instruction.” College English 49.6 (1987): 679-691.

Brophy, Kevin. “Taming the contemporary.” TEXT 4.1 (April 2000) $<$ http://www.textjournal.com.au/april00/brophy.htm>.

Burriesci, Matt. "NEA Report Shows that Steep Decline in American Reading Skills will have Significant Long-Term Negative Effects on Society.” AWP Writer's Chronicle 40.40 (Feb. 2008): 1-2.

Cain, William E. The Crisis in Criticism. Baltimore: John Hopkins UP, 1984.

Cantrell, Mary. "Teaching and Evaluation: Why Bother?” Power and Identity in the Creative Writing Classroom. Ed. Anna Leahy. Clevedon: Multilingual Matters Ltd, 2005. 65-76. 
Carlson, Scott. “The New Generation Goes to College.” The Chronicle of Higher Education. 7 Oct. 2005. 30 Nov. 2008 $<$ http://chronicle.com/free/v52/i07/07a03401.htm>.

Carr, Nicholas. “Is Google Making Us Stupid?” Atlantic. July/Aug. 2008. $<$ http://www.theatlantic.com/doc/200807/google>.

Ciabattari, Jane. "Workshop: A Revolution of Sensibility.” Poets \& Writers (Jan/Feb 2005) <http://www.pw.org> .

Ciardi, John. How Does a Poem Mean? Cambridge: The Riverside P, 1959.

Clark, Kevin. "Study as Practice: On Creative Writing \& the English Curriculum.” Writer's Chronicle (Sept.) 1999 $<$ http://elink.awpwriter.org/m/awpChron/articles/kclark01.lasso $>$.

Clark, Mary Higgins. “Touched by an Angel.” The Washing Post Book World, 2003.

Clausen, Christopher. "Reading Closely Again.” Commentary 103.2 (February 1997): 5457.

Coles, Catherine. "How the University Workshop Hinders New Writers From Engaging with Ideas (And What to Do About It). Segue Online Literary Journal. Miami University Middletown. <www.mid.muohio.edu/segue >:1-13.

Cook, Paul et al. “Creative Writers' Report: Mastering the Craft.” Creative Writing in America. Ed. Joseph Moxley. Urbana: NCTE, 1989. 247-260.

Cooley, Nicole. "Literary Legacies and Critical Transformations: Teaching Creative Writing in the Public Urban University.” Pedagogy 3.1 (2003): 99-103.

Crampton, Jeremy W. and Stuart Elden. "Introduction: Space, Knowledge and Power: Foucault and Geography." Space, Knowledge and Power: Foucault and Geography. Ed. Jeremy Crampton and Stuart Elden. Williston:Ashgate, 2007. 116.

Crow, Angela and Peggy O’Neill. "Introduction: Cautionary Tales about Change.” A Field of Dreams: Independent Writing Programs and the Future of Composition Studies. Ed. Peggy O’Neil et al. Logan: Utah State UP, 2002. 1-18.

Davis, Todd F. and Kenneth Womack. Formalist Criticism and Reader-Response Theory. New York: Palgrave, 2002.

Davidson, Chad and Gregory Fraser. "Poetry.” Teaching Creative Writing. Ed. Graeme Harper. London: Continuum, 2006. 21-33. 
Dawson, Paul. Creative Writing and the New Humanities. Oxford: Routledge, 2005.

Delaney, Edward J. “Where Great Writers are Made.” The Atlantic (Fiction Issue). 2007 $<$ http://www.theatlantic.com/doc/200708/edward-delaney-mfa>.

Delbanco, Nicholas. The Sincerest Form: Writing Fiction by Imitation. (2004).

Deletiner, Carole. “Crossing Lines.” College English 54.7 (1992): 809-817.

Domina, Lynn. "The Body of My Work Is Not Just a Metaphor." Colors of a Different Horse. Urbana: NCTE, 1994. 27-34.

Eagleton, Terry. Literary Theory: An Introduction. Minneapolis: U of Minnesota P, 1983.

Earnshaw, Steven. “The Writer as Artist.” The Handbook of Creative Writing. Edinburgh: Edinburgh UP, 2007. 65-77.

Elliot, Gayle. "Pedagogy in Penumbra: Teaching, Writing, and Feminism in the Fiction Workshop.” Colors of a Different Horse. Urbana: NCTE, 1994. 100-130.

Fenza, D. W. “Creative Writing \& Its Discontents.” Writer’s Chronicle. (March/April) $2000<$ http://www.awpwriter.org/magazine/writers/fenza01.htm>.

Fish, Stanley. Is There a Text in This Class? Cambridge: Harvard UP, 2005.

Foucault, Michael. "Truth and Power.” Power Knowledge: Selected Interviews and Other Writings 1972-1977. (Ed.), trans. C. Gordon et al., New York: Pantheon. 109-33.

Fulkerson, Richard. "Composition Theory in the Eighties: Axiological Consensus and Paradigmatic Diversity.” CCC 41.4 (Dec. 1990): 409-429.

Garber, Eugene and Jan Ramjerdi. "Reflections on the Teaching of Creative Writing: A Correspondence.” Colors of a Different Horse. Urbana: NCTE, 1994. 8-26.

Galef, David. “Words, Words, Words.” Day Late, Dollar Short. Ed. Peter C. Herman. Albany: SUNY P, 2000. 161-174.

Garrett, George. "The Future of Creative Writing Programs.” Creative Writing in America: Theory and Pedagogy. Ed. Joseph Moxley. Urbana: NCTE, 1989. 4761.

Gillman, Charlotte Perkins. “The Yellow Wallpaper.” The Norton Anthology of Short Fiction. Ed. R.V. Cassill and Richard Bausch. $6^{\text {th }}$ edition. New York: W. W. Norton \& Co., 2000. 675-687 
Gioia, Dana. “Can Poetry Matter?” Atlantic Monthly 276 (May 1991): 94-106.

Graff, Gerald. “Conflict Pedagogy and Student Experience.” CCC 46.2 (May 1995): 276279.

---. Professing Literature. Chicago: U of Chicago P, 1987.

Grimes, Tom. "Workshop and the Writing Life” The Workshop: Seven Decades of the Iowa Writers' Workshop. Ed. Tom Grimes. New York: Hyperion, 1999. 1-15.

Green, Chris. "Materializing the Sublime Reader: Cultural Studies, Reader Response, and Community Service in the Creative Writing Workshop.” College English 64.2 (Nov.) 2001.

Guevara, Maurice Kilwein. "Out of the Ashtray: Revivifying Creative Writing Classes.” AWP (March/April), 1998.

Haake, Katharine. "Against Reading.” Can it Really be Taught? Ed. Kelly Ritter and Stephanie Vanderslice. Portsmouth: Boytin Cook, 2007. 14-27.

---. "Dismantling Authority: Teaching What We Do Not Know." Power and Identity in the Creative Writing Classroom. Ed. Anna Leahy. Clevedon: Multilingual Matters Ltd., 2005. 98-105.

---. "Teaching Creative Writing if the Shoe Fits.” Color of a Different Horse. Ed. Wendy Bishop and Hans Ostrom. Urbana: NCTE, 1994. 77-99.

---. What My Speech Disrupts: Feminism and Creative Writing Studies. Urbana: NCTE, 2000.

Hairston, Maxine. "Breaking Our Bonds and Reaffirming Our Connections.” CCC 36.3 (1985): 272-282.

Harper, Graeme. "Introduction.” Teaching Creative Writing. Ed. Graeme Harper. London: Continuum (2006) 1-7.

Healey, Steve. "The Rise of Creative Writing \& The New Value of Creativity.” The Writers Chronicle 41.4 (2009): 30-39.

Hall, Donald. "Poetry and Ambition.” Poetry.org. Feb 2, 2009. (originally published in Kenyon Review ns 5.4 (1983): 90104. $<$ http://www.poets.org/viewmedia.php/prmMID/16915>.

Harper, Graeme. Teaching Creative Writing. Ed. Graeme Harper. London: Continuum, 2006. 
Harris, Judith. "Re-writing the Subject: Psychoanalytic Approaches to Creative Writing and Composition Pedagogy.” College English 64.2 (2001): 175-204.

Howarth, Peter. “Creative Writing and Schiller's Aesthetic Education.” Journal of Aesthetic Education 41.3 (Fall 2007): 41-58.

Hugo, Richard. The Triggering Town: Lectures and Essays on Poetry and Writing. NY: Norton, 1979.

Iser, Wolfgang. The Act of Reading. Baltimore: John Hopkins UP, 1978.

---. "The Reading Process: A Phenomenological Approach. Reader-Response Criticism: From Formalism to Post-Structuralism. Ed. Jane Tompkins. Baltimore: John Hopkins UP, 1980. 50-69.

Kruhl, Nancy. "Personal Therapeutic Writing vs. Literary Writing." Power and Identity in the Creative Writing Classroom. Ed. Anna Leahy. Clevedon: Multilingual Matters Ltd, 2005. 3-12.

Lacan, Jacques. Ecrits. Paris: Editions du Seuil, 1966.

Lardner, Ted. "Locating the Boundaries of Composition and Creative Writing." CCC 51.1 (1999): 72-77.

Leahy, Anna. "Creativity, Caring, and The Easy 'A': Rethinking the Role of Self-Esteem in Creative Writing Pedagogy." Can it Really be Taught? Ed. Kelly Ritter and Stephanie Vanderslice. Portsmouth: Boytin Cook, 2007. 55-66/

---. Power and Identity in the Creative Writing Classroom: The Authority Project. Ed. Anna Leahy. Clevedon: Multilingual Matters Ltd., 2005.

Levine, George. “The Real Trouble.” Profession (1993): 43-45.

Light, Gregory. "Conceiving Creative Writing in Higher Education.” NAWE. $<$ http://www.nawe.co.uk/archive>. Accessed March 4, 2009.

Lim, Shirley Geok-lin. "The Strangeness of Creative Writing: An Institutional Query.” Pedagogy 3 (2003): 151-69.

Lynn, Steven. “A Passage into Critical Theory.” College English 15.3 (1990): 258-267.

Manolis, Argis. "Writing the Community: Service Learning in Creative Writing." Power and Identity in the Creative Writing Classroom: The Authority Project. Ed. Anna Leahy. Clevedon: Multilingual Matters Ltd., 2005. 141-151. 
Mayers, Tim. "Figuring the Future.” Can it Really be Taught? Ed. Kelly Ritter and Stephanie Vanderslice. Portsmouth: Boytin Cook, 2007. 1-13.

---. “One Simple Word: From Creative Writing to Creative Writing Studies.” College English. 71:3 (Jan.) 2009. 217-228.

---. (Re)Writing Craft. Pittsburgh: U of Pittsburgh P, 2005.

McGurl, Mark. “Understanding Iowa: Flannery O’Connor, B.A., M.F.A. American Literary History. 19.2 (2007): 527-545.

Mearns, Hughes. Creative Power. Garden City: Doubleday, 1935.

Menand, Louis. “Show or Tell: Should Creative Writing be Taught?” The New Yorker 8 June 2009

$<$ http://www.newyorker.com/arts/critics/atlarge/2009/06/08/090608crat_atlarge_ menand $>$.

Miller, Evie Yoder. "Reinventing Writing Classrooms: The Combination of Creating and Composing.” Power and Identity in the Creative Writing Classroom: The Authority Project. Ed. Anna Leahy. Buffalo: Multilingual Matters Ltd., 2005. 3948.

Minock, Mary. “Toward a Postmodern Pedagogy of Imitation.” JAC. 15.3 (1995) $<$ http://www.jacweb.org/Archived_volumes/Text_articles/V15_I3_Minock.htm>.

Minot, Stephen. “Creative Writing: Start with the Student's Motive.” CCC 27.4 (Dec. 1976): 392-394.

Moxley, Joseph. “Tearing Down the Walls: Engaging the Imagination.” Creative Writing in America: Theory and Pedagogy Ed. Joseph Moxley. Urbana: NCTE, 1989. 2545.

Murphy, Ann. “Transference and Resistance in the Basic Writing Classroom: Problematics and Praxis.” CCC 40.2 (1989): 175-187.

Murray, Donald. “Unlearning to Write.” Creative Writing in America. Ed. Joseph Moxley. Urbana: NCTE, 1989. 103-113.

Myers. D. G. The Elephants Teach: Creative Writing Since 1880. Chicago: U of Chicago P, 1996, 2006.

---. “The Lessons of Creative Writing's History.” AWP Chronicle 26.1 (Feb 1994) $<$ http://www,awpwriter.org/login/m/awpChron/articles/dgmyers01.lasso>. 
North, Stephen. The Making of Knowledge in Composition. Upper Montclair, New Jersey: Boyton/Cook, 1987.

O’Dair, Sharon. “Stars, Tenure, and the Death of Ambition.” Day Late, Dollar Short. Ed. Peter C. Herman. Albany: SUNY P, 2000. 45-61.

O’Neill, Peggy et al. A Field of Dreams. Eds. Peggy O’Neil et all. Logan: Utah State UP. 2002.

Ostrom, Hans. "Introduction: Of Radishes and Shadows, Theory and Pedagogy." Colors of a Different Horse. Eds. Wendy Bishop and Hans Ostrom. Urbana: NCTE, 1994. xi-xxiii.

Petrosky, Anthony. “Imagining the Past and Teaching Essay and Poetry Writing.”

Perloff, Marjorie. “'Creative Writing’ Among the Disciplines.” MLA Newsletter (President’s Column) 38.1 (Spring 2006): 3-4.

Polkinghorne, Donald. Narrative Knowing and the Human Sciences. New York: State U of NY P, 1988.

Pollack, Eileen. “Flannery O’Connor and the New Criticism: A Response to Mark McGurl.” American Literary History. 19.2 (Summer 2007): 546-556.

Porter, James E. and Patricia A. Sullivan. “Remapping Curricular Geography.” Journal of Business and Technical Communication (1993): 389-422 $<$ http:jbt.sagepub.com/cgi/content/refs/7/4/389>.

Pratt, Mary Louise. “Arts of the Contact Zone.” Ways of Reading, $5^{\text {th }}$ Edition. Ed. David Bartholomae and Adam Petrosky. 06/01/09 $<$ http://www.nwe.ufl.edu/ stripp/2504/pratt.html>.

Prensky, Marc. “Digital Natives, Digital Immigrants.” On the Horizon 9 MCB University P (2001): 1-6.

Prose, Francine. Reading Like a Writer. New York: Harper Collins Pub., 2006.

Radavich, David. "Creative Writing in the Academy.” 15 March 2008 <http://www.ux1.eiu.edu/ daradavich/creative.html>. 110-112.

Ramjerdi, Jan and Eugene Garber. "Reflections on the Teaching of Creative Writing: A Correspondence.” Colors of a Different Horse. Urbana: NCTE, 1994. 8-26.

Revel, Donald. The Art of Attention: A Poet's Eye. Saint Paul: Graywolf Press, 2007. 
Ritter, Kelly. "Professional Writers/Writing Professionals: Revamping Teacher Training In Creative Writing Ph.D. Programs.” College English 64.2 (Nov. 2001):205-227.

--- and Stephanie Vanderslice. "Teaching Lore: Creative Writers and the University." Profession (2005): 102-112.

---. "Introduction: Creative Writing and the Persistence of 'Lore'." Can It Be Taught? Ed. Kelly Ritter and Stephanie Vanderslice. Portsmouth: Boyton/Cook, 2007. xi$\mathrm{xx}$.

Royer, Daniel J. and Roger Gilles. "The Origins of a Department of Academia, Creative, and Professional Writing." A Field of Dreams: Independent Writing Programs and the Future of Composition Studies. Ed. Peggy O'Neil et al. Logan: Utah State UP, 2002. 21-37.

Royster, Brent. "Inspiration, Creativity, and Crisis: The Romantic Myth of the Writer Meets the Contemporary Classroom." Power and Identity in the Creative Writing Classroom: The Authority Project. Ed. Anna Leahy. Clevedon: Multilingual Matters Ltd., 2005. 26-38.

Scholes, Robert. Textual Power. New Haven: Yale UP, 1985.

Shelnutt, Eve. "Notes from a Cell: Creative Writing Programs in Isolation.” Ed. Joseph Moxley. Creative Writing in America: Theory and Pedagogy. Urbana: NCTE, 1989. 3-24.

---. "Transforming Experience into Fiction: An Alternative to the Workshop." Creative Writing in America: Theory and Pedagogy Ed. Joseph Moxley. Urbana: NCTE, 1989. 151-167.

Shulman, Lee. "Pedagogies of Uncertainty.” Liberal Education (Spring 2005) $<$ http://www.aacu.org/liberaleducation/le-sp05/le-sp05feature2.cfm>.

---. "Signature Pedagogies in the Professions.” Daedalus 134.3 (2005): 52-59.

Siegel, Ben. The American Writer and the University. Newark: U of Delaware P. 1989.

Snodgrass, W. D. "Mentors, Fomenters, and Tormentors." A Community of Writers: Paul Engle and the Iowa Writers' Workshop. Iowa City: U of Iowa P, 1999. 119-146.

Sommers, Nancy. "Revision Strategies of Student Writers and Experienced Writers.” English Language Arts Bulletin 20. Winter/Summer, 1980. 8-14. 
Starkey, David. “The MFA Graduate as Composition Instructor: A Self-Analysis.” Can it Really be Taught? Ed. Kelly Ritter and Stephanie Vanderslice. Portsmouth: Boytin Cook, 2007. 26-38.

---. Teaching Writing Creatively. Portsmouth: Boynton/Cook, 1998.

---, and Eloise Klein Healy. “A Better Time Teaching”: A Dialogue About Pedagogy and The Antioch-LA MFA.” Can it Really be Taught? Ed. Kelly Ritter and Stephanie Vanderslice. Portsmouth: Boytin Cook, 2007. 38-45.

Stoll, Elmer Edgar E. “Literature and Life Again,” PMLA, 37, 1932, pp. 296-7

Swander, Mary and Anna Leahy, and Mary Cantrell. "Theories of Creativity and Creative Writing Pedagogy. The Handbook of Creative Writing. Edinburgh: Edinburgh UP, 2007. 11- 23.

Sykes, P. J., I. Meason and P. Woods. Teacher Careers, Crises and Continuities. London: Falmer P, 1985.

Tate, Allen. "What is Creative Writing?” Wisconsin Studies in Contemporary Literature. Vol. 5(3): 181-184. 1964.

Tatum, Stephen. “'The Thing Not Named’: The End of Creative Writing in the English Department.” ADE Bulletin 106 (Winter 1993): 30-34 <http://web2.ade.org/ade/bulletin/n106/106030.htm>.

Tompkins, Jane. “The Reader in History: The Changing Shape of Literary Response.” Reader-Response Criticism: From Formalism to Post-Structuralism. Ed. Jane Tompkins. Baltimore: John Hopkins UP, 1980. 201-223.

Tobin, Lad. "Reading Students, Reading Ourselves: Revising the Teacher's Role in the Writing Class.” The Writing Teacher's Sourcebook. Oxford: Oxford UP, 1981. 77-91.

---. Reading Student Writing: Confessions, Meditations, and Rants. Portsmouth: Boynton/Cook, 2004.

Tyler, Kathryn. “The Tethered Generation.” HR Magazine. May 2007. 53.5, 3 Dec. 2008 <http://www.shrm.org/hrmagazine/articles/0507/0507cover.asp>.

Vandenberg, Peter. “After Words.” Can it Really be Taught? Ed. Kelly Ritter and Stephanie Vanderslice. Portsmouth: Boytin Cook, 2007. 105-110. 
---. "Integrated Writing Programmes in American Universities: Whither Creative Writing?” New Writing: An International Journal for the Practice and Theory of Creative Writing. 1.1 (2004): 6-13.

Vanderslice, Stephanie. “Workshopping.” Teaching Creative Writing. Ed. Graeme Harper. London: Continuum, 2006. 147-157.

Wandor, Michelene. The author is not dead, merely somewhere else. Houndmills:Palgrave, 2008.

Weiss, Theodore. “A Personal View: Poetry, Pedagogy, Per-Versities.” The Writer in the University. Ed. Ben Siegel. Newark: U of Delaware P, 1989. 149-176.

Welch, Nancy. "Revising a Writer’s Identity: Reading and 'Re-Modeling' in a Composition Class.” CCC 47.1 (1996): 41-61.

Wilbers, Stephen. The Iowa Writers’ Workshop: Origins, Emergence, \& Growth. Iowa City: U of Iowa P, 1980.

Winterowd, W. Ross. 1998. The English Department: A Personal and Institutional History. Carbondale: So. Illinois UP. 


\begin{abstract}
ABOUT THE AUTHOR
Dianne Donnelly is a summa cum laude 2001 graduate from the University of Houston where she received her Bachelor's Degree in English with a concentration in Creative Writing. She completed the Masters’ level Creative Writing Program at the University of South Florida, graduating in 2004. She has been teaching composition, expository, and creative writing courses at the University of Florida since 2003.

While at the University of South Florida, Ms. Donnelly received scholarship awards, multiple teaching awards, and one of the university's Provost Awards for Outstanding Teaching. She presents consistently at the Conference on College Composition and Communication and at other discipline crossover conferences as well. Besides her short story and scholarly publications, Ms. Donnelly is the recipient of multiple fiction awards and the editor of the collection, The Writing Workshop Model: Is It Still Working? published by Multilingual Matters, Inc.
\end{abstract}

